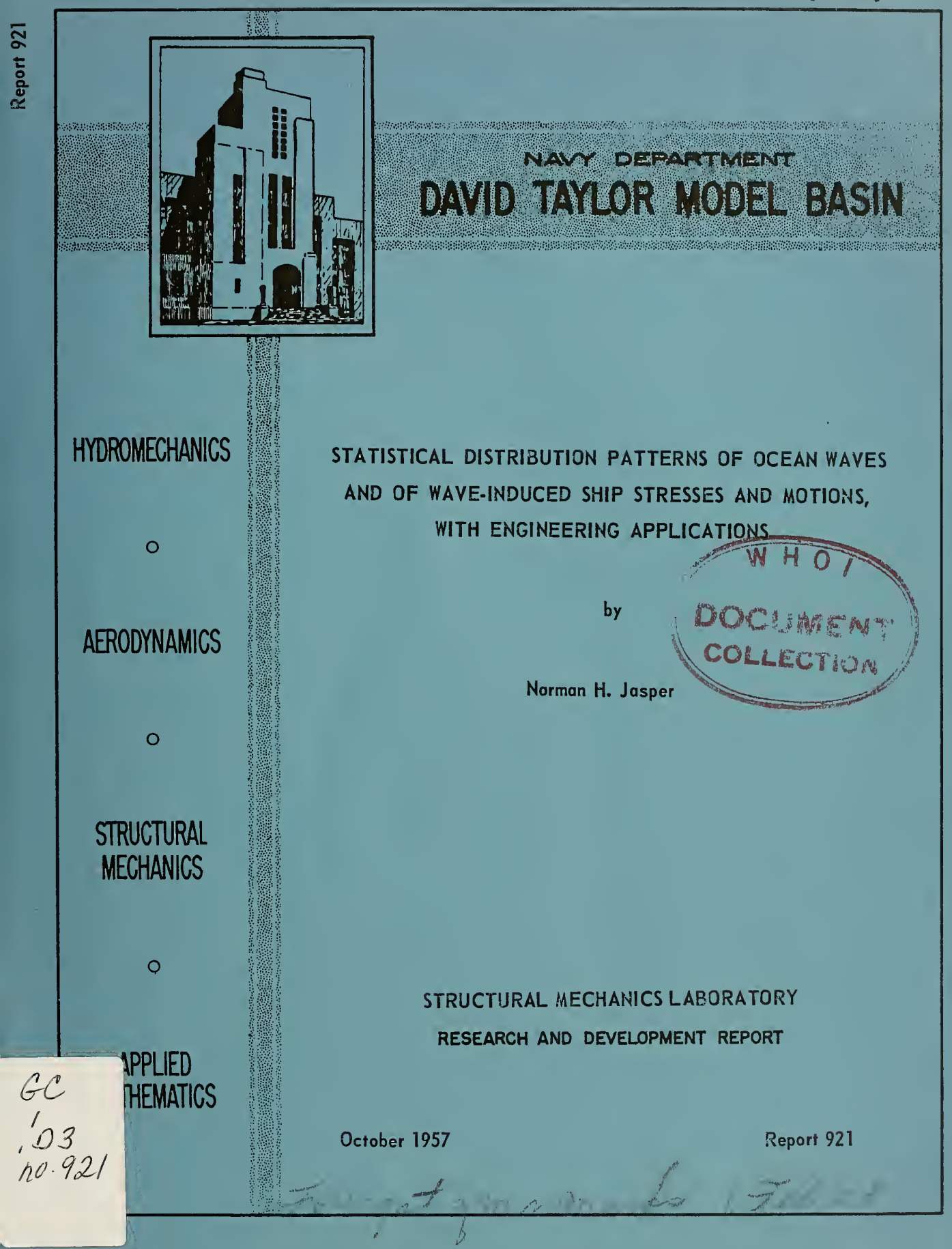




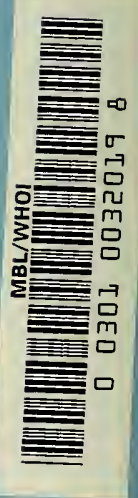




\title{
STATISTICAL DISTRIBUTION PATTERNS OF OCEAN WAVES AND OF WAVE-INDUCED SHIP STRESSES AND MOTIONS, WITH ENGINEERING APPLICATIONS
}

\author{
by \\ Norman H. Jasper \\ Reprint of Paper Published in \\ The Society of Naval Architects and Marine Engineers \\ Transoctions, Vol. 64, 1956.
}




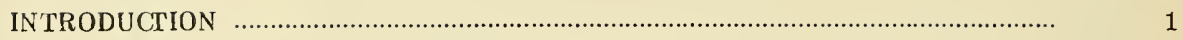

STATISTICAL BACKGROUND ………………...................................................

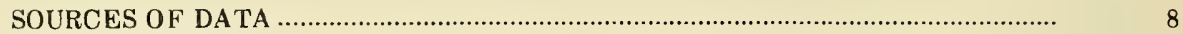

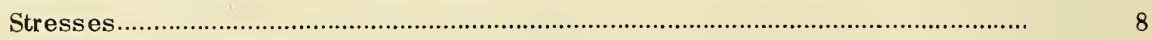

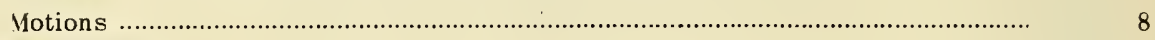

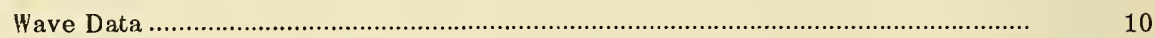

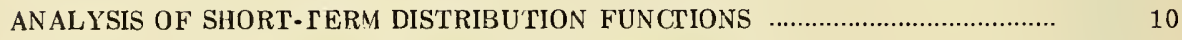

ANALYSIS OF LONG-TERM DISTRIBUTION FUNCTIONS ……................................ 15

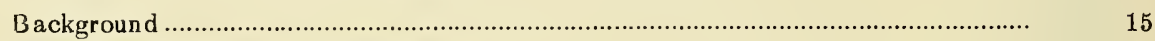

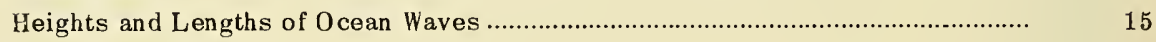

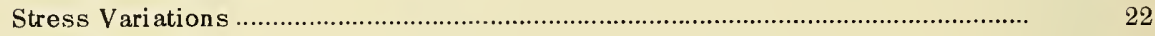

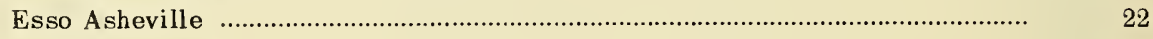

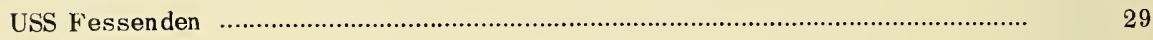

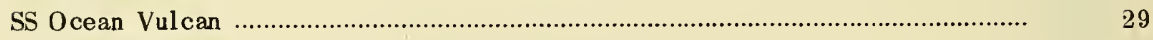

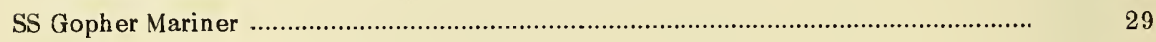

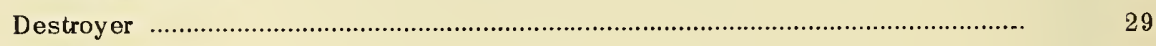

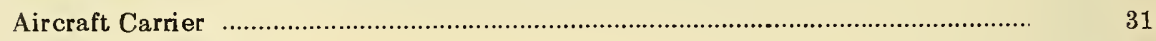

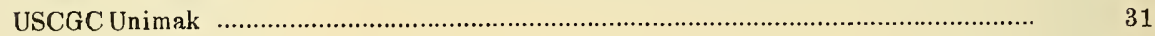

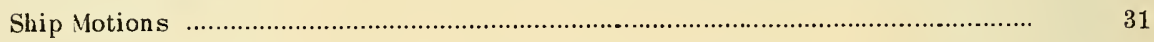

APPLICATIONS OF STATISTICAL DISTRIBUTION PATTERNS ……..................... 33

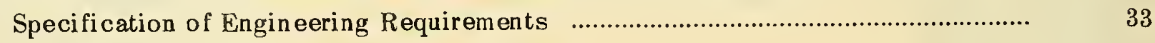

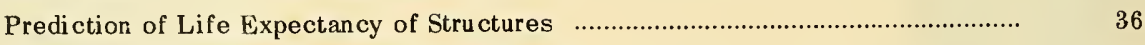

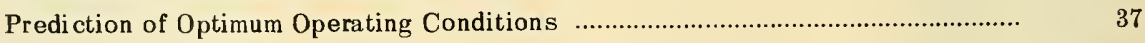

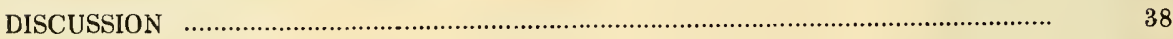

SUMMARY

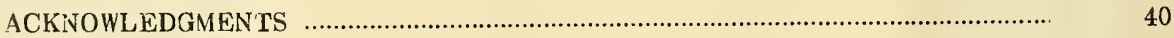

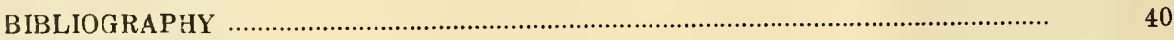

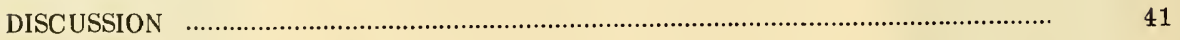




\title{
Statistical Distribution Patterns of Ocean Waves and of Wave-Induced Ship Stresses and Motions, with Engineering Applications
}

\author{
By N. H. Jasper, ${ }^{2}$ Member
}

Little is known about the frequency of occurrence of the various magnitudes of ocean waves. Even less is known about the severity of the wave-induced motions and stresses which ships experience in service. The intent of this research effort is to show that, by utilization of statistical methods, it is possible to describe and predict service conditions for ships in an orderly and relatively simple manner despite the general complexities of the problem. Wave observations taken continuously over a period of 6 years at several weather stations in the Atlantic Ocean were studied. Wave-induced motions and stresses in ships obtained under a wide range of operating conditions were studied for seven different ships. On the basis of an analysis of voluminous experimental data it is concluded that the probability distributions of wave height, wave length, wave-induced pitch, roll, and heave motions of ships, and wave-induced ship stresses may all be approximated by a oneparameter-type distribution function when the environmental conditions are steady, whereas these variables will tend to follow the two-parameter logarithmically normal distribution when the environmental conditions are allowed to vary over a wide range. Applications of the results of this study to the solution of engineering problems are described with the help of pertinent illustrations.

\section{INTRODUCTION}

It is probably correct to state that the shipbuilding industry knows less about the service conditions under which its product must operate than does any other major construction industry. In contrast to the aircraft builders, shipbuilders have made only a small effort to establish actual service stresses and motions or in incorporating

The paper given here was originally submitted to the School of Engineering and Arcbitecture of the Catholic University of America, Wasbington, D. C. in partial fulfillment of the requirements for the Wasbington, D. C., in partial ful

Degree of Doctor of Engineering.

2 Engineer and Deputy Division Head, Vibrations Division
David Taylor Model Basin, Navy Department, Washington, D. C.

Presented at the Annual Meeting, New York, N. Y., November

15-16, 1956, of THE Society of Nayal ARchirects ano Marine ENGINEERS. the results of such studies into methods of ship design. A deterrent to progress in this direction has been the complexity of the problem as evidenced by the extensive variability of the sea and of the response of the ship to the sea. The intent of this paper is to show that, by utilizing statistical methods, it is possible to describe and predict service conditions for ships in an orderly and relatively simple manner, even though the problem appears formidable.

The experimental approach taken in this paper should complement the theoretical work of St. Denis and Pierson although the present study was developed independently of theirs and is not 


\section{Table 1 Statistical Terms and Definitions}

It should be noted that in the present work only estimates of the statistical parameters can be given

variate

$E$

$P\left(x_{a}\right)$

$p(x)$

population

sample

c.d.f.

d.f.

$v$

mean value of $x$

variance of $x$

$\sigma^{2}$

standard deviation

quantile or fractile

confidence bands

random
Property under study, for example, magnitude of stress variation, height of waves.

The mean square value of $x, E=\frac{\sum_{i=1}^{N} x_{i}^{2}}{N}$

Probability of the event $x \leqq x_{a}$ with respect to the random experiment $\epsilon$. The probability $P$ means that in a long series of repetitions of $\epsilon$ it is practically certain that the relative frequency of occurrence of $x<x_{a}$ is equal to $P$ where $0<P<1$. A value of $P=1$ indicates that the event will occur with every experiment $\epsilon, P=0$ indicates that the event will never occur.

$=\frac{d}{d x} P(x)$

Aggregate of all the members of the distribution subject to a statistical study. The members may be individual measurements or the results of individual experiments.

Number of $N$ members drawn (usually at random) from the population. Here $N$ is the "sample size."

Abbreviation of the term "cumulative distribution function" $P(x)$ which denotes the probability that the variate $x$ will take on a value less than or equal to $x$, i.e., $P\left(x_{a}\right)=P\left[x \leqq x_{a}\right]$.

Abbreviation of the term "distribution function" $p(x)$ which is the derivative of $P(x)$ with respect to $x$, i.e.,

$$
p(x)=\frac{d}{d x} P(x) \text { and } \int_{-\infty}^{+\infty} p(x) d x=1
$$

$=\frac{x}{E^{1 / 2}}$

$=\frac{\sum_{i=1}^{N} x_{i}}{N}$ where $x_{i}$ is the individual member of the population or sample and $N$ is the number of members of the population or sample.

Mean value of a sample of values of $x$

Mean value of the population.

$=\frac{\sum_{i=1}^{N}\left(x_{i}-\bar{x}\right)^{2}}{N-1}$ The variance is a measure of the dispersion of the values of

$x$. The greater the variance the greater the dispersion.

Variance of the population.

Square root of the variance

Corresponding to a given value of the c.d.f. $P(x)$, there is a value of the variate below which a fraction $P(x)$ of all the members of the population lie. The value of this variate is the quantile or fractile corresponding to $P(x)$.

Interval within which the "true" distribution will fall with a certain probability.

A method of drawing a sample when each member of the population has an equal chance of selection. 
limited by the assumptions required by their mathematical analysis.

The purpose of this paper is to present evidence that the wave-induced pitching, rolling, and heaving motion of ships, as well as the associated hull-girder stresses follow simple, mathematically defined statistical frequency or probability distributions. It will be shown that the distribution functions of motions and stresses are of the same type as those applicable to the height of ocean waves. $^{3}$ In particular it will be shown that the distribution function approximates the single parameter "Rayleigh" type for a given state of the sea, ship speed, and course. On the other hand, when distributions of wave height, ship motion or stress experienced over a wide range of conditions are considered, the two-parameter "logarithmically normal" distribution is shown to be applicable over the range of conditions observed thus far. The latter distribution is the result of a summation of many distributions of the first type. Finally, the extreme values of ship motions and stresses will be examined to evaluate the feasibility of the prediction of extreme values.

For the sake of brevity, the distribution applicable to uniform conditions of the sea, ship speed, and course will be called "short-term" distribution, whereas the function which represents the distribution obtained when the seas, ship speeds, and courses are allowed to vary over a range of conditions, will be designated as a "long-term" distribution.

The conclusions arrived at in this paper are based on numerous observations of wave height, hull-girder stress ${ }^{4}$ (for seven ships) and ship motions (for five ships). The experimental data were obtained over a period of years and cover a wide range of service conditions.

There are many applications in which a knowledge of the frequency distribution of hull motions, stresses, and the heights of ocean waves can be used to advantage. For example:

1 Prediction of the most probable amplitudes of roll and pitch motion of ships under given environmental conditions.

2 Estimation of the extreme values of ship response or of wave heights encountered over given periods of time.

3 Statistical estimation of the capacity for which shipboard stabilization equipment must be designed.

\footnotetext{
The study of ocean waves originated as a by-product of the hasic investigation of the ship's response to the sea.

- Wherever the term stress is used in this paper, a stress computed from the measured strain is to be inferred.
}

4 Estimation of the endurance strength of the ship structure.

The experimental work carried out in connection with this problem has been a co-operative effort of many people and several organizations. In particular the U. S. Navy, The Society of Naval Architects and Marine Engineers, the U. S. Coast Guard, the U. S. Weather Bureau, and the Esso Company have contributed much to make this research possible. The special instrumentation and methods used to collect the data, as well as some of the sea tests are described in references $(1-4) .^{5}$ This paper will not be concerned with the methods with which the data were obtained except in so far as they are pertinent to the statistical analysis.

The general plan of presentation will be as follows: Some pertinent statistical background information will be given first, followed by a short outline of the sources of the data employed in this study. The analyses of short-term and longterm distributions will be given separately. Each analysis applies statistical tests of significance to the hypothesis that the experimental data are samples from a specified distribution. The results of the analyses are discussed and applications of the results to practical problems are illustrated, followed by a summary of the major conclusions.

\section{Statistical Background}

The wave heights, the variations in ship motions, and hull-girder stresses experienced under a given set of conditions will be described in terms of their distribution functions. The statistical methods applied in the present study comprise techniques which were used to obtain, classify, analyze, and present large masses of experimental data. In particular they were used to:

1 Collect the data by sampling procedures.

2 Classify and condense the data. The data were classified according to the magnitude and frequency of the measured variations. Each variation is understood to mean a fluctuation in the magnitude of the variable from the largest positive value to the succeeding largest negative value; for example in the case of a rolling motion the variation would denote a motion of the ship from the extreme starboard position to the extreme port position.

3 Present the data. The data are given in tabular form as well as in the form of statistical distribution patterns, such as histograms and distribution functions.

4 Analyze the data. With the data presented

Numhers in parentheses refer to the Bibliography at the end of the paper. 


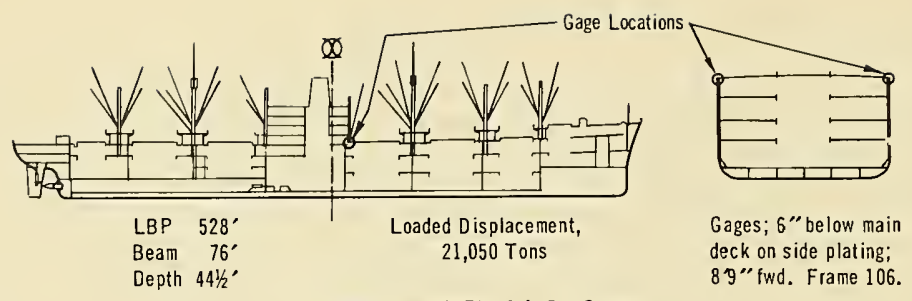

SS GOPHER MARINER, C-4, Dry Cargo

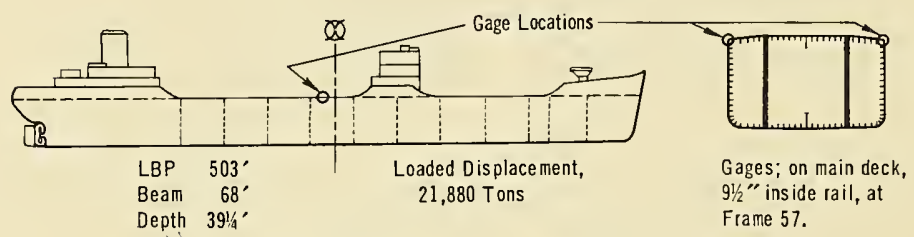

SS ESSO ASHEVILLE, T-2, Tanker
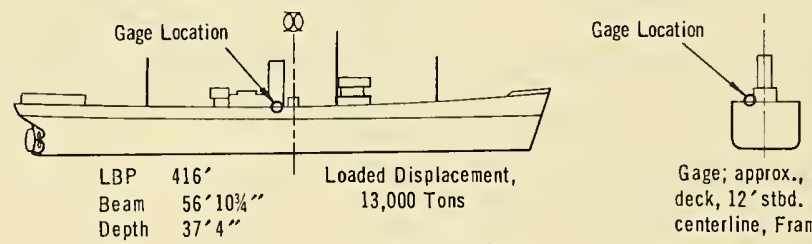

Gage; approx., upper deck, 12'stbd. of centerline, Frame 92.

SS OCEAN VULCAN
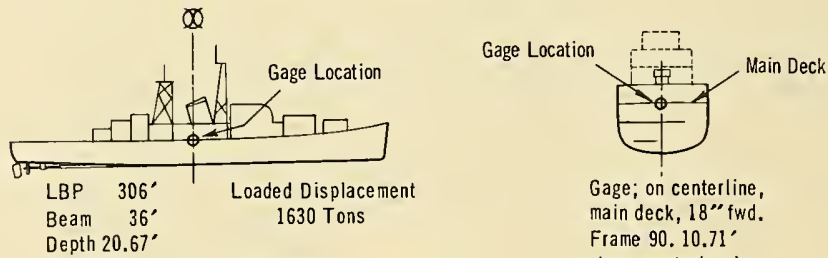

Gage; on centerline, main deck, 18 " fwd.

Frame 90. 10.71'

USS FESSENDEN, DER-142

above neutral axis.

Longit. Hull Girder Stress

at Amidships

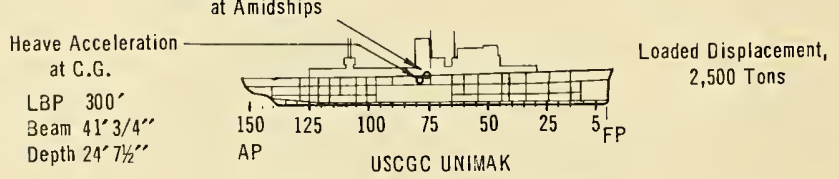

Fig. 1 Locatron of Strain Gages (Circles indicate gage locations.) 
in a suitable manner, analytic functions are fitted to the data, and tests of significance are applied to determine whether certain statistical predictions and conclusions can be reached with confidence on the basis of the available data.

Some basic terms used in statistical work are defined in Table 1. A distribution function indicates the relative frequency or probability of occurrence of a particular event. The best known type of distribution is the "normal" distribution. It is theoretically possible, but not often practicable, to convert distributions which are not "normal" into a normal distribution by a change of variables. One such conversion which will be utilized here is to take the logarithm of the variable. Thus the "log-normal" distribution is obtained, which signifies that the logarithm of the variable is normally distributed. Commercial chart paper (probability chart) is available which is designed so that the integral of the normal or log-normal distribution will plot as a straight line on the chart. The log-normal law has been found applicable in various diversified fields. See, for example, the extensive bibliography given by V. T. Chow (5).

The probability $P(x)$ takes on definite values for a given population. An estimate of $P(x)$ is often desired on the basis of samples of the members of the population. Statistics provide the tools for making such estimates. It will be assumed that the sample is taken from a population for which the quantity under discussion is defined by a certain analytical expression. The reliability of this hypothesis is evaluated by the application of statistical tests of significance which enable one to estimate the expected variation of the measured data from the analytically defined values, if the hypothesis is true.

In order to determine whether the variation of the sample data from the assumed distribution is consistent with the hypothesis, use will be made of a theorem in statistics (6) which states that the sample quantile ${ }^{6} x_{P}$ is asymptotically normal with mean value $\xi$ and standard deviation

$$
\frac{1}{p} \sqrt{\frac{P(1-P)}{N}}
$$

where $N$ is the size of the sample, $p$ the probability density, $P$ the cumulative probability at $x=x_{P}$ and $\xi$ is the corresponding quantile of the population from which the sample is drawn. Otherwise stated: If a sample of $N$-values is chosen at random and if these values are numbered in the order of increasing magnitude, then the magni-

${ }^{6}$ A quantile denotes the variate corresponding to a given fraction; i.e., the 0.40 quantile is that value, of the variate below which 40 per cent of all values lie. tude of any particular value, say the $r$ th cannot be predicted in advance of the drawing of the sample; there exists a certain probability function. If $N$ is large, and if neither $r / N$ nor $(N-r) / N$ is too small, then the probability function for the $r$ th value is approximately normal in form. If $N$ is increased and if $r$ is also increased so as to keep $r / N$ as nearly constant as possible (as for a fixed quantile of the sample) then the approximation to normality increases, becoming perfect in the limit as $N \rightarrow \infty$; the width of the probability spread simultaneously decreases, becoming zero in the limit.

If a curve is plotted on each side of the analytic cumulative distribution curve at a distance of 1.65 standard deviation of the distribution of the corresponding quantiles, then on the average nine tenths of the observed quantiles would be expected to fall between these limits and 10 per cent of the measured quantiles would be expected to fall outside these limits. This control or confidence curve is therefore designated as the 90 per cent significance level ${ }^{7}$ and indicates the probability of a random value falling within the limits when the hypothesis is true. In order for the deviation between the hypothetical distribution and the sample values to be considered not significant at this level, it would be necessary to have less than 10 per cent of a large number of observed values fall outside these limits. In practice it has been found that wrong conclusions will seldom be drawn if the level of significance is set at 90 per cent or less; that is, the hypothesis is probably true if the deviations are no greater than could be expected, on the average, in one out of 10 tests. On the other hand if the deviations lie outside the 99 per cent limits, that is, if they are larger than would be expected once in a hundred similar tests, then the hypothesis should be rejected confidently. A distribution may be of practical significance even though the statistical tests indicate a significant deviation between it and the measured data.

In many cases a visual inspection of the scatter is sufficient to indicate that the assumed distribution is an acceptable representation of the actual distribution. The types of basic distributions that will be considered here are the normal, lognormal, and the Rayleigh distributions.

The normal distribution of $x$ is defined as follows:

$$
p(x)=\frac{1}{\sigma \sqrt{2 \pi}} e^{\frac{-(x-\xi)^{2}}{2 \sigma^{2}}},-\infty<x<+\infty
$$

7 Some statisticians prefer to label the limits according to the prohability with which a random measurement would fall without the limits; i.e., the 90 per cent significance limit would then be referred to as the 10 per cent level. 


$$
P(x)=\int_{-\infty}^{x} p(x) d x
$$

where

$p(x)$ is the probability density of $x$

$x$ is the variate

$\xi \quad$ is the mean value of the variate

$\sigma^{2}$ is the variance of the population

Thus the two parameters $\xi$ and $\sigma$ define the distribution completely.

The logarithmically normal or log-normal distribution is a normal distribution of the logarithm of $x$, and

$$
p(x)=\frac{1}{x \sigma \sqrt{2 \pi}} e^{\frac{-(\log x-u)^{2}}{2 \sigma^{2}}}
$$

where $u$ is the mean value of $\log x$ and $\sigma$ is the standard deviation of $\log x$.

The Rayleigh distribution is defined as follows

$$
p(x)=\frac{2 x}{E} e^{-x^{2} / E}, x>0
$$

where $E$ is the mean value of the squares of $x$; thus
TABle 2 USCGC Unimak-COMPutation of Confi-

\begin{tabular}{|c|c|c|c|c|c|}
\hline \multirow[t]{2}{*}{$\begin{array}{c}x \\
\text { Variation in } \\
\text { Pitch Angle } \\
\text { deg }\end{array}$} & \multirow{2}{*}{ 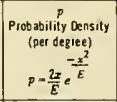 } & \multirow{2}{*}{$\begin{array}{c}P \\
\text { Probability } \\
P-\int_{0}^{x} p d x\end{array}$} & \multirow{2}{*}{$\begin{array}{c}\text { Stand ard Deviation } \\
\text { of Fractile } \\
\sigma=\frac{1}{p} \sqrt{\frac{P(1-P)}{N}}\end{array}$} & \multirow[t]{2}{*}{$\begin{array}{c}z+a \\
\text { Upper Limit } \\
\text { of } z\end{array}$} & \multirow{2}{*}{$\begin{array}{c}z-\sigma \\
\begin{array}{c}\text { Lower Limit } \\
\text { of } z\end{array} \\
\text { Linits, deq }\end{array}$} \\
\hline & & & & & \\
\hline 0.5 & 0.0210 & 0.050 & 0.2186 & 0.72 & 0.26 \\
\hline 1 & 0.0413 & 0.0206 & 0.2239 & 1.22 & 0.78 \\
\hline 2 & 0.0775 & 0.0809 & 0.2290 & 2,23 & 1.77 \\
\hline 3 & 0.1046 & 0.1729 & 0.2353 & 3.24 & 2.76 \\
\hline 4 & 0.1193 & 0.2923 & 0.2482 & 1.25 & 3.75 \\
\hline 5 & 0.1244 & 0.4097 & 0.2573 & 5.26 & 4.74 \\
\hline 6 & 0.1190 & 0.5294 & 0.2730 & 6.27 & 5.73 \\
\hline 7 & 0.1051 & 0.6441 & 0.2965 & 7.30 & 6.70 \\
\hline 8 & 0.0875 & 0.7407 & 0.3260 & 8.33 & 7.67 \\
\hline 9 & 0.0588 & 0.8188 & 0.3644 & 9.36 & 8.63 \\
\hline 10 & 0.0511 & 0.8786 & 0.4160 & 10.42 & 9.58 \\
\hline II & 0.0362 & 0.9221 & 0.4820 & 11.48 & 10.52 \\
\hline 12 & 0.0243 & 0.9519 & 0.5732 & 12.57 & 11.53 \\
\hline 14 & 0.0118 & 0.9784 & 0.8019 & 14.80 & 13.20 \\
\hline 16 & 0.0052 & 0.9911 & 1.1756 & 17.18 & 14,82 \\
\hline \multicolumn{6}{|c|}{ 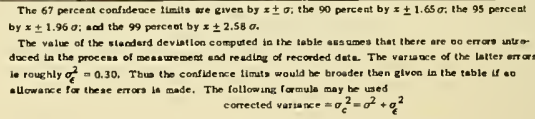 } \\
\hline
\end{tabular}
DENCE LIMITS FOR DATA SHOWN IN Figs. 2 AND 3.

(Pitch angle, sea state 5 , head seas, ship speed $71 / 2$ knots.)

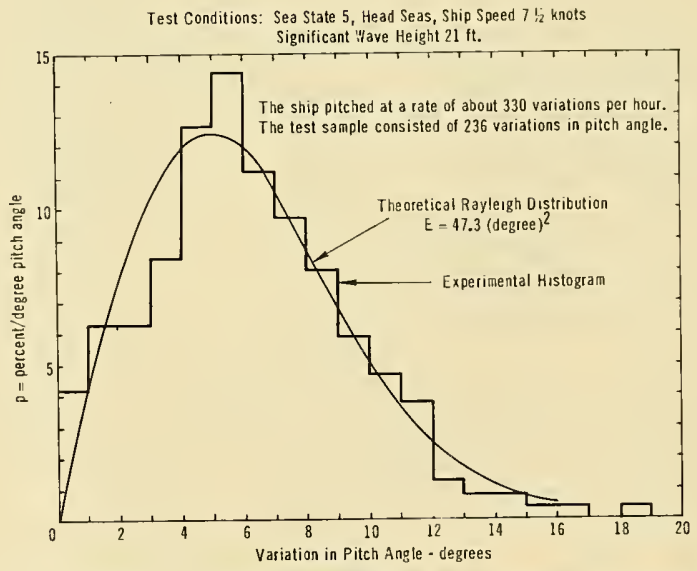

Fig. 2 USCGC Unimak, Distribution of Variation in Pitch ANGLE-SAMPLE 1

( $T$ his sample is representative of 129 samples that were analyzed.)

the single parameter $E$ defines the distribution. It is possible to represent the distributions corresponding to different values of $E$ by a single distribution, employing a change of variables. Thus let

$$
v=\frac{x}{\sqrt{E}} \text { then } \sqrt{E} p(x)=2 v e^{-v^{2}}
$$

Integrating to obtain the cumulative probability $\sqrt{E} \int_{0}^{x_{i}} p(x) d x=\sqrt{E} P\left(x_{i}\right)=\sqrt{E}\left[1-e^{-v^{2}}\right]$ or

$$
P\left(x_{1}\right)=\left[1-e^{-v^{2}}\right]
$$

and 


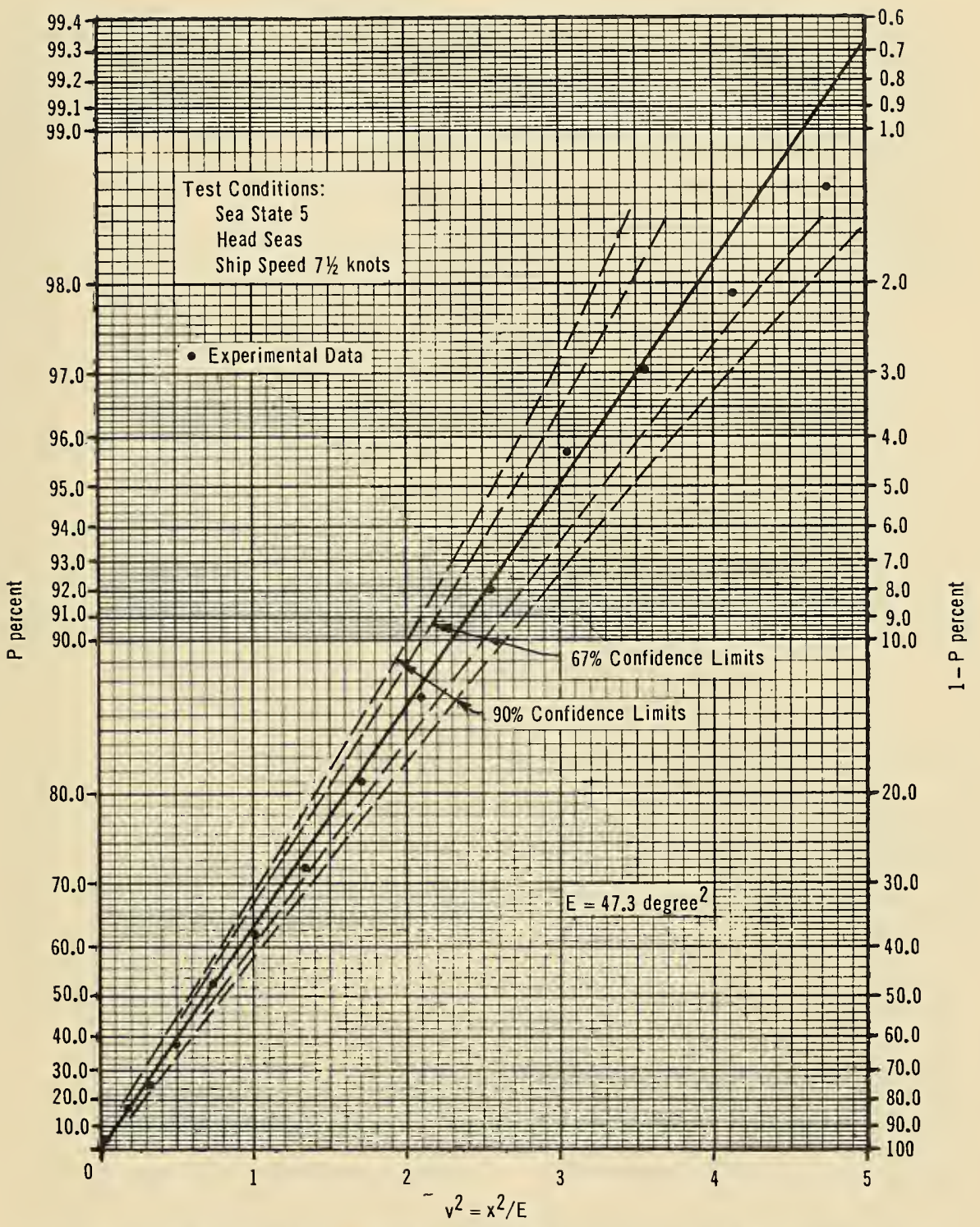

Fig. 3 USCGC Unimak, Cumulative Distribution of Variation in Pitch Angle-Sample 1

(See Fig. 2 for corresponding histogram. Note: The plotted confidence limits do not include an allowance for errors of measurement.) 


$$
1-P\left(x_{i}\right)=e^{-v^{2}}
$$

Therefore if the variable under study is expressed in terms of the standardized variate $v$ then the function $\left[1-e^{-v 2}\right]$ will represent the cumulative distribution of all Rayleigh distributions. This cumulative-distribution function will plot as a straight line if the logarithm of $\left[1-P\left(x_{i}\right)\right]$, that is, the probability of exceeding $x_{i}$, is plotted against $v^{2}$ as has been done in Fig. 3 .

It should be noted that the methods of statistics are strictly valid only if the measured values are independent samples. The physical
5 The USCGC Unimak, a former U.S. Navy AVP class vessel, now fitted as a weather ship, operating at weather station B in the North Atlantic Ocean. Some data also were obtained for a sister ship, the USCGC Casco. These vessels are approximately $300 \mathrm{ft}$ long and displace about 2500 tons.

6 A destroyer approximately $380 \mathrm{ft}$ long operating in the Atlantic Ocean.

7 An aircraft carrier approximately $900 \mathrm{ft}$ long operating in the Atlantic Ocean.

The actual measurements of strain obtained

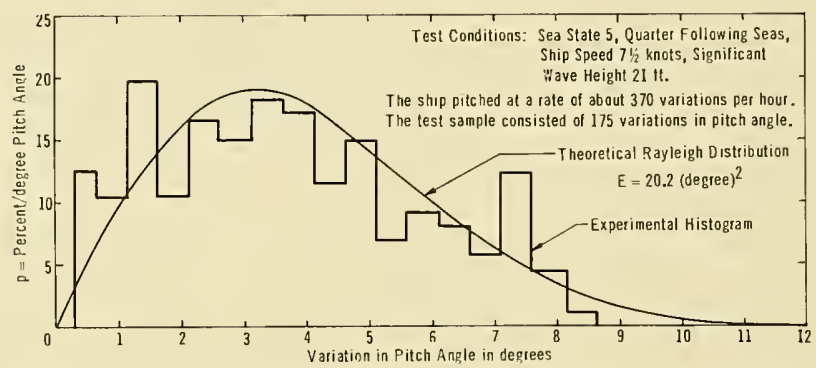

Fig. 4 USCGC Unimak, Distribution of Variation in Pitch Angle-Sample 2 (This sample represents the poorest fit to the Rayleigh distribution of 129 samples that were analyzed.)

data are not, in general, independent of one another. However if the tests of significance indicate, on the basis of assumed independence of all observations, that these data reasonably can be assumed to derive from the distribution specified by the hypothesis, then this conclusion is even more sound than the tests of significance indicate.

\section{SOURCES OF DATA}

\section{Stresses}

Service stresses were obtained for the following ships:

1 The SS Esso A sheville, a T-2 Maritime Commission design tanker, which operated in coastwise service between the United States, Central and South America.

2 The SS Gopher Mariner, a C-4 Maritime Commission design dry-cargo vessel, which operated in the transatlantic service.

3 The SS Ocean V Vulcan (7), a dry-cargo vessel. No specific data are available to the author as to its area of operation.

4 The USS Fessenden, a destroyer escort, operating in coastal waters off the U.S. East Coast. for these ships, excepting the Ocean Vulcan (7), were made by the U.S. Navy's David Taylor Model Basin. In many cases these measurements were obtained by means of automatic instrumentation which did not require the presence of an operator aboard the ship. The strain gages were installed on the strength deck, near amidships, see Fig. 1. The tests of six of these ships (Gopher Mariner, Esso Asheville, Unimak, Fessenden, Destroyer, Carrier) covered a period of about 3 to 8 months, predominantly in the winter season; the Ocean Vulcan data however cover a period of $2 \frac{1}{2}$ years.

\section{Motions}

Ship motions were obtained by Taylor Model Basin personnel on the Esso Asheville, Casco, Unimak, a destroyer, and an aircraft carrier. The motions were recorded by means of an automatic recorder which took a record at preset intervals of time for a predetermined duration of time. The complete tests on the Esso Asheville, Casco, and Unimak are described in references $(3,1$ and 4$)$, respectively. 


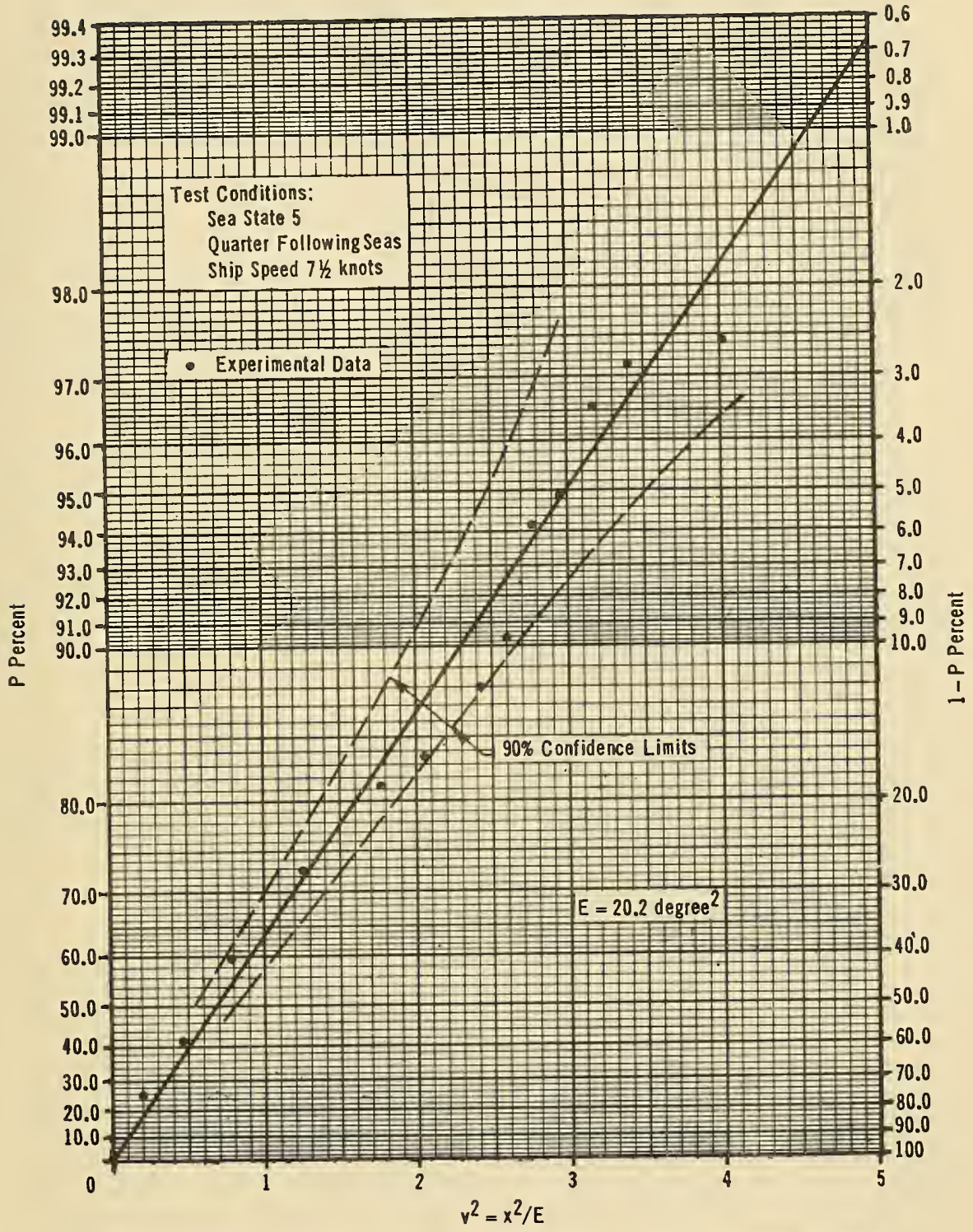

Fig. 5 USCGC Unimak, Cumulative Distribution of Variation in Pitch Angle-Sample 2 (See Fig. 4 for corresponding histogram.) 


\section{Wave Data}

Observation of significant wave height ${ }^{8}$ and wave period, obtained over a period of 6 years, have been made available by the U.S. Weather Bureau. These observations were made every 3 hr by trained weather observers in accordance with instructions prescribed by the U.S. Weather Bureau (8). Only one quantitative measurement was reported each time the sea was observed. Darbyshire (9) obtained measurements of wave heights, at Ocean Stations I and J by means of a wave meter which has been developed in England. Thus one set of measurements is available which may be used as a check of waveheight observations reported by weather ships.

\section{Analysis of Short-Term Distribution Functions}

It is the purpose of this section to show that, on the basis of the experimental evidence, waveinduced motions and stresses of ships are distributed according to the Rayleigh distribution with a high degree of statistical significance provided the sea conditions, ships speed, and heading remain uniform throughout the period under consideration.

It has been accepted generally that the heights of ocean waves passing any given point follow the Rayleigh distribution, provided the associated power spectrum has most of the energy concentrated in a narrow frequency band. This distribution is valid if measurements of wave height are taken over a relatively short period of time, of the order of $1 \mathrm{hr}$, during which interval the sea conditions do not change appreciably. It can be shown that this distribution is the same as that representing all wave heights, in the area under consideration, at one instant of time. The statistics of the Rayleigh distribution were applied by Longuet-Higgins (10) to the analysis of the distribution of wave heights in a sea characterized by a narrow spectrum. This work was extensively applied by Pierson, Neumann, and James (11) to the study of ocean waves.

Inasmuch as hull stresses and motions are caused by the passage of the waves past the ship it will be appropriate to test the hypothesis that the responses of the ship to the waves, i.e., stresses and motions, may similarly be statistically represented by a Rayleigh distribution.

For this purpose a number of tests ${ }^{9}$ were run

\footnotetext{
Significant wave height is the average height of the upper third highest waves.

- Each test yielded a continuous $1 / 2-\mathrm{hr}$ oscillogram record of ship motions and stresses applicable to a specific combination of conditions.
}

Table 3 Chi-Square Test Applied to Test Goodness of Fit of Rayleigh Distribution to Test Results

\begin{tabular}{|c|c|c|c|c|c|}
\hline Sample Tested & Class Lumits & $\begin{array}{l}\text { Number of } \\
\text { Variations } \\
\text { Measured }\end{array}$ & $\begin{array}{l}\text { Expected } \\
\text { Number of } \\
\text { Variations }\end{array}$ & $\begin{array}{l}\text { Value of } \\
\text { Chi } 5 \text { quare }\end{array}$ & Rewarks \\
\hline $\begin{array}{l}\text { UNIUAK } \\
\text { Pitch Angle } \\
\text { See Figures 2,3 }\end{array}$ & $\begin{array}{l}0.3 \text { deg } \\
3-6 \\
6.8 \\
8-10 \\
10-14 \\
14-19\end{array}$ & $\begin{array}{r}0 \\
84 \\
49 \\
33 \\
27 \\
5\end{array}$ & $\begin{array}{r}8 \\
77 \\
50 \\
33 \\
26 \\
2\end{array}$ & $\begin{array}{l}1.33 \\
0.64 \\
0.02 \\
0 \\
0.04 \\
4.5 \\
\end{array}$ & $\left\{\begin{array}{l}\Sigma X^{2}=6.4 \\
\text { Good Fit } \\
P=0.75\end{array}\right.$ \\
\hline $\begin{array}{l}\text { UNisak } \\
\text { Pitch Angle } \\
\text { See Figures 4, } 5\end{array}$ & $\begin{array}{l}0-21 / 8 \text { deg } \\
21 / 8 \cdot 31 / 8 \\
31 / 8-41 / 8 \\
41 / 8 \cdot 51 / 8 \\
51 / 8-61 / 8 \\
61 / 8.81 / 8 \\
81 / 8-101 / 8\end{array}$ & $\begin{array}{r}46 \\
25 \\
31 \\
23 \\
14 \\
27 \\
6\end{array}$ & $\begin{array}{r}35 \\
33 \\
34 \\
28 \\
20 \\
19 \\
6\end{array}$ & $\begin{array}{l}3.46 \\
1.93 \\
0.26 \\
0.89 \\
1.80 \\
3.36 \\
0\end{array}$ & $\begin{array}{l}\Sigma \chi^{2}=11.7 \\
F \text { air Fit } \\
P=0.92\end{array}$ \\
\hline $\begin{array}{l}\text { OE5TROYER } \\
\text { Pitch Angle } \\
\text { See Figutes } 6,7\end{array}$ & $\begin{array}{l}0.1 \text { des } \\
1-2 \\
2-3 \\
3-4 \\
4-5 \\
5-6 \\
6-7 \\
7-10\end{array}$ & $\begin{array}{l}14 \\
34 \\
55 \\
56 \\
45 \\
37 \\
18 \\
11\end{array}$ & $\begin{array}{l}16 \\
41 \\
54 \\
54 \\
43 \\
30 \\
17 \\
15\end{array}$ & $\begin{array}{l}0.25 \\
1.20 \\
0.02 \\
0.07 \\
0.09 \\
1.63 \\
0.06 \\
1.07\end{array}$ & $\begin{array}{l}\sum x^{2}=4.4 \\
\text { Vety Good Fit } \\
P=0.30\end{array}$ \\
\hline $\begin{array}{l}\text { AIRCRAFT CARRIER } \\
\text { Pitch Angle } \\
\text { See Figules } 8,9\end{array}$ & $\begin{array}{l}0.5 \text { deg } \\
5.9 \\
9-12 \\
12-15 \\
15-18 \\
18-23\end{array}$ & $\begin{array}{r}43 \\
76 \\
36 \\
32 \\
15 \\
8\end{array}$ & $\begin{array}{r}45.96 \\
69.59 \\
43.69 \\
27.93 \\
14.23 \\
7.42 \\
\end{array}$ & $\begin{array}{l}0.19 \\
0.59 \\
1.35 \\
0.59 \\
0.04 \\
0.05\end{array}$ & $\begin{array}{l}\Sigma_{X^{2}}=2.8 \\
\text { Very Good Fit } \\
P=0.30\end{array}$ \\
\hline $\begin{array}{l}\text { AIRCRAFT CARRIER } \\
\text { Stress in Main Oeck } \\
\text { See Figutes } 10,11\end{array}$ & $\begin{array}{c}0.750 \text { psi } \\
750-1500 \\
1500-2250 \\
2250-3000 \\
3000-3750 \\
3750-5500\end{array}$ & $\begin{array}{l}35 \\
66 \\
61 \\
31 \\
25 \\
10\end{array}$ & $\begin{array}{r}28.75 \\
66.47 \\
66.40 \\
41.29 \\
18.97 \\
8.13\end{array}$ & $\begin{array}{l}1.36 \\
0.04 \\
0.44 \\
2.56 \\
1.92 \\
0.43\end{array}$ & $\begin{array}{l}\sum \chi^{2}=6.8 \\
G 00 d F i t \\
P=0.75\end{array}$ \\
\hline
\end{tabular}

on the USCGC Unimak under a wide variety of combinations of sea, speed and ships heading to the waves. The hull stresses, pitching, rolling, and heaving motions were measured for 39 sets of these combinations. The parameter $E$ which defines the Rayleigh distribution

$$
p(x)=\frac{2 x}{E} e^{-x^{2} / E}
$$

was computed for each of the frequency distributions of motions and stresses measured under the various combinations of environmental conditions. The individual histograms were plotted and compared with the Rayleigh distributions corresponding to the computed value of $E$. A typical distribution, thus determined, is shown in Figs. 2 and 3. The pattern which evidenced the poorest agreement between the experimental and the Rayleigh distribution is shown in Figs. 4 and 5.

It has been shown in the section "Statistical Background," that all Rayleigh distributions may be represented by a single analytic expression if a new variable $v$ is used rather than $x$ directly. The cumulative distribution function then plots as 
Table 4 USCGC Unimak-Prtch Angle-Comparison of Predicted and Measured Maximum Values

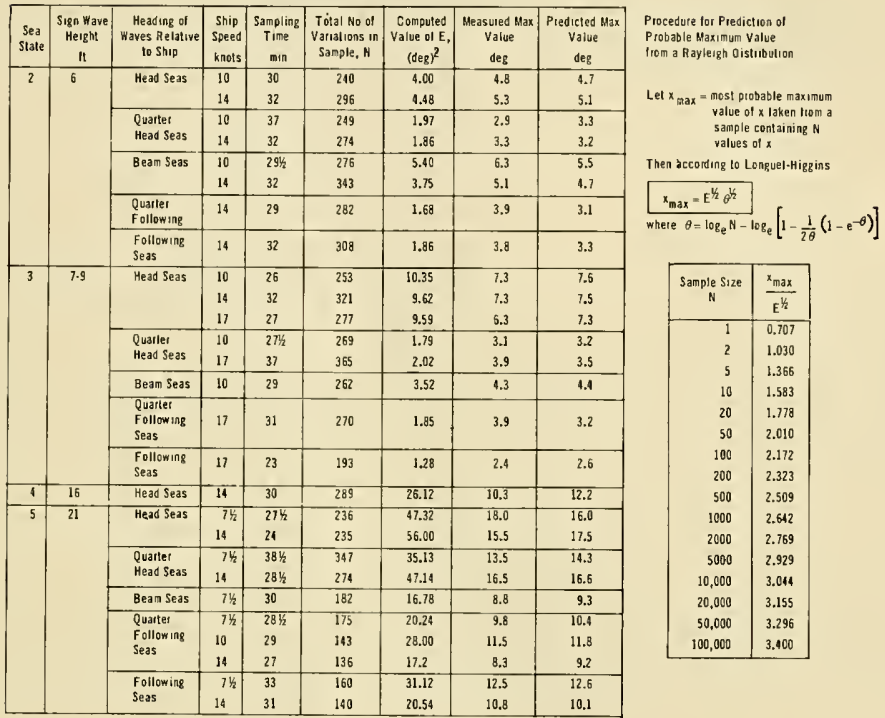

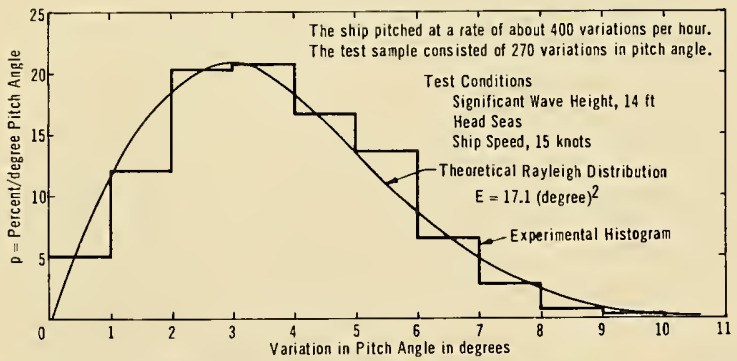

Fig. 6 Distribution of Variation in Pitch Angle, Destroyer

a straight line on the type of probability chart that was devised in the section mentioned (see Fig. 3).

A statistical test of significance was applied to the hypothesis: "The variations of the measured sample from the assumed population, specified by $E$, are no larger than may be expected according to the laws of chance."

Aside from the deviations attributable to chance it was necessary to consider the expected vari- ations due to the inaccuracies of the measurement process. The variances of the fractiles for the sample under consideration were computed according to the theorem stated in the section cited. Fig. 3 which represents the results for a typical test indicates that the measured data fall well within the 90 per cent limits; a second set of curves, the 67 per cent limits also was computed and the data satisfy this more restrictive test. Thus a high degree of confidence can be placed in the hy- 


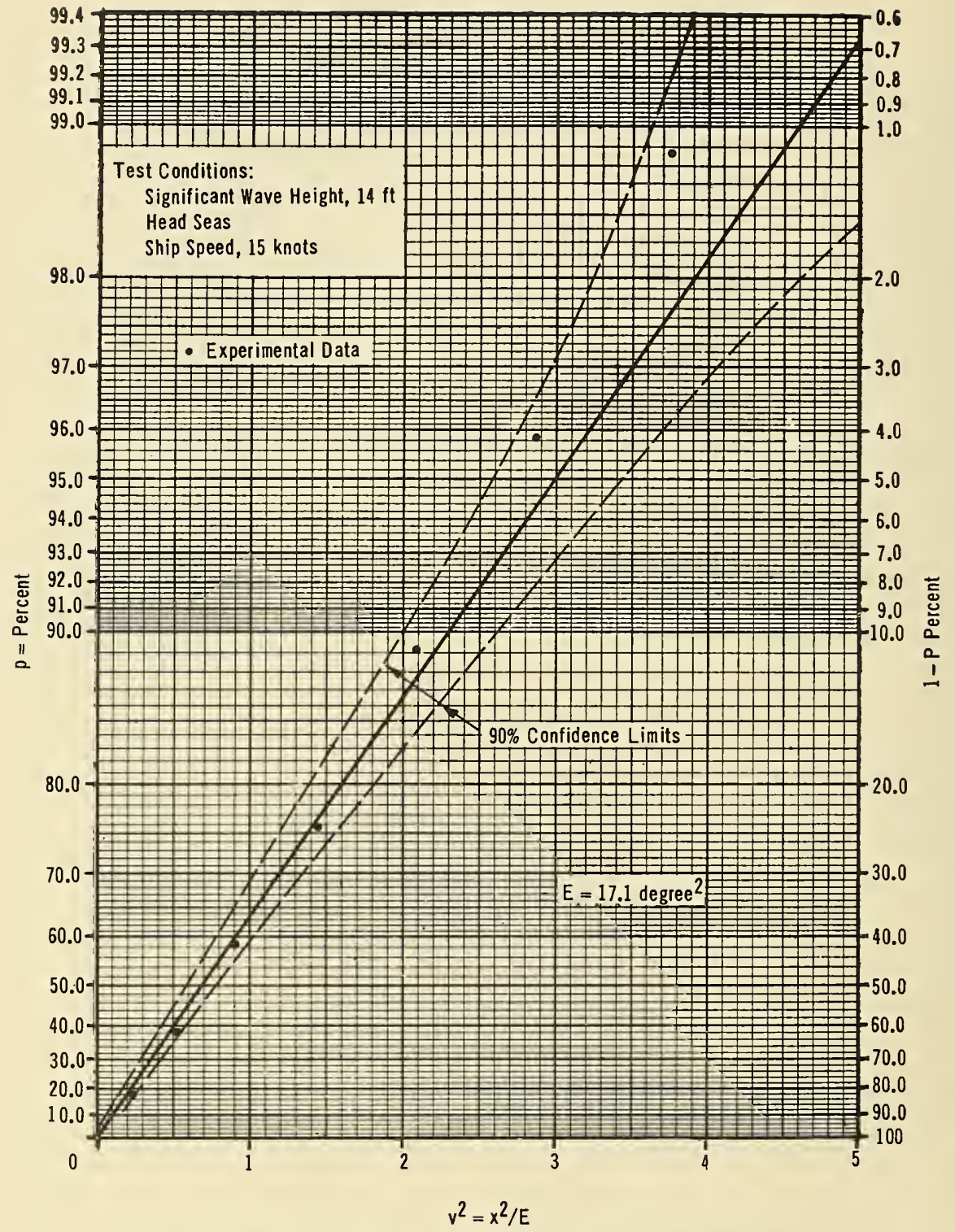

Fig. 7 Cumulative Distribution of Variation in Pitch Angle, Destroyer (See Fig. 6 for corresponding histogram.) 


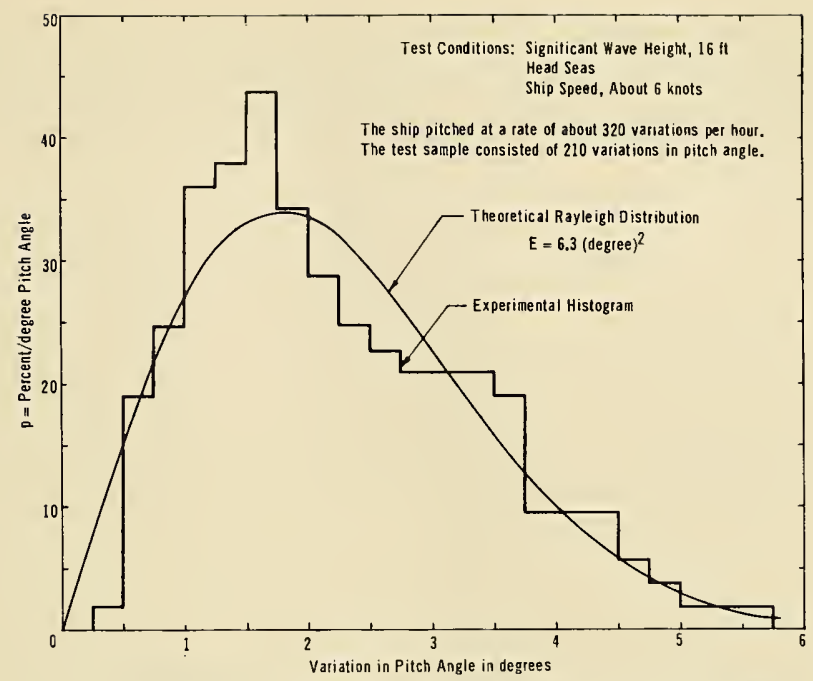

Fig. 8 Distribution of Variation in Pitch ANgle, Aircraft Carrier

Table 5 Statistics of Log-Normal Distribution of WaveHeight Observations in the North Atlantic Ocean

\begin{tabular}{|c|c|c|c|c|c|c|c|}
\hline $\begin{array}{l}\text { Period of } \\
\text { Recoids }\end{array}$ & $\begin{array}{c}\text { Ocean } \\
\text { Station }\end{array}$ & $\begin{array}{r}\text { Latitude } \\
\text { deg, min }\end{array}$ & $\begin{array}{l}\text { Longitude } \\
\text { deg, mın }\end{array}$ & $\begin{array}{c}\text { Number of } \\
\text { observations* }\end{array}$ & $\begin{array}{l}\text { Median Value of } \\
\text { Sign. Wave Heigh! }\end{array}$ & $\begin{array}{c}\text { Mean Value of } \\
\text { Logarithm of } \\
\text { Sign, Wave Height }\end{array}$ & $\begin{array}{l}\text { Variance }\left(\sigma^{2}\right) \text { of } \\
\text { Logarithm of } \\
\text { Sign. Wave Height }\end{array}$ \\
\hline$V / 49 \cdot 6 / 54$ & A & $62^{\circ} 00^{\circ} \mathrm{N}$ & $33^{\circ} 00^{\circ} \mathrm{W}$ & 12,891 & 6.34 & 1.8472 & 0.4524 \\
\hline $1 / 49-12 / 54$ & B & $569^{\circ} \mathrm{N}$ & $5100 \%$ & 15,547 & 6.59 & 1.8659 & 0.4434 \\
\hline $1 / 49 \cdot 12 / 54$ & c & $52^{\circ} 45^{\circ} \mathrm{N}$ & $35^{\circ} 30^{\prime} \mathrm{W}$ & 16,857 & 6.75 & 1.9100 & 0.3763 \\
\hline $1 / 49-12 / 54$ & 0 & $44^{\circ} 00^{\prime} \mathrm{N}$ & $41^{\circ} 007$ & 16,804 & 6.26 & 1.8338 & 0.3843 \\
\hline $1 / 49-12 / 54$ & $E$ & $35^{\circ} 00^{\circ} \mathrm{x}$ & $48^{\circ} 007$ & 16,777 & 4.56 & 1.5164 & 0.3765 \\
\hline $1 / 47 \cdot 6 / 53$ & 1 & $61^{\circ} 00^{\prime} \mathrm{N}$ & $15^{\circ} 20^{\circ} \mathrm{W}$ & 11,274 & 7.36 & 1.9960 & 0.3747 \\
\hline $1 / 47 \cdot 6 / 53$ & J & $52^{\circ} 30^{\circ} \mathrm{N}$ & $20^{\circ} 00^{\prime} w$ & 12,016 & 7.40 & 2.0021 & 0.3863 \\
\hline $1 / 49-12 / 53$ & K & $45^{\circ} 0 \sigma^{N}$ & 160007 & 11.182 & 6.20 & 1.8240 & 0.3033 \\
\hline $1 / 49-12 / 53$ & H & $66^{\circ} 00^{\prime} \mathrm{N}$ & $02^{\circ} 00^{\circ} \mathrm{E}$ & 14,324 & 4.99 & 1.6076 & 0.2344 \\
\hline $1 / 49-6 / 54$ & N & $35^{\circ} 00^{\prime} \mathrm{N}$ & $70^{\circ} 00^{\circ} \%$ & 14,607 & 5.08 & 1.6251 & 0.4237 \\
\hline
\end{tabular}

pothesis that this sample was taken from a Rayleigh distribution. Consideration of the variances due to instrument errors would have resulted in wider confidence limits, Table 2.

As a further check on the validity of the hypothesis, the chi-square test was applied to the grouped data, in accordance with the method of chapter 23 , reference (12). This test gave a rather low value of chi-square, Table 3 , thus indicating that there are no inconsistencies between the test data and the hypothesis.

Figs. 4 and 5 show the distribution for the poorest set of data obtained in the sea tests of the Unimak. In this case also there are no signifi- cant differences between test data and the hypothetical Rayleigh distribution on the basis of either the chi-square test or the variation in the distribution of quantiles.

Inasmuch as none of the more than one hundred distributions of ship motion or hull stresses (longitudinal, hull-girder bending moments) indicated significant deviations from the hypothesis, this hypothesis may be accepted confidently for ships of the type tested.

Thus far only the results of the Unimak sea trials have been discussed. A similar analysis also has been made of the results obtained from sea tests (in the Atlantic Ocean) on a destroyer 


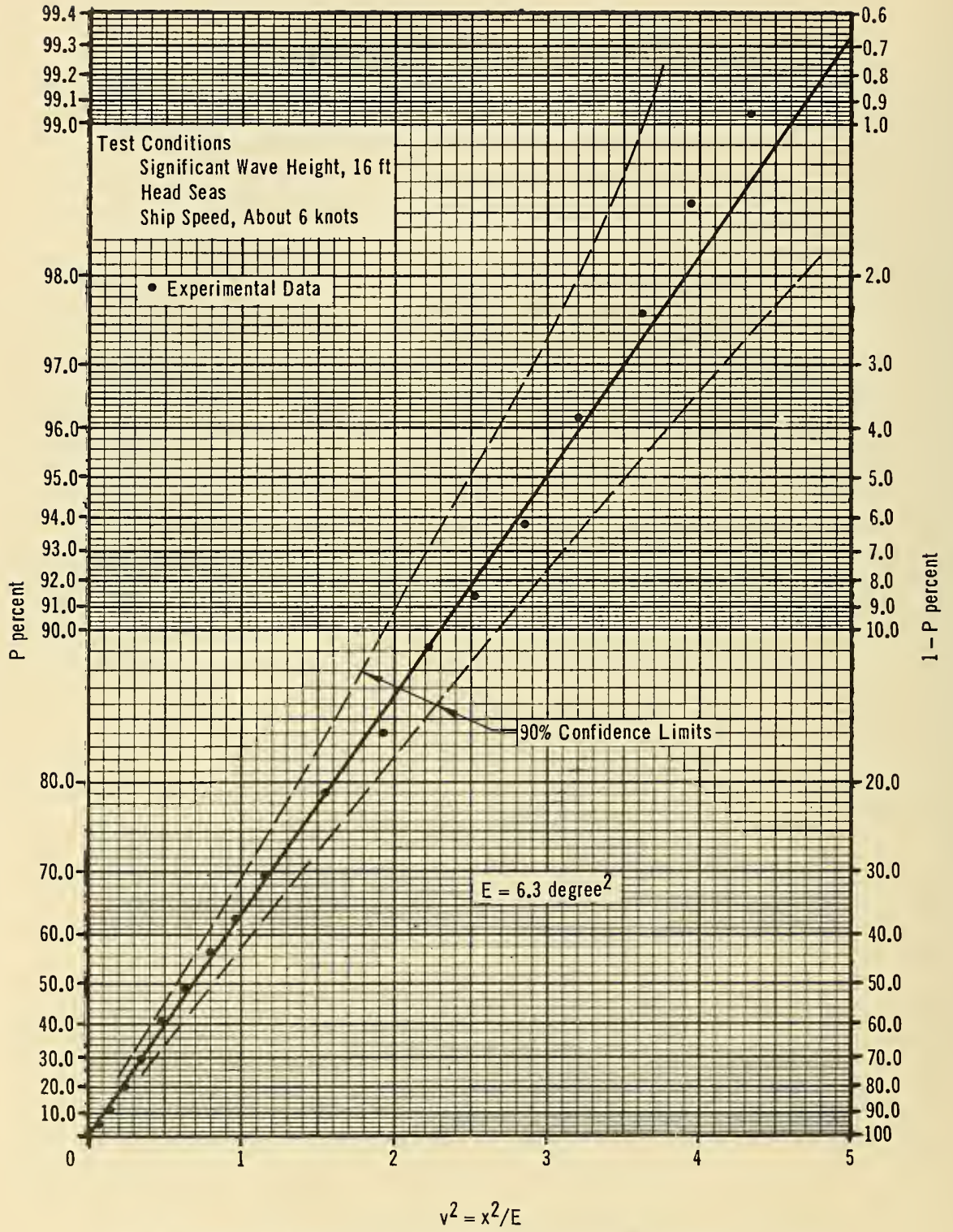

Fig. 9 Cumulative Distribution of Variation in Pitch Angle, Aircraft Carrier (See Fig. 8 for corresponding histogram.) 
and a large aircraft carrier. Figs. 6 through 11 show typical distributions obtained from the sea trials of the destroyer and carrier. It is again evident that there is no significant difference between the measured data and the hypothesis that the data are samples taken from a Rayleigh distribution.

It will be of interest to compare the largest measured value out of a given number of measurements with the most probable largest value predicted by the statistical theory. LonguetHiggins shows that the largest probable value $x_{\max }$ out of $N$-measurements is $\sqrt{E}$ times a constant if the population is of the Rayleigh type where the constant is a function of $N$ only. For $N$ large this constant becomes approximately equal to $\sqrt{\log _{e} N}$. Table 4 gives the comparison of predicted and measured values for a number of tests. There appears to be satisfactory agreement between measurement and predicted values.

On the basis of these data, applicable to a wide variety of sea conditions and ship types, it is concluded that the wave-induced motions and stresses of ships are distributed according to the Rayleigh distribution, for any given set of steady conditions of the sea, ship speed and heading.

\section{ANalysis of Long-Term Distribution Functions}

\section{Background}

It is the main purpose of this section to show that wave-induced hull stresses and motions of ships may be approximated by a logarithmically normal distribution if the environmental conditions under which the data are secured include a wide variety of sea conditions, ship's headings and speeds, such as a ship would be likely to encounter over a period of weeks, months or years. It is a secondary objective to show that the heights of ocean waves may be represented by a log-normal distribution.

When this study was initiated several years ago, there were few data available on the motions and hull-girder bending moments which ships experience in service. It was realized that large quantities of data would have to be collected in order to provide a reasonably firm basis for the objective of this program which is the specification and prediction of the service stresses and motions of ships. Statistical methods were to be utilized in the planning of the tests and the collection, presentation, and analysis of test results. It was felt desirable, early in the planning stage, to have a preliminary idea of the general type of frequency distributions which might be applicable as well as of the length of time over which meas- urements would have to be made in order to establish the desired distribution patterns.

Because the stresses and motions of ships are caused by the passage of the waves past the ship, it was thought desirable to study the extensive wave-height observations that had been collected over a period of many years both in the Atlantic and Pacific Oceans with the expectation that the frequency-distribution patterns of ship response would, to some degree, be similar to those applicable to the wave data. Inasmuch as the waveheight data comprise visual observations, the distributions will be evaluated in a qualitative sense only; that is, it will not be possible to assign statistical significance levels. The wave observations will be analyzed first, followed by the hullgirder stress and ship-motion data. Most of the analysis will be concentrated on the hull stresses because much more stress than ship-motion data have been measured to date.

\section{Heights and Lengths of Ocean Waves}

Fig. 12 shows a chart on which the several weather stations, manned by weather ships, are marked. For each of these stations the U.S. Weather Bureau has collected observations of the significant wave height ${ }^{10}$ and wave period, reported every $3 \mathrm{hr}$, over a period of about 6 years in accordance with instructions of the U.S. Weather Bureau (8). Detailed study of these observations indicate that if the data are plotted on log-normal probability paper and if a lognormal distribution is fitted to the plotted data, ${ }^{11}$ very good agreement is obtained. Fig. 13 shows the distribution for Station C. This curve is typical of the distributions obtained from the U.S. Weather Bureau data. Station $\mathrm{C}$ is the one at which the sea trials of the USCGC Casco (1) were held. The essential statistical data for significant wave height are given in Table 5 . Comparison of the distributions obtained for each year with the sum of the observation over a period of about 6 years indicates that one year's observation gives a good approximation to the distribution obtained over the longer period of time. The details of the comparison will not be given here.

Recently J. Darbyshire (9) has obtained measurements of wave heights by means of a wave meter installed on a weather ship. The measurements were made over a period of about a yearFebruary 1953 to January 1954-at the North

\footnotetext{
10 The significant wave height is the mean height of the upper third highest waves.

11 The fitted log-normal distribution corresponds to the value of the mean and variance computed directly from the wave data.
} 


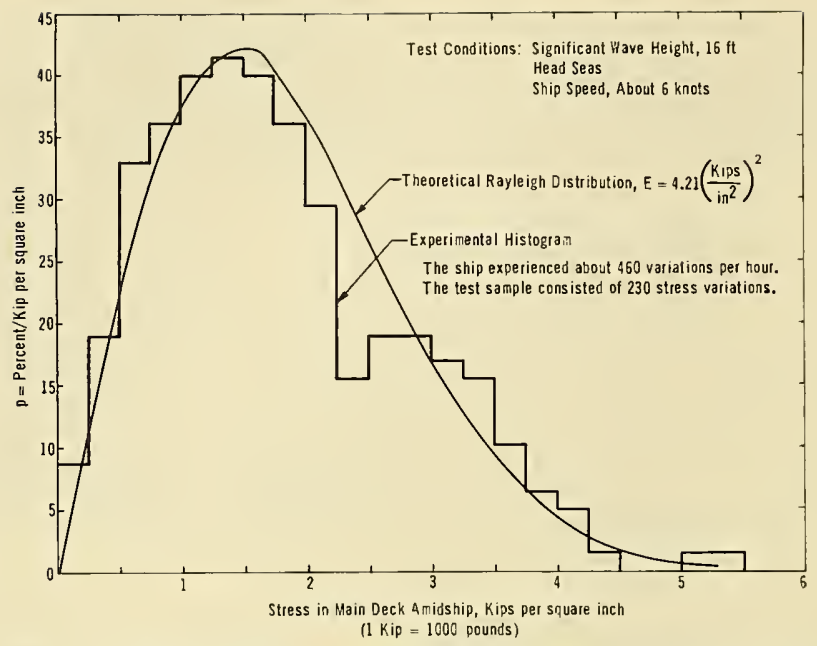

Fig. 10 Distribution of Variation in the Longitudinal Stress, Main Deck, AMIDSHIP, AIRCRAFT CARRIER

Atlantic weather stations I and J, see Fig. 12. Darbyshire reported the maximum wave height measured each time observations were made at 3-hr intervals, while the ship was at sea. The visual observations made by weather observers, on the other hand, are reported as the significant wave height. It will be of interest to compare the visual observations with the measurements that have been obtained with the wave meter. If the hypothesis is accepted that the short-term distribution of wave height follows the Rayleigh distribution, then the maximum wave height and the significant wave height are related by a constant factor. Thus the distributions of maximum and significant wave heights should both be of the same type, $\log$ normal in this case, and differ only in their mean values. The U.S. Weather Bureau data indicate that the standard deviation ${ }^{12}$ of the $\log _{e}$ (significant wave height) is 0.62 at Station $J$ and 0.61 at Station $I$ as compared to a value of 0.57 for the $\log _{e}$ (maximum wave height) for the measurements at Stations I and J reported by Darbyshire, Fig. 15. The wave-meter data have been fitted with a log-normal distribution on the assumption that the distribution of the maximum wave heights is $\log$ normal, Fig. 15 . The experimental data indicate excellent agreement with the fitted

\footnotetext{
12 The numerical values given here refer to wave heights measured
} in feet. distribution, well within the accuracy of the wave measurements. The latter fact, together with the good agreement between the standard deviations of the distribution of significant and maximum wave heights, support the hypothesis that the distribution of wave heights may be approximated by Rayleigh and log-normal distributions for the short and long term respectively. It is realized that the visual estimates of significant wave heights obtained by the U.S. Weather Bureau may not be accurate estimates of the mean value of the third highest waves. But as long as these estimates are proportional to the actual significant wave height, the form of the cumulative distribution (log-normal type) and its variance remain unchanged; only the mean value would change since $\log$ (constant) $x$ is equal to $\log$ (constant) plus $\log x$.

Fig. 14 shows the distribution of the predominant wave periods observed at Ocean Station B. Here again the log-normal distribution appears to provide a reasonably good fit. If these wave periods are converted to wave lengths by means of the formula, ${ }^{13} L=5.12 T^{2}$, where $L$ is the length of the wave in feet and $T$ is its period in seconds, which is applicable to gravity waves in deep water, it may be seen that the wave length will follow the log-normal distribution in-

${ }_{13}$ The numerical valtue of the constant $(5.12)$ does not affect the type of distribution. 


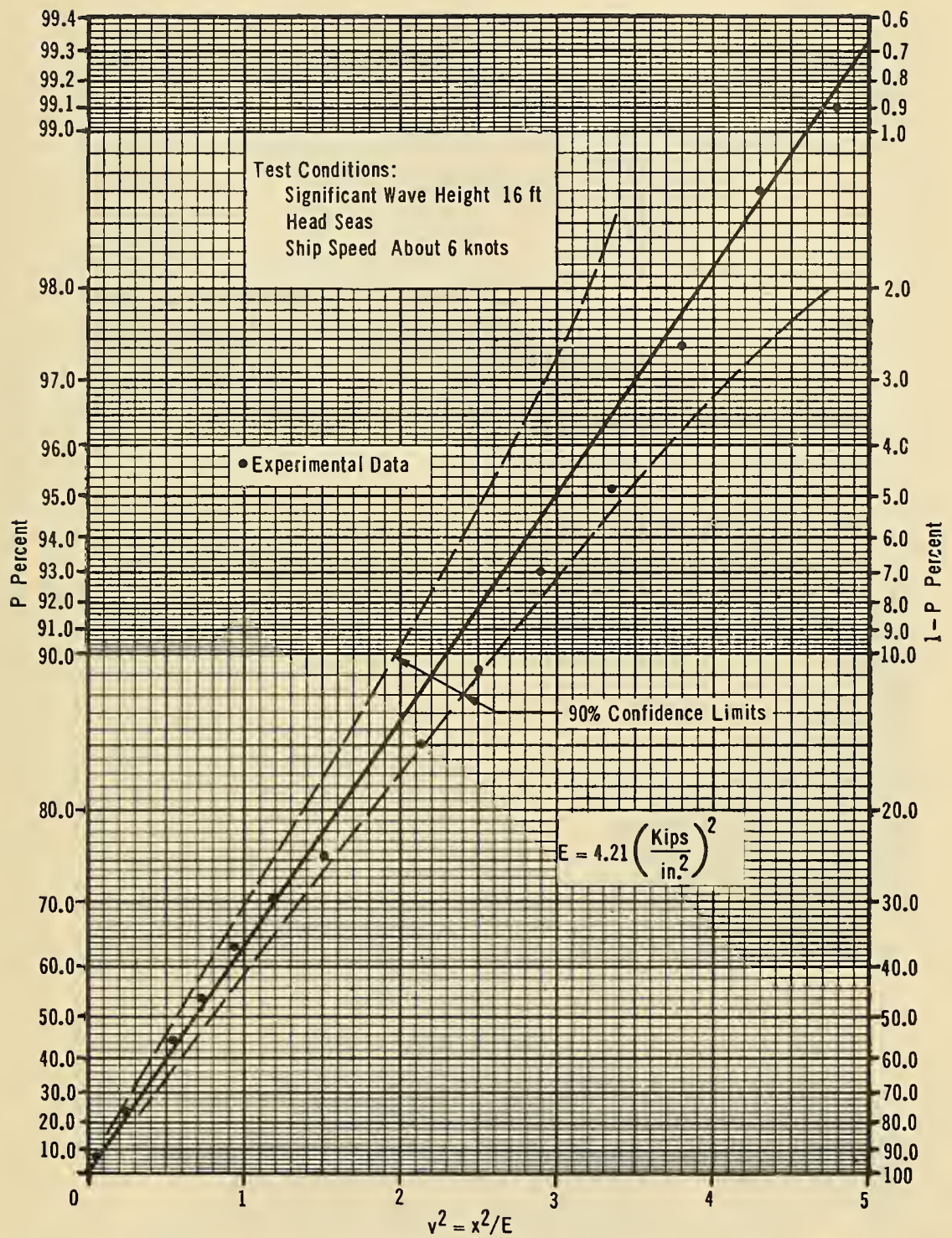

Fig. 11 Cumulative Distribution of Variation in Stress for Main Deck of Aircraft Carrier Amidship (See Fig. 10 for corresponding histogram.) 


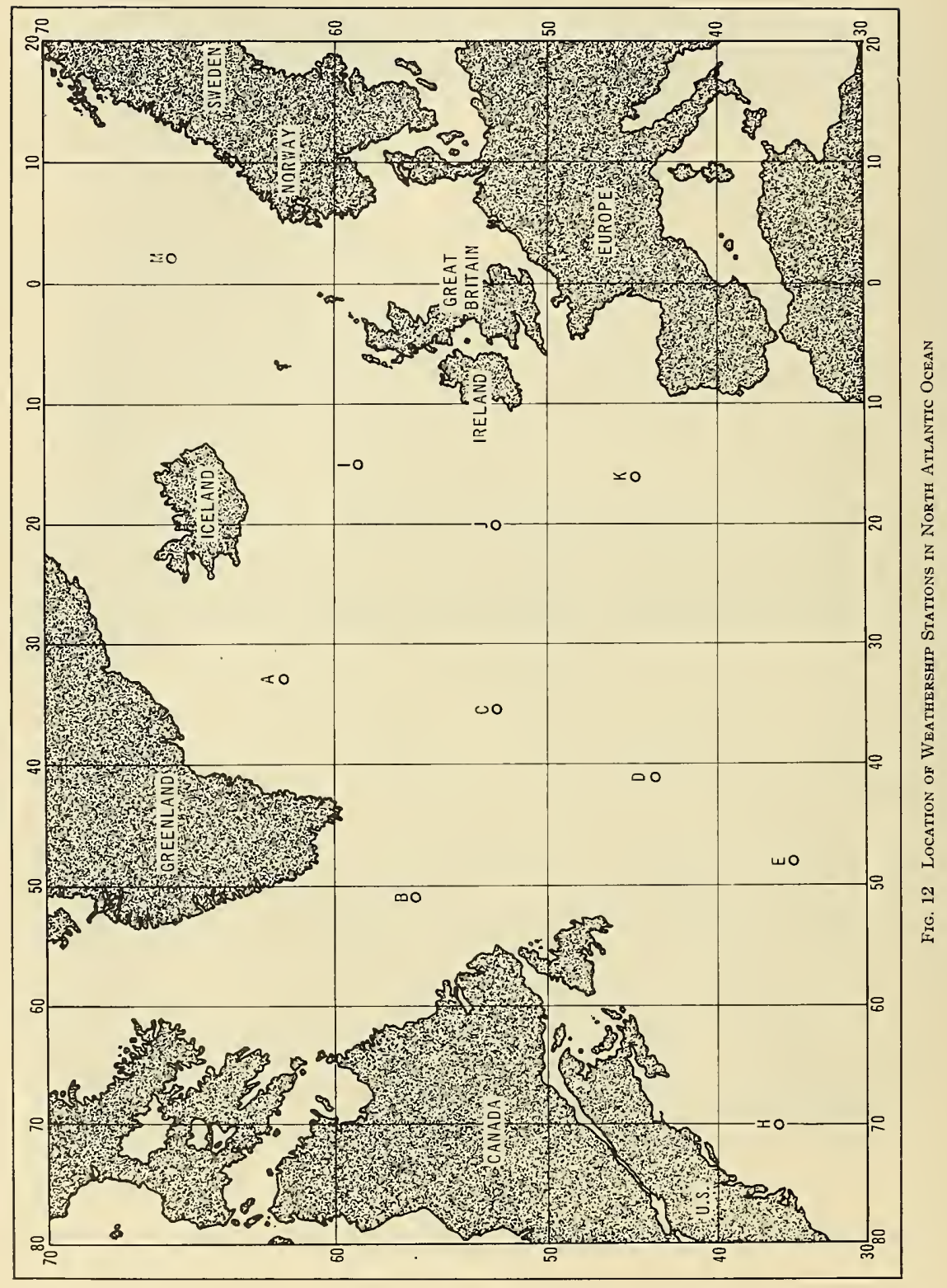




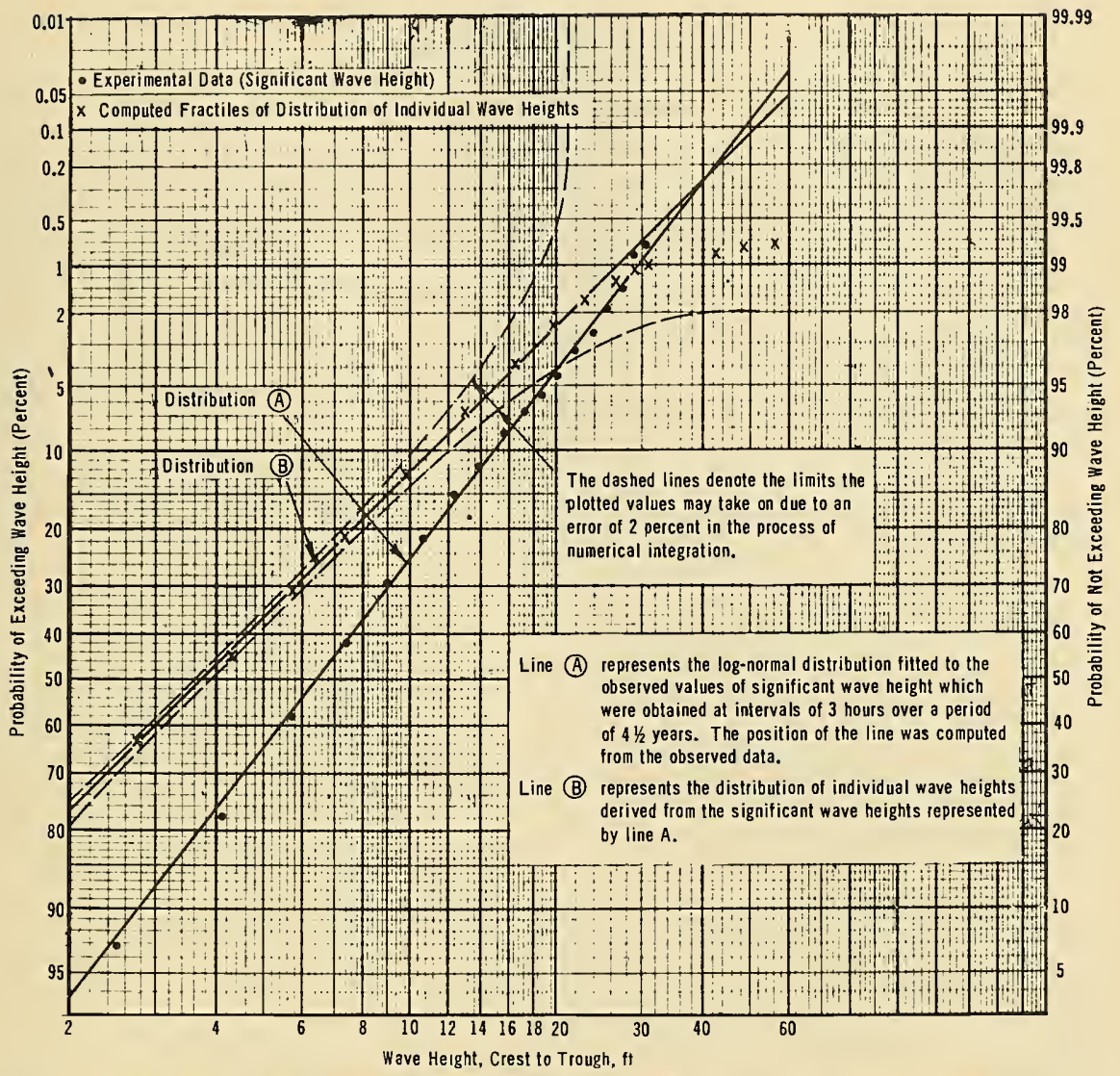

Fig. 13 Distribution of the Heights of Ocean Waves at Weather Station C, $52^{\circ}$ N $37^{\circ}$ W, North Atlantic OCEAN

(This distribution is based on 12,365 observations made over a period of $4 \frac{1}{2} \mathrm{yr}$ by U.S. Weather Bureau personnel.)

volving only a change in scale from the distribution of periods, Fig. 14.

Observations of significant wave heights in the Pacific Ocean made by merchant vessels have also been studied (13). Although these data are not as extensive or systematic as the Weather Bureau data for the North Atlantic Ocean, the indication is that the cumulative distribution functions of significant wave heights in the Pacific Ocean are approximately log normal.

The log-normal distribution of "significant" wave heights may be thought of as a distribution of $E$ where each value of $E$ corresponds to a definite sea state which may be alternatively specified by a significant wave height, if it may be assumed that the Rayleigh distribution holds for the distribution of individual wave heights in a given sea state. This assumption appears to be justified (11). On the basis of this assumption it is possible to arrive at the long-term distribution of wave heights (as apart from significant wave heights) in accordance with the following approach. 
Table 6 SS Esso Asheville-Basic Data on Wave-Induced Stresses for the Period SeptemBER 1, 1953 TO APRIL 3, 1954

\begin{tabular}{|c|c|c|c|c|c|c|c|c|c|c|c|c|c|c|c|c|c|c|c|c|}
\hline \multirow{3}{*}{ 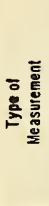 } & \multirow{3}{*}{\multicolumn{2}{|c|}{ 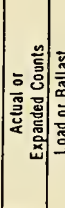 }} & \multirow{3}{*}{ 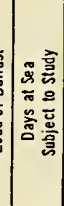 } & \multirow{3}{*}{ 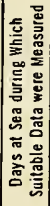 } & \multirow{3}{*}{ 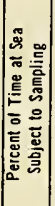 } & \multirow{3}{*}{ 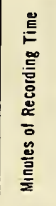 } & \multicolumn{14}{|c|}{ Number of Stress Cycies Falling between Stated Limits $f($ or a 30 -Day Period at Sea) } \\
\hline & & & & & & & \multicolumn{7}{|c|}{ For a Sample of $2 \mathrm{~min}$ Taken Evely Hour } & \multicolumn{7}{|c|}{ For a Sample of 2 min Taken Every Fourth Hourtt } \\
\hline & & & & & & & 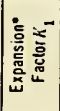 & 总 & 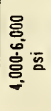 & 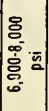 & 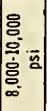 & 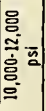 & 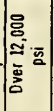 & 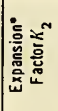 & 号官 & 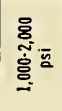 & 总 & 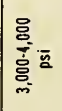 & 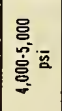 & 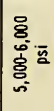 \\
\hline $\begin{array}{l}\text { Stress } \\
\text { Stbd }\end{array}$ & $\begin{array}{l}A \\
E \\
A \\
E\end{array}$ & $\begin{array}{l}\mathrm{L} \\
\mathrm{L} \\
\mathrm{L} \\
\mathrm{L}\end{array}$ & 75 & $\begin{array}{l}59 \\
40.9\end{array}$ & 79 & $\begin{array}{l}2,832 \\
2,136\end{array}$ & 15.25 & $\begin{array}{r}1,208 \\
18,422\end{array}$ & $\begin{array}{c}221 \\
3,370\end{array}$ & \begin{tabular}{|r|}
31 \\
473 \\
\end{tabular} & $\begin{array}{r}3 \\
46\end{array}$ & $\begin{array}{l}0 \\
0\end{array}$ & $\begin{array}{l}0 \\
0\end{array}$ & 80.89 & $\begin{array}{r}1,226 \\
99,171\end{array}$ & $\begin{array}{r}758 \\
61,315 \\
\end{array}$ & $\begin{array}{r}206 \\
16,663 \\
\end{array}$ & $\begin{array}{r}7 \\
95 \\
7,685\end{array}$ & $\begin{array}{r}=43 \\
3,178\end{array}$ & 324 \\
\hline $\begin{array}{c}\text { Stress } \\
\text { Stbd }\end{array}$ & $\begin{array}{l}\text { A } \\
\text { E } \\
A \\
\text { E }\end{array}$ & $\begin{array}{l} \\
B \\
B \\
B \\
\end{array}$ & $\begin{array}{l}69 \\
61.9\end{array}$ & $\begin{array}{l}65 \\
61.9\end{array}$ & 100 & $\begin{array}{l}3,120 \\
3,304\end{array}$ & 13.85 & $\begin{array}{r}1,690 \\
23,406\end{array}$ & $\begin{array}{r}142 \\
1,967\end{array}$ & $\begin{array}{r}14 \\
194\end{array}$ & $\begin{array}{l}0 \\
0\end{array}$ & $\begin{array}{l}0 \\
0\end{array}$ & $\begin{array}{l}0 \\
0\end{array}$ & $\begin{array}{c}\cdot \\
52.3 \\
\end{array}$ & $\begin{array}{r}1,409 \\
73,691 \\
\end{array}$ & $\begin{array}{r}1,336 \\
69,873 \\
\end{array}$ & $\begin{array}{r}427 \\
22,332 \\
\end{array}$ & $\begin{array}{r}115 \\
6,015 \\
\end{array}$ & $\begin{array}{r}17 \\
889 \\
\end{array}$ & $\begin{array}{r}5 \\
262 \\
\end{array}$ \\
\hline $\begin{array}{c}\text { Stress } \\
\text { Port }\end{array}$ & $\begin{array}{l}A \\
E \\
A \\
E\end{array}$ & $\begin{array}{l}\mathrm{L} \\
\mathrm{L} \\
\mathrm{L} \\
\mathrm{L}\end{array}$ & 75 & $\begin{array}{l}65 \\
34.8\end{array}$ & 87 & $\begin{array}{l}3,120 \\
1,888\end{array}$ & 13.85 & $\begin{array}{r}1,767 \\
24,473\end{array}$ & $\begin{array}{r}343 \\
4,751\end{array}$ & $\begin{array}{r}55 \\
762\end{array}$ & $\begin{array}{r}8 \\
111\end{array}$ & $\begin{array}{r}4 \\
55\end{array}$ & $\begin{array}{l}0 \\
0\end{array}$ & 91.53 & $\begin{array}{r}987 \\
90,340\end{array}$ & $\begin{array}{r}706 \\
64,620\end{array}$ & $\begin{array}{r}222 \\
20,320\end{array}$ & $\begin{array}{r}77 \\
7,048\end{array}$ & $\begin{array}{l}0 \\
0\end{array}$ & $\begin{array}{r}1 \\
92\end{array}$ \\
\hline $\begin{array}{c}\text { Stress } \\
\text { Port }\end{array}$ & $\begin{array}{l}A \\
E \\
A \\
E\end{array}$ & $\begin{array}{l}\text { B } \\
8 \\
B \\
B\end{array}$ & 61.9 & 35.2 & 57 & $\begin{array}{l}2,784 \\
1,922\end{array}$ & 15.52 & $\begin{array}{r}1,442 \\
22,380\end{array}$ & $\begin{array}{r}280 \\
4,345\end{array}$ & $\begin{array}{r}38 \\
590\end{array}$ & $\begin{array}{r}2 \\
31\end{array}$ & $\begin{array}{l}0 \\
0\end{array}$ & $\begin{array}{l}0 \\
0\end{array}$ & 89.90 & $\begin{array}{r}785 \\
70,752\end{array}$ & $\begin{array}{r}685 \\
61,582\end{array}$ & $\begin{array}{r}280 \\
25,172\end{array}$ & $\begin{array}{r}125 \\
11,238\end{array}$ & $\begin{array}{r}48 \\
4,315\end{array}$ & $\begin{array}{r}18 \\
1,618\end{array}$ \\
\hline
\end{tabular}

- The factors $K_{1}$ and $K_{2}$ are the tactors by which the cycles measured on the oscillogram samples are multiplied in order to estimate the number of stress cycles that would have been obtained if continuous measurements had been taken over a period of 30 days at sea.

tPeak-to-peak variation.

HEvery lourth sample recorded was utilized in this analysis.

Mathematical Synthesis of Cumulative LongTerm Distribution of Wave Heights Based on Assumption of a Log-Normal Distribution of Significant Wave Height. Let the instantaneous distribution of the wave heights pertaining to a particular sea, be defined by the Rayleigh distribution, thus

$$
p(x)=\frac{2 x}{E_{i}} e^{-x^{2} / E_{i}}
$$

where $^{14} E_{l}$ is the mean square value of all the individual wave heights comprising the $i$ th sea. Let $\bar{E}=c E^{1 / 2}$ be the significant wave height where $c$ is a constant. The distribution of $E$ is $\log$ normal, thus

$$
p(\log \bar{E})=\frac{1}{\sigma \sqrt{2 \pi}} e^{\frac{-(\log \bar{E}-u)^{2}}{2 \sigma^{2}}}
$$

where $\sigma^{2}$ is the variance, and $u$ is the mean value of $\log \bar{E}$. Therefore

16 $E_{i}$ is also equal to the total area under the power spectrum. See references (14.15) for a discussion of the power-spectrum concept.

$$
p(\bar{E})=\frac{1}{\bar{E}} p(\log \bar{E})
$$

and the probability $P$ that $x$ take on a value $\leq x_{2}$ is

$$
P\left(x_{i}\right)=\int_{\bar{E}=0}^{\bar{E}=\infty} \frac{1}{\sigma \bar{E} \sqrt{2 \pi}} e^{\frac{-(\log \bar{E}-u)^{2}}{2 \sigma^{2}}} \int_{x=0}^{x=x_{i}} \frac{2 c^{2} x}{\bar{E}^{2}} e^{\frac{-c^{2} x^{2}}{\bar{E}^{2}}} d x d \bar{E}
$$

The second integral is integrable, thus

$$
\begin{aligned}
P\left(x_{i}\right)=\int_{\bar{E}=0}^{\bar{E}=\infty} \frac{1}{\sigma \bar{E} \sqrt{2 \pi}} e^{\frac{-(\log \bar{E}-u)^{2}}{2 \sigma^{2}}} & {\left[1-e^{\frac{-c^{2} t^{2}}{\bar{E}^{2}}}\right] d \bar{E} }
\end{aligned}
$$

The integral may be evaluated numerically by a summation, thus

$$
P\left(x_{i}\right) \approx \sum_{j=1}^{j=N} f_{j}\left[1-e^{-x_{i}^{2} / E_{i}}\right]
$$




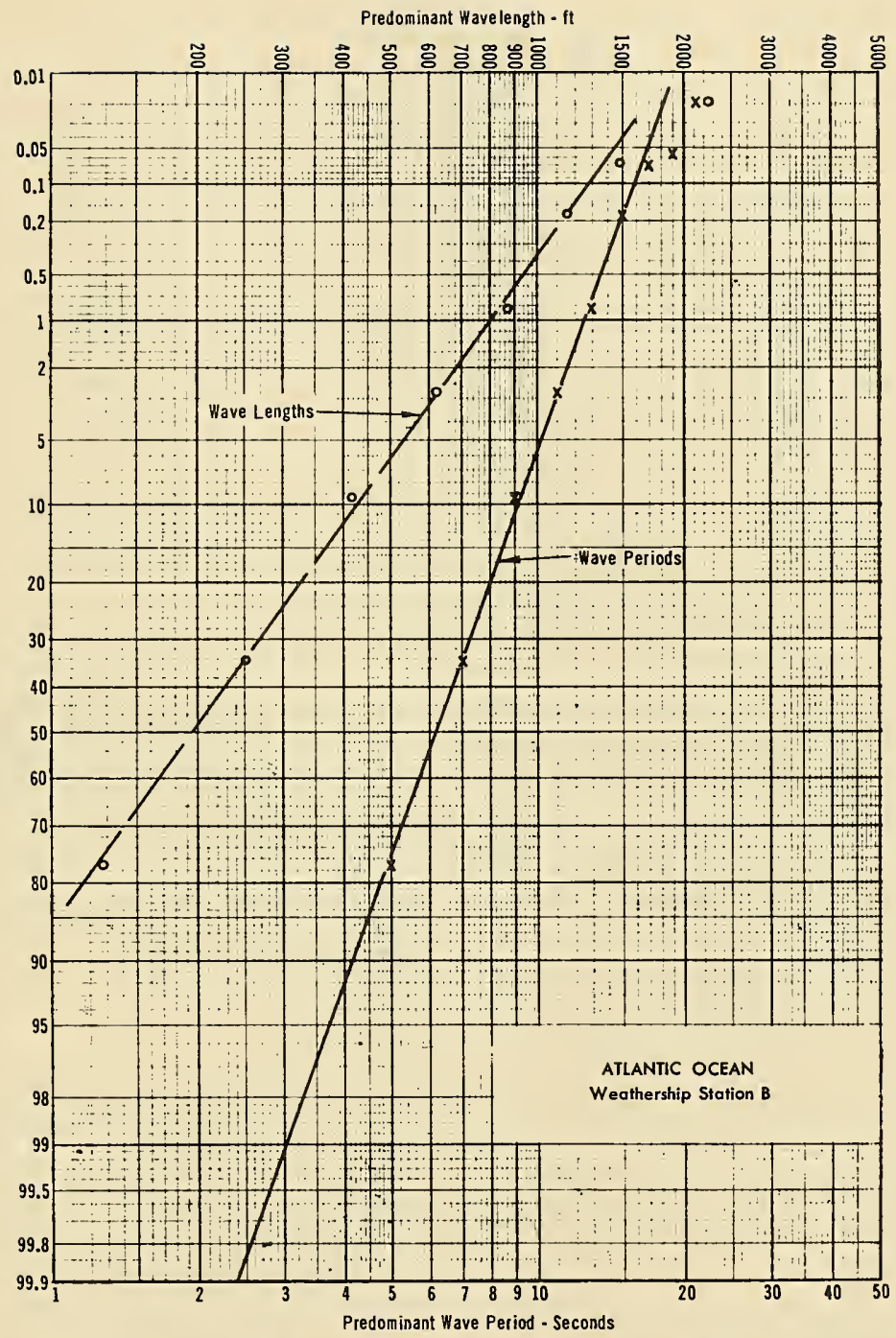

Fig. 14 Distribution of Significant Wave Periods and Lengths for Period, January, 1949 , to June, 1955 , Based on 16,060 Observations

Where $f_{f}$ is the fraction of all observed sea states defined by $E_{j}$.

The summation also could be carried out by computation of the individual probability density distribution corresponding to each value of $E_{\text {, }}$ which defines an observed significant wave height and then summing over-all values of observed significant wave heights. Both processes were 
Table 7 SS Esso Asheville-Distribution of Wave-Induced Stress Variations for a Period of 30 Days at Sea between Sep-

TEMBER 1, 1953 AND APRIL 3, 1954

(Average period of measured stress variation was about $9.2 \mathrm{sec}$. Most frequently observed period was in range 5 to 7 sec; see Fig. 3 .)

\begin{tabular}{|c|c|c|c|c|c|c|c|c|c|}
\hline \multirow{3}{*}{$\begin{array}{c}\text { Stress } \\
\text { psi }\end{array}$} & \multicolumn{9}{|c|}{$\begin{array}{l}\text { Estimated Number of Cycles of Magnitude } f \text { Greater than the Indicated Stress } \\
\text { (For a period of } 30 \text { deya at sea) }\end{array}$} \\
\hline & \multirow{2}{*}{$\begin{array}{l}\text { Average No. Cycles } \\
P \text { and } S \\
\text { Load and Ballast }\end{array}$} & \multicolumn{4}{|c|}{ Ship Loaded } & \multicolumn{4}{|c|}{ Ship in Ballast } \\
\hline & & \multicolumn{2}{|c|}{ Starboard Gage } & \multicolumn{2}{|c|}{ Port Gage } & \multicolumn{2}{|c|}{ Starboard Gage } & \multicolumn{2}{|c|}{ Port Gage } \\
\hline & $\because$ & • & & • & & - & $\ddot{0}$ & - & $\bullet$ \\
\hline 500 & 181,128 & & 188,123 & & 188,007 & & 174,072 & & 173,710 \\
\hline 1,000 & 97,640 & & 89,552 & & 97,667 & & 100,381 & & 102,958 \\
\hline 2,000 & 33,292 & 22,311 & 28,237 & 30,152 & 33,047 & 25,567 & 30,508 & 27,346 & 41,376 \\
\hline 3,000 & 12,170 & & 11,574 & & 12,127 & & 8,176 & & 16,204 \\
\hline 4,000 & 4,174 & 3,889 & 3,889 & 5,679 & 5,679 & 2,161 & 2,161 & 4,966 & 4,966 \\
\hline 5,000 & 1,139 & & 843 & & 1,020 & & 456 & & 2,239 \\
\hline 6,000 & 566 & 519 & 519 & 928 & 928 & 194 & 194 & 621 & 621 \\
\hline 8,000 & 61 & 46 & 46 & 166 & 166 & 0 & 0 & 31 & 31 \\
\hline 10,000 & 13 & 0 & 0 & 55 & 55 & 0 & 0 & 0 & 0 \\
\hline 12,000 & 0 & 0 & 0 & 0 & 0 & 0 & 0 & 0 & 0 \\
\hline \multicolumn{10}{|c|}{$\begin{array}{l}\text { - This estimate is based on oscillograms taken for a duration of } 2 \text { min at intervals of } 1 \mathrm{hr} \text {. } \\
\text { - This estimate is similar to the preceding one except that, for stress values less than 4,000 p 31, sample } \\
\text { oscillograms of } 2 \text {-min duration, taken at intervals of } 1 \mathrm{hr} \text {, were utilized in Figure } 2 \text {. }\end{array}$} \\
\hline
\end{tabular}

carried out for the wave-height data observed at ocean station $\mathrm{C}$. The method of summation given by the last expression is by far the more convenient of the two choices. The computed cumulative probabilities for the wave heights are plotted in Fig. 13. Inspection of this figure shows that the cumulative distribution of wave heights derived from the distribution of significant wave heights also may be represented by a lognormal distribution.

It is concluded on the basis of this analysis of the extensive available wave observations, that the distribution functions of both the significant wave heights and the wave heights proper of ocean waves are approximated by the log-normal distribution. This conclusion has not been evaluated by use of standard statistical tests of significance because the data consist principally of visual observations and the accuracy of these observations has not been determined thus far.

\section{Stress Variations}

The stress and ship-motion data given in this paper furnish a "truncated" or "censored" distribution ${ }^{15}$ thus named because only values larger than a specific lower limit are given. Fisher (16) has devised a method for determining the parameters $\sigma$ and $\xi$ which define the normal (or lognormal) distribution from the measured truncated

15 Truncated at the lower end of the distribution. data. If the analytically expressed distribution, thus determined, fits the measured data reasonably well, it is probable that the data follow the normal distribution. The method devised by Fisher will be applied here, except for the cases of the Gopher Mariner and Ocean Vulcan for which the degree of truncation is so large that a better estimate probably can be made on the basis of the estimated average periodicity of stress variation. The latter two cases are given only to help support the conclusions based on other more extensive tests.

\section{Esso Asheville}

The period covered by the data is from September 1, 1953 to April 3, 1954 . Oscillograms of strain, taken at hourly intervals for a duration of $2 \mathrm{~min}$ each, were analyzed in terms of stress variations (see Tables 6 and 7 ) and classified according to the magnitude of these variations. The measured number of variations were then multiplied by a factor to give the estimated number of variations which would have been recorded if continuous measurements had been made. Application of the Fisher method to the truncated data yields the log-normal distribution patterns shown in Fig. 16. The plotted points in Fig. 16 were obtained by use of the theoretical degree of truncation; their scatter from the straight lines should give an unbiased measure of the applicability of the assumed normal distri- 


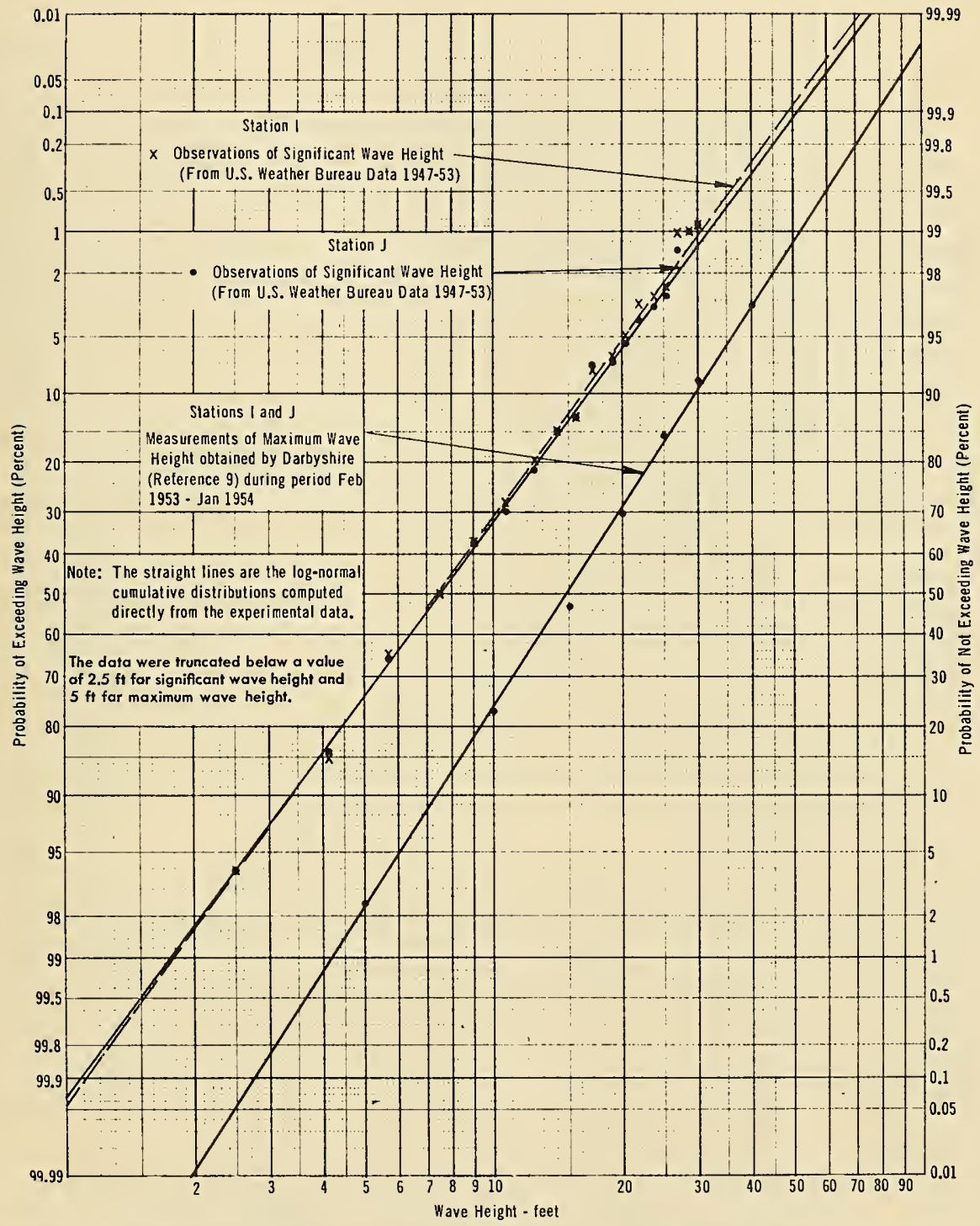

Fig. 15 Comparison of Wave-Height Distributions Derived from Visual ObSERvations and from MEasurements of Wave Heights at Atlantic Ocean Stations I and J

bution, within the range throughout which stress data were obtained.
Let the hypothesis be examined that, for this vessel and service, the logarithm of the sea-induced 


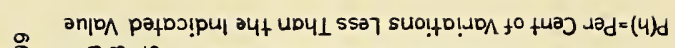

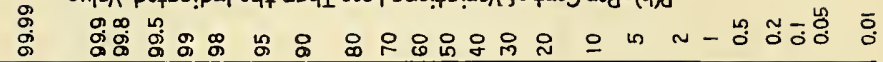

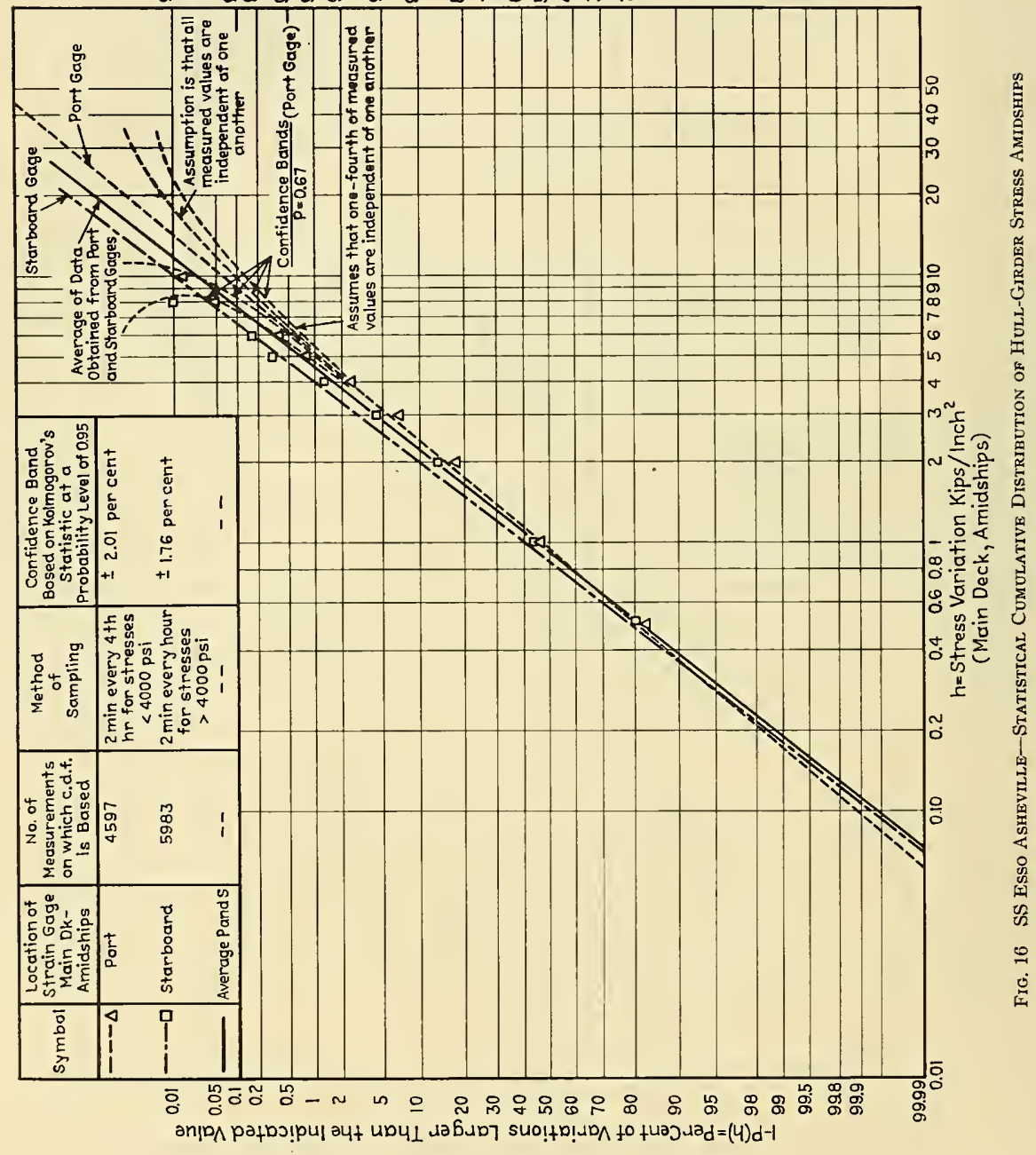


Table 8 SS Esso Asheville-Computation of Confidence limits for Distribution of Stress Variations, Port Side, Shown in Fig. 16

\begin{tabular}{|c|c|c|c|c|c|c|c|c|c|c|c|}
\hline \multirow{2}{*}{$\begin{array}{c}\text { Stress } \\
\text { psi } \\
x\end{array}$} & \multirow{2}{*}{$\begin{array}{c}\log _{10} \text { Stress } \\
x_{L}{ }^{*}\end{array}$} & \multirow{2}{*}{$\begin{array}{c}\left(\bar{x}_{L}-x_{L}\right) \\
y\end{array}$} & \multirow{2}{*}{$\gamma^{2}$} & \multirow{2}{*}{$f\left(x_{L}\right)^{* * *}$} & \multirow{2}{*}{$\begin{array}{c}q= \\
(1-p) \times 10^{2}\end{array}$} & \multirow{2}{*}{$p^{3}$} & \multirow{2}{*}{$\begin{array}{l}\frac{1}{f} \sqrt{\frac{p q}{N}} \\
=S_{x}\end{array}$} & \multirow{2}{*}{$\begin{aligned} & x_{L}+S_{x} \\
= & \log x_{\text {upper }}\end{aligned}$} & \multirow{2}{*}{$\begin{aligned} & x_{L}-S_{x} \\
= & \log x_{\text {1ower }}\end{aligned}$} & \multicolumn{2}{|c|}{$\begin{array}{c}\text { Confidence Limits } \\
\qquad \mu=0.67\end{array}$} \\
\hline & & & & & & & & & & $\begin{array}{l}x_{\text {upper }} \\
\text { psi }\end{array}$ & $\begin{array}{l}x_{\text {lower }} \\
\text { psi }\end{array}$ \\
\hline 20,000 & 4.3010 & -1.3255 & 1.757 & $\begin{array}{l}1.980 \\
\times 10^{-4}\end{array}$ & 0.0011 & 0.99999 & $\begin{array}{c}0.247 \\
(0.494) \dagger\end{array}$ & $\begin{array}{c}4.5480 \\
(4.7950)\end{array}$ & $\begin{array}{c}4.0540 \\
(3.8370)\end{array}$ & $\begin{array}{c}35,300 \\
(62,400)\end{array}$ & $\begin{array}{l}11,300 \\
(6,400)\end{array}$ \\
\hline 16,000 & 4.2041 & -1.2286 & 1.5095 & $\begin{array}{l}6.798 \\
\times 10^{-4} \\
\end{array}$ & 0.005 & 0.99995 & $\begin{array}{c}0.153 \\
(0.306) \\
\end{array}$ & $\begin{array}{c}4.3571 \\
(4.5101) \\
\end{array}$ & $\begin{array}{r}4.0511 \\
(3.8981) \\
\end{array}$ & $\begin{array}{r}22,800 \\
(32,400) \\
\end{array}$ & $\begin{array}{l}11,100 \\
(7,900) \\
\end{array}$ \\
\hline 14,000 & 4.1461 & -1.1706 & 1.3703 & $\begin{array}{l}1.361 \\
\times 10^{-3}\end{array}$ & 0.009 & 0.97991 & $\begin{array}{c}0.103 \\
(0.205)\end{array}$ & $\begin{array}{c}4.2491 \\
(4.3521)\end{array}$ & $\begin{array}{c}4.0431 \\
(3.9401)\end{array}$ & $\begin{array}{c}17,900 \\
(22,500)\end{array}$ & $\begin{array}{l}10,900 \\
(8,700)\end{array}$ \\
\hline 10,000 & 4.0000 & -1.0245 & 1.050 & $\begin{array}{l}6.718 \\
\times 10^{-3}\end{array}$ & 0.050 & 0.9995 & $\begin{array}{c}0.0491 \\
(0.0982)\end{array}$ & $\begin{array}{c}4.0491 \\
(4.0982)\end{array}$ & $\begin{array}{c}3.9509 \\
(3.9018)\end{array}$ & $\begin{array}{c}11,300 \\
(12,700)\end{array}$ & $\begin{array}{r}8,900 \\
(8,000)\end{array}$ \\
\hline 8,000 & 3.9031 & -0.9276 & 0.8604 & 1.729 & 0.150 & 0.9985 & $\begin{array}{c}0.0335 \\
(0.0670)\end{array}$ & $\begin{array}{c}3.9366 \\
(3.9701)\end{array}$ & $\begin{array}{c}3.8696 \\
(3.8361)\end{array}$ & $\begin{array}{c}8,600 \\
(9,300)\end{array}$ & $\begin{array}{l}7,400 \\
(E, 900)\end{array}$ \\
\hline 4,000 & 3.6021 & -0.6266 & 0.3926 & 0.1781 & 2.3 & 0.977 & $\begin{array}{c}0.0128 \\
(0.0252)\end{array}$ & $\begin{array}{c}3.6147 \\
(3.6273)\end{array}$ & $\begin{array}{c}3.5695 \\
\left(3.576^{9}\right)\end{array}$ & $\begin{array}{c}4,100 \\
(4,200)\end{array}$ & $\begin{array}{r}3,900 \\
(3,800)\end{array}$ \\
\hline 1,000 & 3.0000 & -0.0245 & 0.00060 & 1.256 & 47.0 & 0.53 & $\begin{array}{c}0.0060 \\
(0.0120)\end{array}$ & $\begin{array}{c}3.0060 \\
(3.0120)\end{array}$ & $\begin{array}{c}2.940 \\
(2.99 .80)\end{array}$ & $\begin{array}{l}1,010 \\
(1,040)\end{array}$ & $\begin{array}{r}990 \\
(970)\end{array}$ \\
\hline
\end{tabular}

*The quantiles of $x_{L}$ are distributed normally with the mean value $x_{L}$ and standard deviation $\frac{1}{f\left(x_{L}\right)} \sqrt{\frac{p q}{N}}$ where $p$ is the theoretical value of the cumulative distribution function corresponding to $x_{L}$ and $f\left(x_{L}\right)$ is the value of the logarithmic distribution function corresponding to $x_{L}$. $N=4,597$ observations.

**The distribution function of $x_{L}\left(\log\right.$ of stress on port side of deck) has a mean value $\bar{x}_{L}=2.9755$ and a standard deviation $\sigma_{L}=0.3167$, that is $f=\frac{1}{a_{L} \sqrt{2 \pi}} \exp \left[-\frac{\left(\bar{x}_{L}-x_{Z}\right)^{2}}{2 \sigma_{L}{ }^{2}}\right] \operatorname{or} \log _{10} f=0.1004-2.1650\left(\bar{x}_{L}-x_{L}\right)^{2}$.

tThe figures in parentheses are computed on the basis of the assumption that every fourth observation was an independent random observation, $N=\frac{1}{4}(4,597)$.

stresses is normally distributed. Statistical tests of significance assume that the data consist of random independent observations. Consecutive cycles of stress and motion are not independent. ${ }^{16}$ Thus it will not be possible to give accurate probabilities for the hypothesis considered. However if it is assumed, falsely, that all data are random and independent then a better fit will be required between the assumed log-normal distribution and the experimental data than is necessary at the given confidence level.

One rather simple test of significance is Kolmogorov's statistic (17) which permits one to assert with a specified level of probability that the true continuous probability distribution function is contained within the confidence band everywhere. A more accurate (and tedious) test is to compute the expected variation of the 15 Autocorrelations have been computed for typical stress and
pitch variations; these computations indicate that observations separated hy about 6 cycles are "reasonably" independent. quantiles of samples taken from the hypothetical population. The latter method has been utilized to fit confidence limits to the distribution of stress variations measured on the port side amidships, see Fig. 16 and Table 8 . It is evident from an inspection of Fig. 16 that the experimental data are approximated by the log-normal distribution with a good degree of probability, especially when the accuracy with which the stress measurements were obtained is considered. To avoid confusion, confidence bands have not been fitted to those straight lines in Fig. 16 which represent the cumulative distribution function of the starboard and of the. average stresses. However, visual inspection indicates that here too there is good agreement.

Finally, the hypothesis may be tested by inquiring into the relationship that exists between the underlying cumulative distribution of all stress variations and the cumulative "extreme value" distribution of the stress variations. 


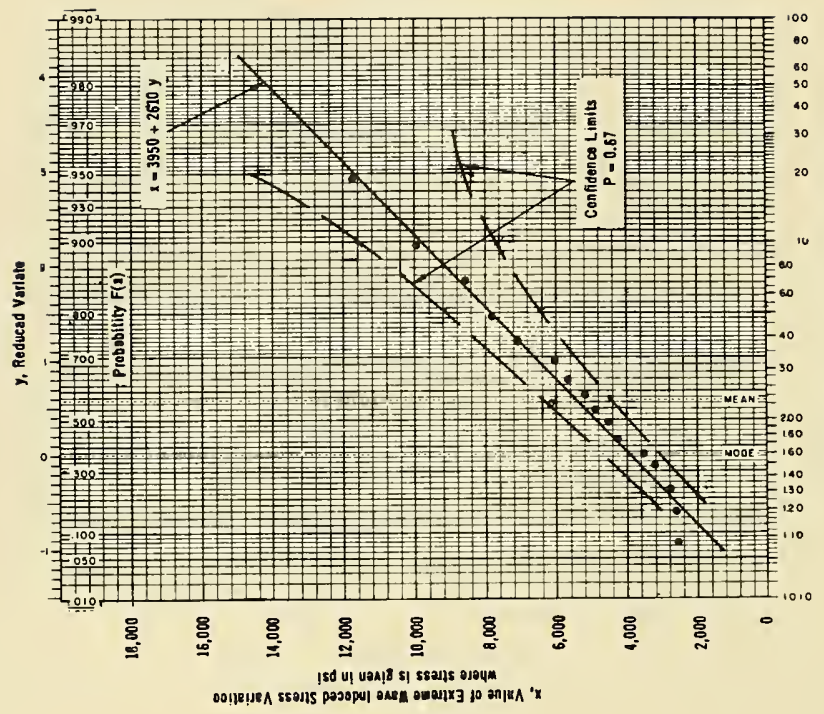

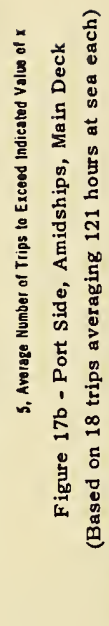

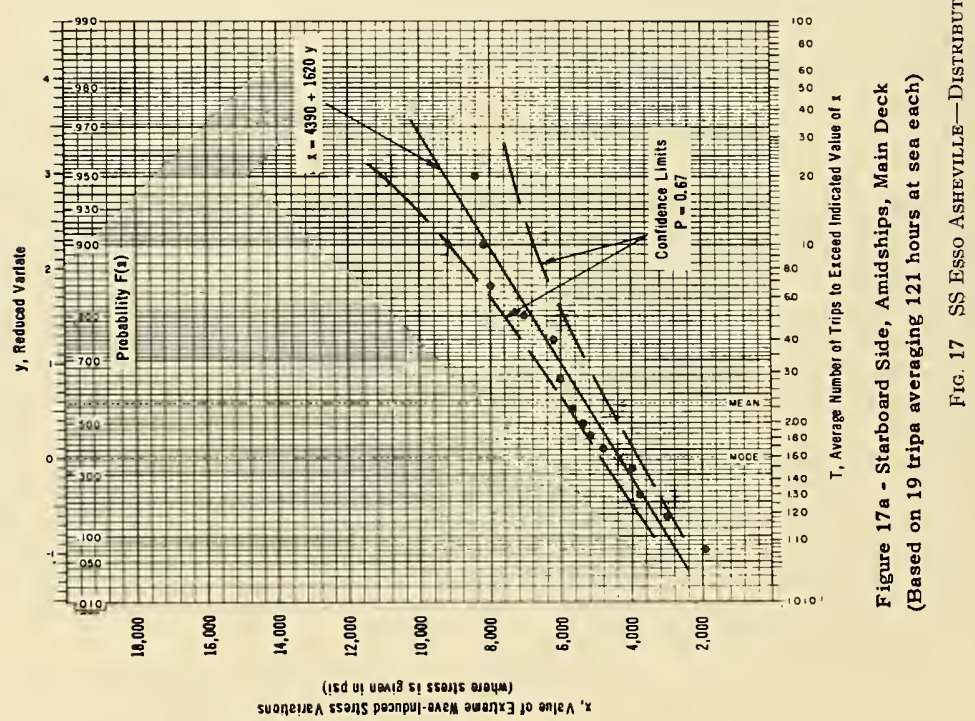


Table 9 Hull-Girder Strain Variations Measured on Strength Deck or Keel Amidships

\begin{tabular}{|c|c|c|c|c|c|c|c|c|c|c|c|c|c|c|c|c|}
\hline \multirow{2}{*}{ 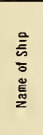 } & \multirow{2}{*}{ 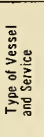 } & \multirow{2}{*}{ 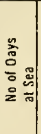 } & \multirow{2}{*}{ 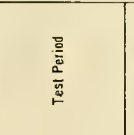 } & \multirow{2}{*}{ 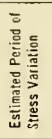 } & \multirow{2}{*}{ 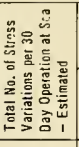 } & \multicolumn{10}{|c|}{ Frequency 0istribution of Stress } & \multirow{2}{*}{ 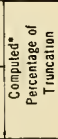 } \\
\hline & & & & & & \multicolumn{10}{|c|}{$\begin{array}{l}\text { Number of Stress Variations per } 30 \text { Day Period of Sea Duly } \\
\text { (The class limits are given in kups per square Inch) }\end{array}$} & \\
\hline \multirow{3}{*}{ 号岂 } & \multirow{3}{*}{ 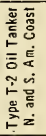 } & \multirow{3}{*}{144} & \multirow{2}{*}{1 Sep $53-3$ Apr 54} & \multirow{2}{*}{ - } & \multirow{3}{*}{220,000} & $12-1$ & $1-2$ & 2-3 & 3-4 & $4-5$ & $5-6$ & 6-8 & $8-10$ & $10-12$ & $\begin{array}{l}\text { Class } \\
\text { Limits }\end{array}$ & \multirow{3}{*}{18.4} \\
\hline & & & & & & 83,488 & 64,348 & 21,122 & 7996 & 3035 & 573 & 505 & 48 & 13 & & \\
\hline & & & \multicolumn{2}{|c|}{ Average of Load and Ballast Conditions } & & \multicolumn{10}{|c|}{$\begin{array}{l}\text { This distribution is based on } 10,580 \text { measured stress variations. The average of the port and starboard } \\
\text { gage data was used. }\end{array}$} & \\
\hline \multirow{3}{*}{ 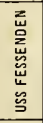 } & \multirow{3}{*}{ 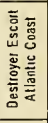 } & \multirow{3}{*}{74} & \multirow{3}{*}{$\begin{array}{l}\text { Dec } 52 \text { - Apr } 53 \\
\text { Oct } 53 \text { - Nov } 54\end{array}$} & \multirow{3}{*}{ - } & \multirow{3}{*}{ - } & & & $2-4$ & & $4-8$ & & $8-10$ & $10-14$ & $>14$ & $\begin{array}{l}\text { Class } \\
\text { Limits }\end{array}$ & \multirow{3}{*}{13.9} \\
\hline & & & & & & & & 121,706 & & 39,215 & & 2381 & 176 & 39 & & \\
\hline & & & & & & & This & distributio & in is based & on 403,343 & azasured $\mathrm{s}$ & tress variatı & & & & \\
\hline 苂 & 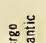 & \multirow{3}{*}{50} & \multirow{3}{*}{5 Feb $54-15$ May 54} & \multirow{3}{*}{$7 \mathrm{Sec}$} & & & & $2-4$ & 4-6 & 6.6 & $8 \cdot 10$ & $10-12$ & $12-20$ & $>20$ & $\begin{array}{l}\text { Class } \\
\text { Limıts } \\
\end{array}$ & \multirow{3}{*}{97.6} \\
\hline 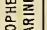 & 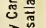 & & & & 362,000 & & & - & 7784 & 966 & 100 & 19.5 & 1.8 & 0.65 & & \\
\hline 踥 & 各愛 & & & & & $\begin{array}{r}\text { This dis } \\
\text { gage data }\end{array}$ & $\begin{array}{l}\text { tibution is } \\
\text { was used. }\end{array}$ & based on : & 7,747 meas & uled siress & aitations. & The averag & of the por & it and sta & larboard & \\
\hline$\sum \frac{z}{d}$ & 号 & - & $24 y_{e}$ als & $85 e$ & 324000 & & & $2.2 \cdot 4.5$ & $4.5-6.7$ & $6.7-9.0$ & $9.0-11.2$ & $11.2 \cdot 13.4$ & $13.4-15.7$ & $>15.7$ & $\begin{array}{l}\text { Class } \\
\text { Limits }\end{array}$ & \\
\hline 岂 & 춘 & - & 2he Years & 8 sec. & 324,000 & & & 16,690 & 773 & 46 & 3 & 0.17 & 0.08 & 0 & & 94.6 \\
\hline & & & & & & & This 0 & distribution & is based on & $210,177 \mathrm{~m}$ & asured sti & ess varlation & & & & \\
\hline 密 & 产 & & & & & & & $2-4$ & $4-6$ & 6.8 & $8-10$ & $10-20$ & $>20$ & & Class & \\
\hline 恕 & 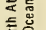 & 46 & Kinter 55.56 & - & - & & & 109,250 & 40,660 & 2000 & 1213 & 127 & 0.3 & & & 6.4 \\
\hline 㟧 & $\bar{c}^{\circ}$ & & & & & & This d & istribution & is based on & 235,010 me & sured stre & ss varration & & & & \\
\hline 戈采 & 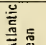 & & & & & $\frac{1}{2}-1$ & $1-1 h_{2}$ & $11^{\prime}-2$ & $2-2 / 2$ & $2 h-5$ & $>5$ & & & & $\begin{array}{l}\text { Class } \\
\text { Limits }\end{array}$ & 6. \\
\hline 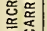 & 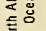 & 17 & Winter $55-56$ & - & - & 62,122 & 31,733 & 13,126 & 5868 & 3198 & 65 & & & & & 16.6 \\
\hline & $\overline{\bar{c}}$ & & & & & & This & distribution & is based on & $65,797 \mathrm{me}$ & isured stre & 55 variations & & & & \\
\hline & פ & & & & & $\mid 0.67-1.34$ & 1.34-2.01 & $2.01-2.68$ & $2.68-3.35$ & $3.35-6.7$ & $>6.7$ & & & & $\begin{array}{l}\text { Class } \\
\text { Limuts }\end{array}$ & \\
\hline$\frac{x}{z}$ & 旁产 & 61 & Winter 54-55 & - & - & 64,603 & 34,617 & 9444 & 5365 & 2480 & 2 & & & & & 14.8 \\
\hline$\overline{\bar{\Xi}}$ & 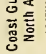 & & & & & & This dist & tribution is & based on 23 & 6,905 meas & irements of & stress varia & atian. & & & \\
\hline
\end{tabular}

It has been shown in the literature $(6,19)$, that, if a distribution is normal or log normal, the largest values in repeated large samples from this distribution have a cumulative distribution $F(x)$ of their own $(18,19,20)$ which approaches, as the sample size becomes larger and larger, the form

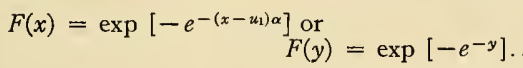

where $y=\left(x-u_{1}\right) \alpha$ and is called the reduced variate.

In the present case $x$ is a possible value of the extreme of the stress, and $u_{1}$ and $\alpha$ are constants for a particular distribution. Special co-ordinate paper has been devised, Fig. 17, on which such a distribution will plot as a straight line. Gumbel (19) has devised a method for estimating the parameters $u_{1}$ and $\alpha$ of the distribution of ex- tremes on the basis of measurements of extremes. The method is applied here to the extreme seainduced stress variations measured in 2-min samples taken at hourly intervals during 19 trips, each averaging $121 \mathrm{hr}$ underway.

The resulting extreme-value distributions for the port and starboard strain gages are plotted in Fig. 17. If all values of $x$ are different, $F(x)$ for each observed point equals $i /(n+1)$ where $i$ is the order number of the observed value when they are arranged in order of increasing magnitude and $n$ is the total number of observed extremes. The plotted points represent the individual measured extremes whereas the straight line in Fig. 17 represents the best fit to the measured data, utilizing the method of Gumbel (19) under the assumption that the underlying distribution is of the log-normal type.

On this assumption, $F(x)$ represents the frac- 


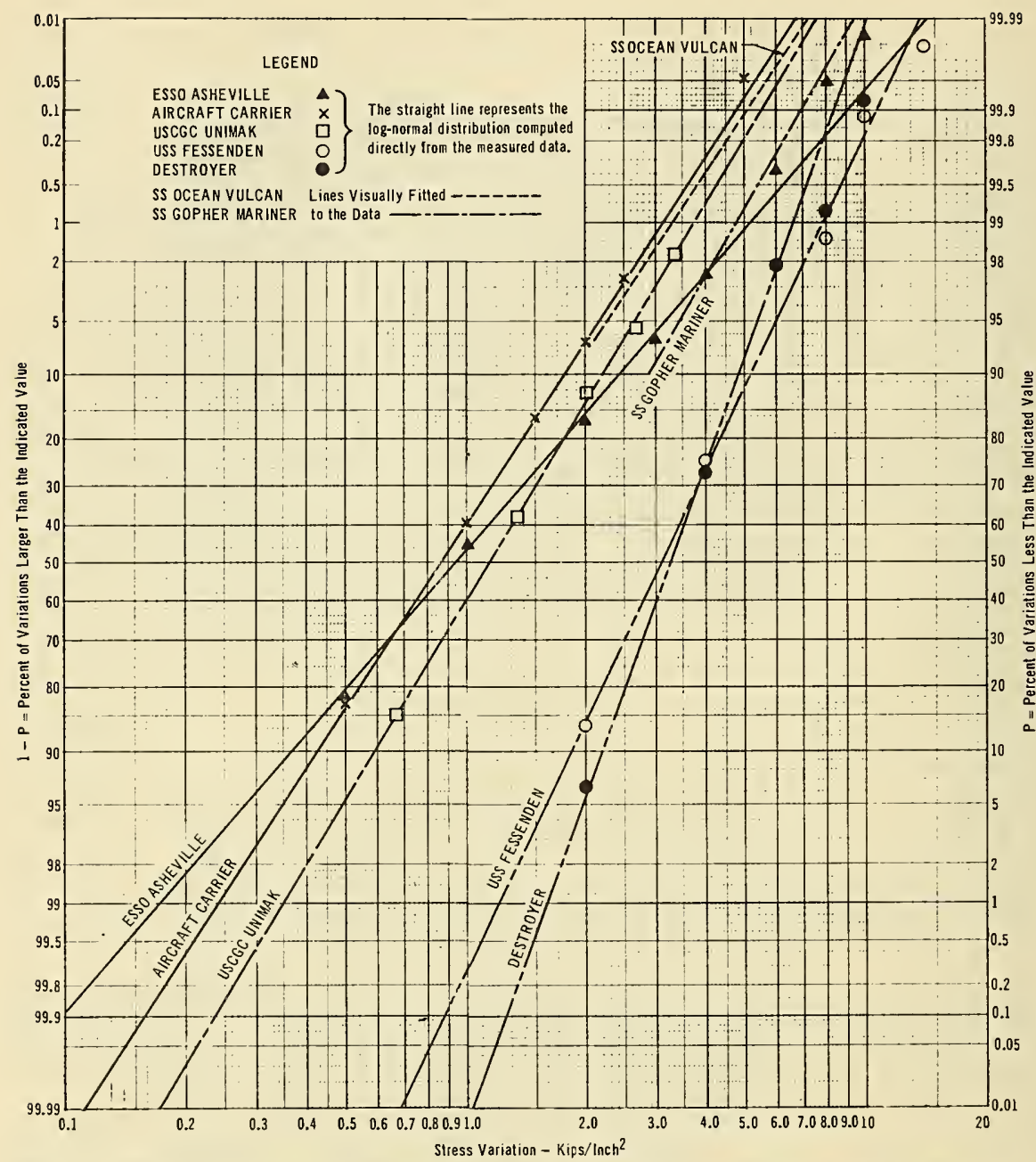

Fig. 18 Cumulative "Long-Term" Distribution of Wave-Induced, Hull-Girder Stresses for Several Ships

tion of all trips which, on the average, are expected to give an extreme value of the stress less than $x$. On the bottom scale, values of $1 /(1-$ $F$ ), denoted by $T$, are shown; $T$ is the number of trips the ship must make, on the average, in order to exceed the limit during at least one of the 2min sampling periods. The dashed confidence limits drawn in Fig. 17 denote the limits within which 67 per cent of the experimental data would be expected to fall if measurements of extremes were conducted indefinitely and if the assumed distribution were valid. Inasmuch as the scatter lies well within these limits, it is concluded that, for the service conditions encountered, the extreme-value distribution (from hourly 2-min samples) of the sea-induced hull-girder stresses 
Table 10 SS Gopher Mariner-Excerpts of Data for Several Severe Sea Conditions

\begin{tabular}{|c|c|c|c|c|c|c|c|c|c|c|c|c|c|c|c|c|c|c|c|c|c|c|c|c|c|c|c|c|}
\hline \multirow{3}{*}{ 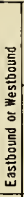 } & \multicolumn{3}{|c|}{ Date, Time } & \multicolumn{2}{|c|}{$\begin{array}{l}\text { Location } \\
\text { Approx. }\end{array}$} & \multicolumn{2}{|c|}{$\begin{array}{l}\text { Direction Rel } \\
\text { to Ship } \\
\text { Est'd }\end{array}$} & \multicolumn{3}{|c|}{$\begin{array}{l}\text { Wind and Sea } \\
\text { Observed Cond. }\end{array}$} & \multicolumn{4}{|c|}{$\begin{array}{l}\text { Computed Data for Waves } \\
\text { Fully Developed Under } \\
\text { Observed Conditions" }\end{array}$} & \multirow{2}{*}{ 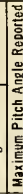 } & \multirow{3}{*}{ 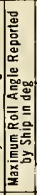 } & \multicolumn{12}{|c|}{$\begin{array}{l}\text { Number of Cyclic Stress Varıtions Falling Between Given Limits } \\
\text { Stresses Were Measured at Main Deck Near Amidships"* }\end{array}$} \\
\hline & \multirow{2}{*}{ 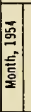 } & \multirow[t]{2}{*}{ 离 } & \multirow{2}{*}{ 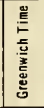 } & \multirow{2}{*}{ 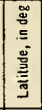 } & \multirow{2}{*}{ 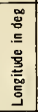 } & \multirow{2}{*}{ 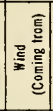 } & \multirow{2}{*}{ 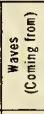 } & \multirow[t]{2}{*}{$\begin{array}{l}+ \\
\text { ș } \\
\text { s } \\
\text { 怘 } \\
\text {. }\end{array}$} & \multirow{2}{*}{ 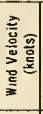 } & \multirow{2}{*}{ : } & \multirow{2}{*}{ 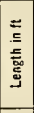 } & \multirow{2}{*}{ 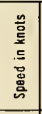 } & \multirow{2}{*}{$\begin{array}{l}\text { 요 } \\
\text { 동 } \\
\text { 흠 } \\
\text { 몸 }\end{array}$} & \multirow{2}{*}{ 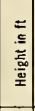 } & & & \multicolumn{2}{|c|}{$\begin{array}{l}4000 \text { psi to } \\
6000 \text { psi }\end{array}$} & \multicolumn{2}{|c|}{$\begin{array}{c}6000 \text { psi } 10 \\
8000 \text { psi }\end{array}$} & \multicolumn{2}{|c|}{$\begin{array}{l}8000 \text { psi to } \\
10,000 \text { psi }\end{array}$} & \multicolumn{2}{|c|}{$\begin{array}{c}10,000 \text { ps } 1 \text { to } \\
12,000 \text { psi }\end{array}$} & $\begin{array}{r}12,000 \\
20,00\end{array}$ & 00 pSI 10 & 20,0 & $\begin{array}{l}\text { ver } \\
00 \text { psi }\end{array}$ \\
\hline & & & & & & & & & & & & & & & 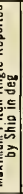 & & Port & Stod & Port & Stbd & Port & Stbd & Port & Stbd & Port & Stbo & Port & Stbd \\
\hline E & 2 & $13-14$ & 0600 & N & 11.8 & $\begin{array}{l}\text { Poit } \\
\text { Beam }\end{array}$ & $\begin{array}{l}\text { Port } \\
\text { Beam }\end{array}$ & $6^{1}$ & $0-37$ & 1400 & 750 & 37.5 & 12.2 & 14.0 & 8 & 30 & 38 & 1822 & 6 & 415 & 0 & 38 & 0 & 0 & 0 & 0 & 0 & 0 \\
\hline$w$ & 2 & $25-26$ & 0400 & $\begin{array}{c}48.4 \\
N\end{array}$ & 8 & $\begin{array}{l}\text { Stbd } \\
\text { Bow }\end{array}$ & $\begin{array}{l}\text { Stbd } \\
\text { Bow }\end{array}$ & $6^{2}$ & 37 & 1800 & 800 & 39.0 & 12.6 & 14.1 & 18 & 33 & 1339 & 1595 & 109 & 181 & 22 & 18 & 0 & 3 & 0 & 0 & 0 & 0 \\
\hline$W$ & 3 & 4. 5 & 1245 & 35 & 67 & $\begin{array}{l}\text { Port } \\
\text { Bow }\end{array}$ & $\begin{array}{l}\text { Port } \\
\text { Bow }\end{array}$ & $5^{3}$ & 30 & 450 & 360 & 26.1 & 8.4 & 7.0 & 8 & s & 298 & 918 & 0 & 157 & $B$ & 24 & 3 & 12 & 0 & 3 & 0 & 0 \\
\hline$w$ & 4 & 8. 9 & 1130 & $\begin{array}{r}49 \\
\mathrm{~N}\end{array}$ & $\begin{array}{c}19 \\
H\end{array}$ & Bow & Bow & 10 & 23 & 2100 & 570 & 32.5 & 10.5 & 8.7 & 12 & 10 & 1061 & 1819 & 83 & 314 & 21 & 35 & 3 & 20 & 0 & 0 & 0 & 0 \\
\hline$w$ & 4 & $13-14$ & 1000 & \begin{tabular}{|r}
41 \\
N
\end{tabular} & $\begin{array}{l}57 \\
W\end{array}$ & & trable & $4-5$ & $4-27$ & 350 & - & - & - & - & 6 & 15 & 144 & 446 & 8 & 6 & 7 & 14 & 0 & 8 & 0 & 1 & 0 & 1 \\
\hline & otes & $T$ & 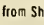 & 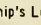 & & & & & & & & & & & & & & & & & & & & & & & & \\
\hline & ${ }^{1} 210$ & 00,13 & Feb to & 0100, & Eeh. & reen & 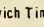 & & . & 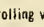 & very he & (1) & and yaw & 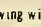 & ? & 等 & y high & $h W-N$ & sea and & $d$ very & 药 & swells. & & & & & & \\
\hline & ${ }^{2} 000$ & 0 to 080 & $00,26 \mathrm{~F}$ & Feb, $G$ & eenwic & ch Time: & & & $\begin{array}{l}\text { ery roug } \\
\text { atei ove }\end{array}$ & $\begin{array}{l}\text { ggh and } \\
\text { er bow }\end{array}$ & $\begin{array}{l}\text { high } \\
\text { and st }\end{array}$ & $\begin{array}{l}\text { W-NW se } \\
\text { tbd side }\end{array}$ & $\begin{array}{l}\text { seas. L } \\
\text { le. }\end{array}$ & $\mathrm{ng}$, he & heavy & NH sW & wells. & Vess & rolling & $g$ and pit & hing v & very hea & avily, & yawing n & moderate & ly an & hippI & \\
\hline & 3090 & 001013 & $300,5 \mathrm{~N}$ & March, & Greenw & wich TIme & & & $\begin{array}{l}\text { Ssel pI } \\
\text { ot higl }\end{array}$ & $\begin{array}{l}\text { pitching } \\
\text { gh west }\end{array}$ & $\begin{array}{l}\text { heavi } \\
\text { erly sh }\end{array}$ & $\begin{array}{l}\text { ily and } \\
\text { wells. }\end{array}$ & $\begin{array}{l}\text { poundi } \\
\text { Reduce }\end{array}$ & $\begin{array}{l}\text { ing occ } \\
\text { e speed }\end{array}$ & $\begin{array}{l}\text { casion } \\
\text { ed to e }\end{array}$ & gally. & $\begin{array}{l}\text { Shipp } \\
\text { yessel. }\end{array}$ & piag w & I oyer & bow an & porl si & side of & main de & leck. Ve & ery rough & h wester & rly sea & as and \\
\hline & tSea & a State & Code a & is given & by $H y$ & ydlograph & hisc off & $P$ & ication & on No & $606-e$ & publish & hed 1950 & & & & & & & & & & & & & & & \\
\hline & Comp & nputed & from d & Pra & & It of & The & & $\mathrm{Se}$ & ea & Swel & "Haves" & " Naval & Hea & & etvice & Memora & tandu & $0.13 \mathrm{~s}$ & $3 / 45$ & talty, & L Londo & lon, & & & & & \\
\hline
\end{tabular}

is approximately of the form given by Equation [1] and that the cumulative distribution functions of both the underlying and the extreme-value distributions are compatible.

It is concluded, on the basis of these several tests of significance, that the basic hypothesis to be tested is "probably" true; that is, the logarithm of the sea-induced stresses is, at least approximately, normally distributed.

\section{USS Fessenden}

The cumulative distribution function of stress variation was obtained from data measured during the periods December 1952 to April 1953 and October 1954 to November 1954. The vessel was instrumented with a 10 -in. mechanical statistical strain gage and counter (2). The measured data are given in Table 9 and the corresponding distribution pattern is shown in Fig. 18. The deviation of the plotted experimental points from the hypothetical distribution, which was computed from the measured data on the assumption that the stresses do follow the log-normal distribution, was within the accuracy of measurement. Thus it may be concluded, for the USS Fessenden, that the distribution of hullgirder stresses or bending moments can be approximated by a log-normal distribution.

\section{SS Ocean Vulcan}

This vessel has been subjected to extensive sea tests. The general construction of the vessel as well as the statistical strain gage installed thereon have been described elsewhere (21). Stress variations which were measured over a period of $2 \frac{1}{2}$ years, have been reported in reference (7) from which the values given in Table 9 have been taken. Owing to the high degree of truncation of the data, it was thought best to estimate the degree of truncation from the measured average period of stress variation. The data for this vessel appear to follow the log-normal distribution, Fig. 18.

\section{SS Gopher Mariner}

This vessel was instrumented with two TMB mechanical strain-cycle gages and counters (2). Measurements were made during six consecutive transatlantic crossings, during which the vessel encountered several days of very rough weather. Excerpts of data are given in Table 10 in order to give some idea as to the environmental conditions encountered. The degree of truncation of the data was estimated from the estimated average period of stress variation. Fig. 18 indicates no disagreement with the assumption that the lognormal distribution applies.

\section{Destroyer}

The cumulative distribution of hull stress experienced amidships in the keel of a destroyer was obtained from measurements made during the winter season '55-'56 during operations in the North Atlantic Ocean. The strains were meas- 

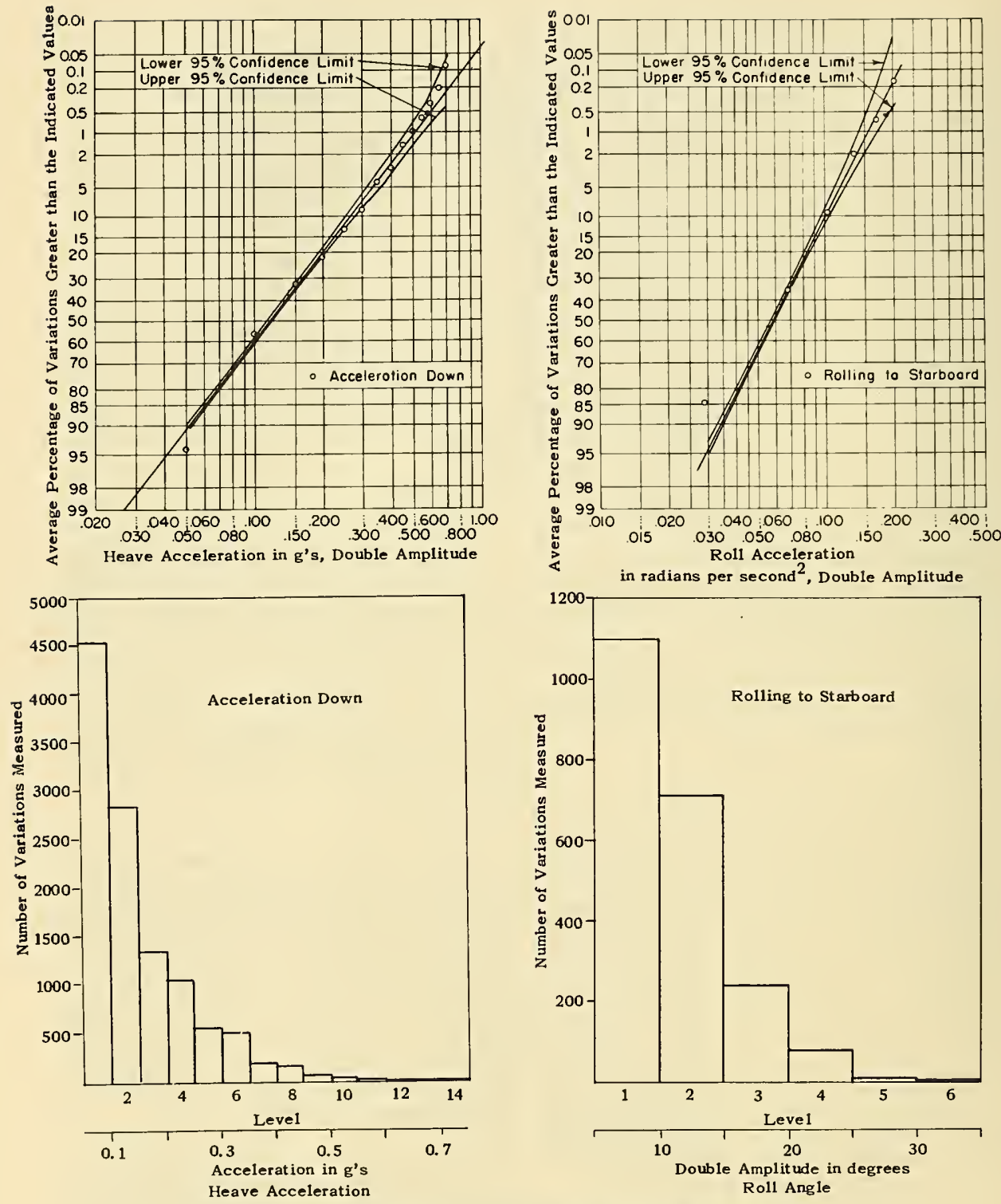

Fig. 19 USCGC Casco-Statistical Distribution Patterns of Ship Motions (Data were measured during March and April, 1951, in the North Atlantic.) 

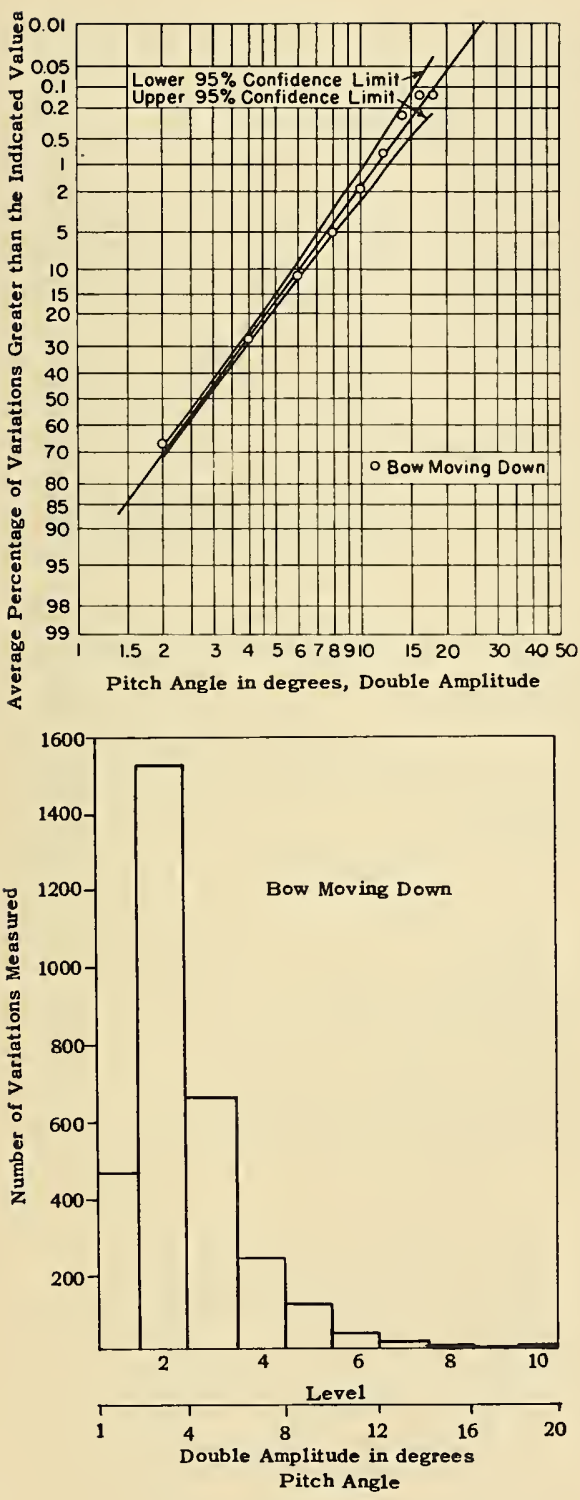

F1G. 19 (continucd) ured by means of electric wire strain gages. The measured data are given in Table 9 and the lognormal distribution which was computed for the truncated data is shown in Fig. 18. The fractiles corresponding to the larger, relatively rarely experienced stress variations do not check the fitted distribution too well. However, inasmuch as the sampling period did not cover an entire winter season it can be seen that a single storm can account for a disproportionate number of the relatively rare, high-stress values.

\section{Aircraft Carrier}

The stress data were obtained during the ship's winter season ' 55 -' 56 operations in the North Atlantic Ocean. The strains were measured by means of electric strain gages mounted on the keel amidships. The measured data are tabulated in Table 9 and the corresponding log-normal distribution is shown in Fig. 18. The fractiles of the experimental distribution agree unusually well with the computed log-normal distribution, well within the experimental accuracy of the measurements. Thus it may be concluded, for this ship, that the hull-girder stress or bendingmoment variations can be approximated by a log-normal distribution.

\section{USCGC Unimak}

The stress data were obtained during the vessel's operation as a weather ship in the winter season '54-'55. The log-normal distribution, fitted to the truncated experimental data, is shown in Fig. 18. Excellent agreement between the plotted experimental fractiles and the computed log-normal distribution is indicated.

It is concluded on the basis of this analysis of extensive measurements of hull-girder stresses obtained on seven ships of widely different size, type, and service that the long-term distribution of hull-girder stress may be approximated by a log-normal distribution.

\section{Ship Motions}

The long-term distributions of ship motions have been studied for the USCGC Casco and the Esso A sheville.

USCGC Casco. Cumulative distributions of heave, pitch, and roll motions taken from reference (1), are shown in Fig. 19. It is apparent that the logarithmically normal distribution fits the data quite well.

Esso Asheville. Tables 11 and 12 give the variations of pitching and heaving accelerations, classified according to magnitude and frequency of occurrence for both the ballast and load conditions of the ship. The Fisher method for treat- 
Table 11 SS Esso Asheville-Basic Ship-Motion Data for the Period September 1, 1953 TO APRIL 3, 1954

\begin{tabular}{|c|c|c|c|c|c|c|c|c|c|c|c|c|c|c|c|c|c|c|}
\hline \multirow{3}{*}{$\begin{array}{l}\text { 总 } \\
\text { 空 } \\
\text { 今心 }\end{array}$} & \multirow{3}{*}{ 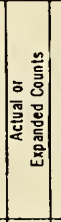 } & \multirow{3}{*}{ 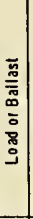 } & \multirow{3}{*}{ 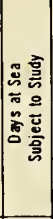 } & \multirow{3}{*}{ 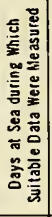 } & \multirow{3}{*}{ 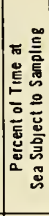 } & \multirow{3}{*}{ 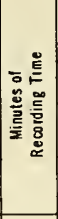 } & \multicolumn{12}{|c|}{$\begin{array}{l}\text { Number of Cycles Falling between Stated Limits* (Peak-to-Peak) } \\
\text { for a Period of } 30 \text { Days at Sea }\end{array}$} \\
\hline & & & & & & & \multicolumn{5}{|c|}{ For Sample of 2 min every Hour } & \multicolumn{7}{|c|}{ For Sample of 2 min every Fourth Hour } \\
\hline & & & & & & & 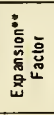 & 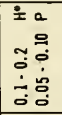 & 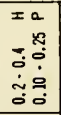 & \begin{tabular}{cc|}
$x$ & $a$ \\
& 0 \\
0 & 0 \\
0 & 0 \\
$\vdots$ & $\dot{0}$ \\
$\vdots$ & 0 \\
0 & 0
\end{tabular} & 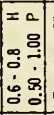 & 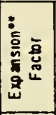 & 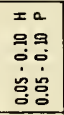 & 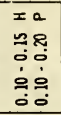 & $\begin{array}{l}\text { xa } \\
28 \\
0 \\
0 \\
\dot{0} \\
\dot{0} \\
0 \\
0\end{array}$ & $\begin{array}{|ll|} & 0 \\
\cdots & 0 \\
0 & 0 \\
\dot{8} & \dot{0} \\
0 & 0 \\
0 & 0 \\
\end{array}$ & $\mid \begin{array}{ll}x & 0 \\
0 & 0 \\
0 & 0 \\
0 & 0 \\
\dot{2} & \dot{0} \\
0 & 0 \\
0 & 0 \\
\end{array}$ & 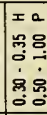 \\
\hline $\begin{array}{c}\text { Heave } \\
\text { Accel. } \\
\text { (Amidships) }\end{array}$ & $\begin{array}{l}A \\
E \\
A \\
E\end{array}$ & $\begin{array}{l}L \\
L \\
L \\
L\end{array}$ & $\begin{array}{l}75 \\
68\end{array}$ & $\begin{array}{l}59 \\
58.2\end{array}$ & $\begin{array}{l}79 \\
86\end{array}$ & $\begin{array}{l}2,832 \\
3,030\end{array}$ & 15.25 & $\begin{array}{r}339 \\
5,170\end{array}$ & $\begin{array}{r}14 \\
214\end{array}$ & $\begin{array}{l}0 \\
0\end{array}$ & $\begin{array}{l}0 \\
0\end{array}$ & 57.03 & $\begin{array}{r}1,031 \\
58,798\end{array}$ & $\begin{array}{r}130 \\
7,414\end{array}$ & $\begin{array}{r}14 \\
798\end{array}$ & $\begin{array}{r}3 \\
171\end{array}$ & $\begin{array}{l}0 \\
0\end{array}$ & $\begin{array}{l}0 \\
0\end{array}$ \\
\hline $\begin{array}{c}\text { Heave } \\
\text { AcceJ. } \\
\text { (Amıdships) }\end{array}$ & $\begin{array}{l}A \\
E \\
A \\
E\end{array}$ & $\begin{array}{l}B \\
B \\
B \\
B\end{array}$ & $\begin{array}{l}71 \\
61.9\end{array}$ & $\begin{array}{l}51 \\
51.7\end{array}$ & 72 & $\begin{array}{l}2,448 \\
2,792\end{array}$ & 17.65 & $\begin{array}{r}1,080 \\
19,062\end{array}$ & $\begin{array}{r}58 \\
1,024\end{array}$ & $\begin{array}{l}0 \\
0\end{array}$ & $\begin{array}{l}0 \\
0\end{array}$ & 61.89 & $\begin{array}{r}1,341 \\
82,994 \\
\end{array}$ & $\begin{array}{r}291 \\
18,010\end{array}$ & $\begin{array}{r}55 \\
3,404\end{array}$ & $\begin{array}{r}12 \\
743\end{array}$ & $\begin{array}{r}1 \\
62\end{array}$ & $\begin{array}{l}0 \\
0\end{array}$ \\
\hline $\begin{array}{l}\text { Pitch } \\
\text { Accel. }\end{array}$ & $\begin{array}{l}A \\
E \\
A \\
E\end{array}$ & $\begin{array}{l}L \\
L \\
L \\
L\end{array}$ & $\begin{array}{l}75 \\
68\end{array}$ & 74 & $\begin{array}{l}99 \\
100\end{array}$ & $\begin{array}{l}3,552 \\
3,518\end{array}$ & 12.16 & $\begin{array}{r}1,819 \\
22,119\end{array}$ & $\begin{array}{r}809 \\
9,837\end{array}$ & $\begin{array}{r}41 \\
499\end{array}$ & $\begin{array}{l}0 \\
0\end{array}$ & 49.12 & $\begin{array}{r}1,208 \\
59,337\end{array}$ & $\begin{array}{r}333 \\
16,570\end{array}$ & $\begin{array}{r}33 \\
1,621\end{array}$ & $\begin{array}{r}1 \\
200\end{array}$ & $\begin{array}{r}1 / 4 \\
13\end{array}$ & $\begin{array}{l}0 \\
0\end{array}$ \\
\hline $\begin{array}{l}\text { Pitch } \\
\text { Accel. }\end{array}$ & $\begin{array}{l}A \\
E \\
A \\
E\end{array}$ & $\begin{array}{l}B \\
B \\
B \\
B\end{array}$ & $\begin{array}{l}69 \\
61.9\end{array}$ & $\begin{array}{l}53 \\
51.9\end{array}$ & 77 & $\begin{array}{l}2,544 \\
3,196\end{array}$ & 16.98 & $\begin{array}{r}1,410 \\
23,941\end{array}$ & $\begin{array}{r}1,099 \\
18,660\end{array}$ & $\begin{array}{r}56 \\
951\end{array}$ & $\begin{array}{l}0 \\
0\end{array}$ & 54.08 & $\begin{array}{r}949 \\
60,337\end{array}$ & $\begin{array}{r}565 \\
30,550\end{array}$ & $\begin{array}{r}56 \\
3,028\end{array}$ & $\begin{array}{r}4 \\
216\end{array}$ & $\begin{array}{r}1 \\
54\end{array}$ & $\begin{array}{l}0 \\
0\end{array}$ \\
\hline $\begin{array}{l}\text { - H denote } \\
\text { P denote } \\
\text { (angular ace } \\
\text { in rad/ }\end{array}$ & Ilerati & n) & lerat & its it & $2 \frac{\mathrm{ft}}{\mathrm{sec}}$ & $=\frac{\text { gravi }}{100 \mathrm{f}}$ & $\frac{11 \mathrm{ts}}{8 \mathrm{th}}$ & ns & equi & ne & רe & celer & in $u$ & $\mathrm{tgr}$ & & value $\mathrm{I}$ & is ed & al to \\
\hline
\end{tabular}

Table 12 SS Esso Asheville-Distribution of Heave and Pitch Accelerations for a 30-Day Period at Sea

(Average estimated period of measured motions is $9.2 \mathrm{sec}$ taken from stress oscillograms.)

\begin{tabular}{|c|c|c|c|c|c|c|c|c|c|c|c|c|}
\hline \multicolumn{2}{|c|}{ Pitch } & \multirow{3}{*}{$\begin{array}{l}\text { Heave } \\
\begin{array}{l}\text { Units of } \\
\text { Gravity }\end{array}\end{array}$} & \multicolumn{10}{|c|}{ 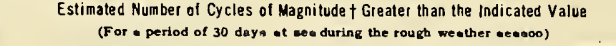 } \\
\hline \multirow{2}{*}{$\begin{array}{l}\text { Radians } \\
\text { Sec }^{2}\end{array}$} & \multirow{2}{*}{$\begin{array}{c}\text { G's } \\
100 \mathrm{ft}\end{array}$} & & \multicolumn{5}{|c|}{ Heave Acceleration } & \multicolumn{5}{|c|}{ Pitch Acceleration } \\
\hline & & & $\begin{array}{l}\text { Average } \\
L \& B\end{array}$ & \multicolumn{2}{|c|}{ Loaded } & \multicolumn{2}{|c|}{ Ballas? } & $\begin{array}{l}\text { Average } \\
\text { L \& B }\end{array}$ & \multicolumn{2}{|c|}{ Loaded } & \multicolumn{2}{|c|}{ Ballast } \\
\hline & & & 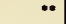 & - & $\bullet$ & - & ** & $\bullet$ & - & ** & - & ** \\
\hline 0.016 & 0.05 & 0.05 & 86,328 & & 67,224 & & 105,432 & 85,964 & 32,455 & 77,741 & 43,552 & 94,185 \\
\hline 0.032 & 0.10 & 0.10 & 15,432 & 5,384 & 8,426 & 20,086 & 22,438 & $26,12^{\mathrm{c}}$ & 10,336 & 18,404 & 19,611 & 33,848 \\
\hline 0.064 & 0.20 & 0.15 & 2,720 & & 1,012 & & 4,428 & 2,566 & & 1,834 & & 3,298 \\
\hline 0.081 & 0.25 & 0.20 & 619 & 214 & 214 & 1,024 & 1,024 & & 499 & & 951 & \\
\hline 0.097 & 0.30 & 0.25 & 31 & & 0 & & 62 & 242 & & 213 & & 270 \\
\hline 0.129 & 0.40 & 0.30 & 0 & & 0 & & 0 & 34 & & 13 & & 54 \\
\hline 0.161 & 0.50 & 0.35 & 0 & & 0 & & 0 & 0 & 0 & 0 & 0 & 0 \\
\hline 0.193 & 0.60 & 0.40 & 0 & 0 & 0 & 0 & 0 & & & & & \\
\hline 0.322 & 1.00 & 0.60 & 0 & 0 & 0 & 0 & 0 & & & & & \\
\hline
\end{tabular}


ing a truncated distribution was applied to obtain the results shown in Figs. 20 and 21. The classification used for the motion data (accelerations) was coarser than that used for the stress data on this ship. Kolmogorov's statistic was the only measure of significance applied in these cases. An inspection of Figs. 4 and 5 indicates that the log-normal distribution fits the data fairly well.

\section{Applications of Statistical Distribution PatTerns}

A knowledge of the distribution of waveinduced ship motions and stresses together with the height and length of ocean waves is of considerable interest in many applications such as engineering specification and design and operational studies of merchant and combatant ships. Following is a discussion of a few representative examples illustrating some problems the solution of which may benefit from this study.

\section{Specification of Engineering Requirements}

There are numerous occasions where it is desired to specify the environmental conditions to which shipborne equipment, personnel, and structures are subjected. In many cases the ship motion will be among the more important items that need to be specified. Several methods of presenting such information have been given in this work; for example histograms, basic and cumulative probability distributions.

In the design of a ship-stabilization system it is necessary to estimate the required capacity of pumps, motors (22), and so on. The cost of the installation is very much a function of the required capacities. The designer must therefore be able to predict the percentage of time that the roll angle will be less than any specified value in order to evaluate the desirability of the installation of the proposed stabilizer. The distribution patterns given here are directly applicable to this problem.

In the design of fire-control equipment, aircraft launching and landing apparatus, it may be necessary to predict the maximum ship motion that may be expected under given sea conditions. Although it may not be practical to design for operation under rare, extremely severe conditions it is desirable to have an estimate of the conditions under which satisfactory operations can be expected. The distributions of significant wave heights and wave lengths together with the distribution of ship motions for various combinations of sea condition, heading and ship speed should make an evaluation of the operational possibilities practicable.
Often it is desired to estimate the extreme value of stress or motion that a ship structure may be expected to experience over a specified period of time. For example, the extreme value of the wave-induced, hull-girder stress that can be expected over the service life of a ship is of interest inasmuch as the safety of the ship depends upon keeping the total hull-girder stress below the ultimate strength of the structure.

Therefore, it will be of interest to make an estimate of the largest stress to be expected in a given period of time. As an example such an estimate will be made on the basis of the underlying log-normal distribution for the Esso Asheville shown in Fig. 18. For this purpose a formula will be developed which will give the fraction $f$ of all samples of size $N$ (belonging to a given underlying distribution) which will have at least one (extreme) value of $x>x_{m 1}$. The formula is as follows

$$
f=1-e^{-N\left[1-P\left(x_{m}\right)\right]} \ldots \ldots \ldots[2]
$$

This formula may be developed as follows (as was pointed out to the author by Dr. Lieblein of the National Bureau of Standards):

Let $P\left(x_{m 1}\right)$ be the fraction of the underlying (basic) distribution of $x$ with $x<x_{m 1}$.

Take a sample of $N$ values of $x$ in such a way that each $x$ is chosen at random from the basic distribution, and repeat such sampling many times. Then the probability of choosing a value less than $x_{m 1}$ when one single value of $x$ is chosen from one sample of size $N$, is $P\left(x_{m 1}\right)$ and consequently the probability that some members of the sample of size $N$ exceed $x_{m 1}$ is

$$
1-\left[P\left(x_{m_{1}}\right)\right]^{\mathrm{v}}
$$

Therefore the fraction $f$ of all (a very large number) samples of size $N$ which will have one or more values of $x$ greater than $x_{m_{1}}$ is

$$
f=1-\left[P\left(\mathrm{x}_{m_{1}}\right)\right]^{N}
$$

This formula is exact, but for large $N$ it is inconvenient. Now for large $N$ it is practically certain that in any given sample, $x_{m_{1}}$ has such a value that $P\left(x_{m_{1}}\right)$ is close to 1 . For values of $x_{m_{1}}$ such that $1-P\left(x_{m_{1}}\right)$ is small, a more convenient approximate formula can be found. We have

$$
\begin{gathered}
\log _{e}(1-f)=N \log _{e} P\left(x_{m 1}\right)= \\
\quad N \log _{e}\left\{1-\left[1-P\left(x_{m:}\right)\right]^{\prime}\right. \\
\log _{e}(1-f) \approx-N\left[1-P\left(x_{m 1}\right)\right]
\end{gathered}
$$

by use of the series

$$
\log _{e}(1-x)=-x-x^{2} / 2 \ldots
$$




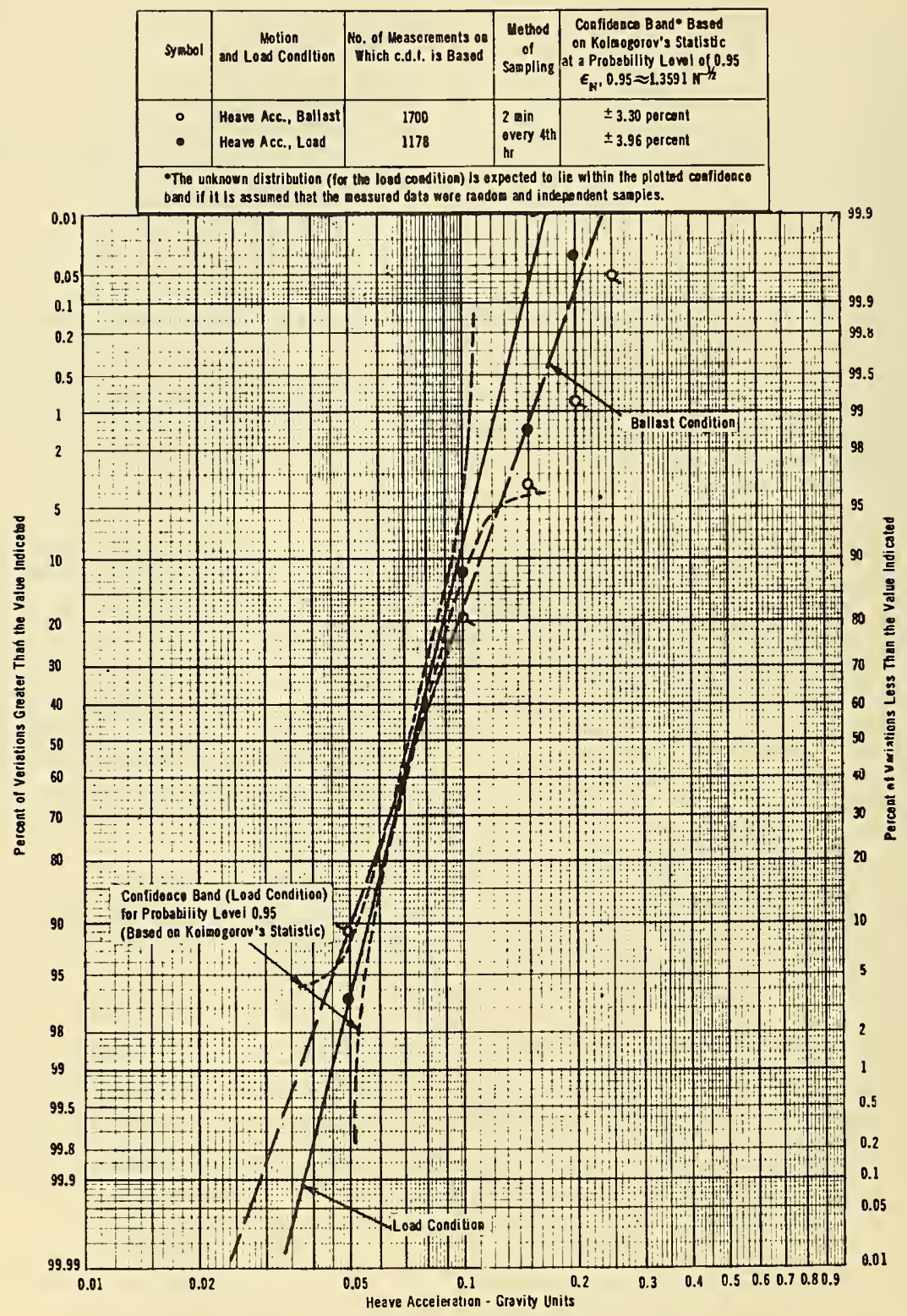

Fig, 20 SS Esso Asheville-Statistical Cumulative Distribution of Heave Acceleration (These distributions are based on data given in Tables 11 and 12.) 


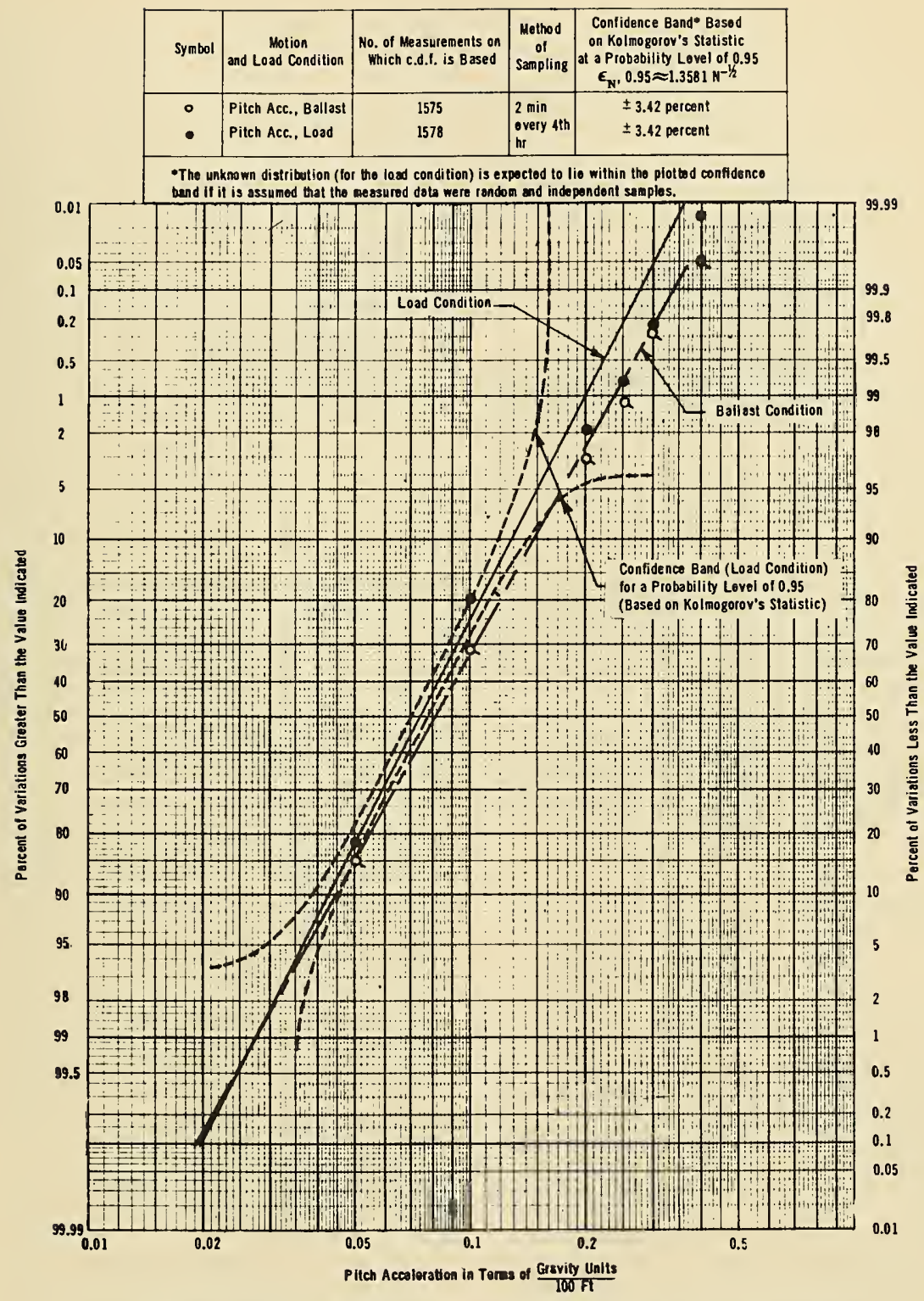

Fig. 21 SS Esso Asheville-Statistical Cumulative Distribution of Pitch Acceleration (These distributions are based on data given in Tables 11 and 12.) 
Miner's Rule for Estimation of "Cumulative Damage" o

$D=\frac{n_{1}}{N_{1}}+{ }_{N_{2}}^{n_{2}}+{ }_{n_{3}}^{n_{3}}+\ldots n_{n} ; D=1$ Corresponds to failure

where $n_{i}$ denotes the number of stress cycles applied at stress

$N_{i}$ denotes the number of stress cycles of magnitude $i$, which if applied alone would cause a fatigue failure.
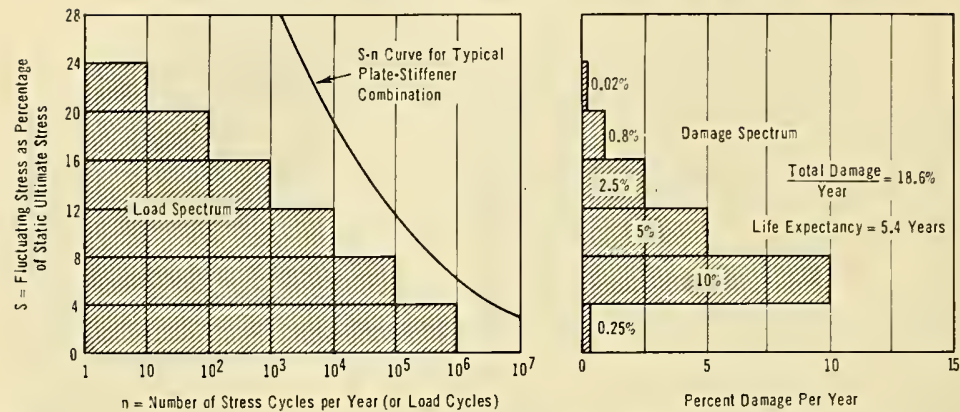

Fig. 22 Illustration of the Application of a Load Spectrum to the Design for Endurance STRENGTH

Thus $f$ is given approximately by the expression shown in Equation [2]. This result is independent of the form of $P$. As a first example of the application of Equation [2] let it be required to estimate the extreme stress variation that would be exceeded by one half of all ships ${ }^{17}$ $(f=1 / 2)$ if 10,400 random stress measurements $(N=10,400)$ were made on each of many ships. Assume that the underlying distribution applicable to these ships is that given for the port side of the main deck amidships in Fig. 16.

$$
f=1 / 2, \quad N=10400
$$

From Equation [2]

$$
\begin{aligned}
& f=1 / 2=1-e^{-10400\left[1-P\left(x_{m 1}\right)\right\rfloor} \\
& -10400\left[1-P\left(x_{m 1}\right)\right]=-0.6931
\end{aligned}
$$

or

$$
1-P\left(x_{m 1}\right)=6.66 \times 10^{-5}
$$

The corresponding value of the stress variation $x_{m_{1}}$ is read from Fig. 16 as 16,000 psi (from hog to sag). Similarly an estimate of the stress variation which will be exceeded in 20 winter seasons $(26,700,000$ stress variations) in one half of all ships $(f=1 / 2)$ is about 50,000 psi (from hog to sag).

Not much confidence can be placed in the accuracy of this last prediction because the measurements on which the prediction is based did not include magnitudes of the order of the estimate;

17 Shlps of the Esso Asheville type which would eocounter service conditlons similar to those applicable to the Esso Asheville. i.e., the estimates are not expected to be reliable if the estimated extreme value lies far outside the range in which experimental data are available.

A better method for making an estimate of the probable extreme stress is by use of the experimentally obtained distribution of extreme values; this being the most direct method.

\section{Prediction of Life Expectancy of Structures}

The results of the study of hull-girder stresses (bending moments) given here can contribute to the rational design of ship structures on the basis of the prediction of the life expectancy of such structures.

The information that is necessary to make such a prediction is as follows:

1 It is necessary to know the service loads or stresses that the ship structure is required to withstand throughout its service life. The statistical distributions given in this paper provide the waveinduced load data in a convenient form. The more or less steady stresses such as dead load stresses, temperature-induced stresses, and built-in stresses also must be estimated.

2 Adequate data on the endurance strength of the ship's structural components are necessary. Probably such data will only be needed for typical components as well as for those portions of the structure in which a failure. could be disastrous.

3 Finally, it will be necessary to have a suitable method or theory available which relates the applied service loads to expected structural dam- 
age. Several empirical methods for providing such a correlation have been proposed. The best known and simplest of these is the cumulativedamage law proposed by Miner.

As an illustration of the manner in which the endurance life of a typical structural component, say a plate-stiffener combination, can be predicted, consider Fig. 22. For the sake of simplicity it will be assumed that the mean stress level in the structure is zero. The histogram of stress variations shown in the left of the figure is also known as a load spectrum. The damage due to each component of the load spectrum is computed and the result is plotted as a damage spectrum. For example, 100,000 applications of a stress variation occur in the range of 4 to 8 per cent of the static ultimate stress. According to the $S-N$ curve approximately 1 million applications of this stress are required to cause failure. Therefore, according to Miner's criterion, the damage due to the application of 100,000 applications of this stress is $100,000 / 1,000,000$, equal to 10 per cent. The integral of the damage spectrum over the stress range experienced in service gives the expected total damage during 1 year. In the illustrative example the expected life of the structure is 5.4 yr. Owing to the variability of the endurance strength of nominally identical structural components, as well as the variability of the service loads for structures which presumably are subjected to the same service, it is necessary to reduce the expected life of the structure by a factor in order to arrive at a "safe life" which may be expected to be attained with an acceptably high degree of probability.

The illustrative example was applied to a simple case in which the mean stress level was zero. The method can be extended easily to the more realistic case where the sea-induced stresses are superimposed on various mean levels of stress. In the latter case it is only necessary to sum the damage resulting from the load spectra associated with each mean level of stress.

An interesting exposition of this general approach to the design of airplane structures has been given by $\mathrm{W}$. Tye (23).

\section{Prediction of Optimum Operating Conditions}

In ship operations it is often necessary to select a heading of the ship relative to the direction of the waves and a ship speed such that the pitching or rolling motions are below a level beyond which certain operations would become impractical. Examples of such operations are fueling at sea and the launching and landing of aircraft. For this purpose it is convenient to have a graphical or numerical presentation of a parameter

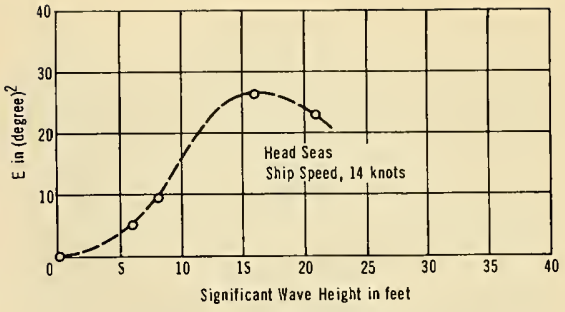

USCGC UNIMAK

Variation of the Statistic E with the Severity of the Sea (Variations in Pitch Angle)

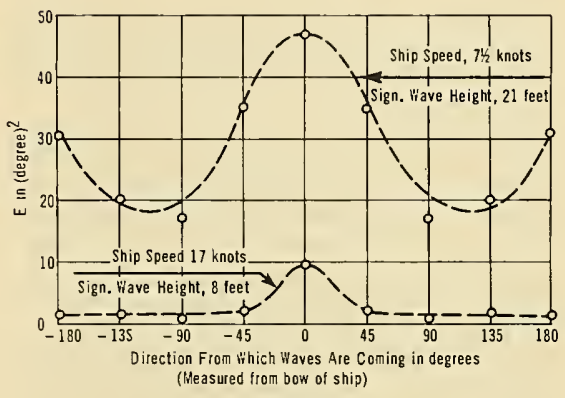

USCGC UNIMAK

Variation of the Statistic $E$ with Ship Heading (Variations in Pitch Angle)

Fig. 23 Typical Presentation of the Statistic $E$ Which Defines the Probability Distributions (Statistic $E$ is integral of power spectrum. Maximum expected magnitude of pitch angle is proportional to $\sqrt{E}$.)

which, at a glance, indicates the relative severity of motion to be expected for any given ship speed, heading, and sea condition.

Accepting the hypothesis that the short-term distributions of ship motions and stresses can be represented by the Rayleigh distribution, then one can plot the parameter $E$, which defines this distribution, as a function of ship heading, ship speed, and sea state. Fig. 23 illustrates such a plot. The most probable maximum value of the ship motion expected in a given number of oscillations is proportional to $\sqrt{E}$. Table 4 gives the number by which $\sqrt{E}$ is to be multiplied in order to give the magnitude of the expected maximum.

Tables or graphs could be prepared for any given ship type to cover the range of operating conditions likely to be encountered in service.

The foregoing examples are illustrations of some useful applications of the statistical distributions discussed in this paper. 


\section{Discussion}

It has been the main objective in this paper to show that the distribution of wave-induced variations in the pitch, roll and heave motions of ships as well as the wave-induced, ${ }^{18}$ hull-girder stress variations may be represented by a Rayleigh distribution for steady conditions of the sea, ship speed, and course, whereas these responses of the ship to the sea will be approximated by a logarithmically normal distribution when distributions are considered which extend over a period of weeks, months, or longer, during which period the ship is subjected to a wide variety of operating conditions.

A secondary objective has been to show that the foregoing hypothesis is also applicable to the distribution patterns of the heights and lengths of ocean waves.

Over 100 individual short-term distributions of ship motions and stresses obtained for a wide range of environmental conditions on the USCGC Unimak were analyzed. A smaller number of similar short-term distributions of stresses and motions for a large aircraft carrier and for a destroyer were analyzed in a similar manner. No significant difference was found between the hypothesis and the test data. On the basis of the statistical tests of significance, the quantity and the scope of the data, one may accept confidently the hypothesis that the "short-term" distribution of ship motion and stress approximates to the Rayleigh type.

The long-term distribution of hull-girder stresses or motions was determined for a wide variety of ship types and operating conditions. The ships studied included an oil tanker in coastwise service, two dry-cargo vessels, a Coast Guard weathership, a destroyer escort, an aircraft carrier, and a destroyer. Extensive statistical analysis and tests of significance were applied to the results of the Esso Asheville tests. In this case, it was possible to study the extreme-value distribution as well as the basic distribution of hull stresses which were arrived at by independent methods. The distribution patterns evidenced by these two distributions complement each other; that is, if the basic distribution is log-normal then the extreme-value distribution of the stress should be of the type

$$
F(x)=\exp \left[-e^{-y}\right]
$$

The confidence limits applied to the cumulative distributions as well as the chi-square test applied to the grouped measured data indicate that the hypothesis may be accepted with confidence;

18 It should be noted that the vibratory response of the ship incident to slamming is not included in this analysis. i.e., the wave-induced stresses and motions, over the long term may be represented by a log-normal distribution.

Finally, from a utilitarian point of view, one also may accept the hypothesis that the shortterm distribution of wave heights follows the Rayleigh pattern and that the long-term distribution of wave heights and wave lengths follows the log-normal pattern. The latter conclusion cannot be evaluated by the use of standard statistical tests of significance since most wave observations were made by eye and no measure of the accuracy of these observations has been determined thus far. Nevertheless the very extensive data obtained by independent observers, the consistent accommodation of these data to the lognormal pattern, and the fact that the response of the ship to the waves may be represented by a log-normal distribution, all tend to the conclusion that the log-normal distribution is applicable to the specification and prediction of wave heights and wave lengths.

The existence of a predictable distribution pattern will greatly simplify the collection and analysis of service data, as well as furnish a concise and graphic manner for the specification and prediction of ship stresses and motions for given ships in a given service. Prediction of the largest stresses and motions to be expected over a specified period of time can be made readily, although the prediction of extreme values is basically less reliable than a prediction of those values which occur more frequently. The method for predicting extreme values eventually breaks down by predicting values which are too large. This occurs because the theoretical distribution cannot be relied upon at the extreme ranges of the function. For example, the theory could predict stresses in excess of the ultimate strength of a structure, obviously an invalid prediction. Rejection of predicted values lying outside the range of experience would provide a proper safeguard against too extreme an estimate.

The parameters computed for the distribution functions discussed in this paper are not affected appreciably by variations or scatter of those values or events which occur relatively infrequently. For this reason, provided the type of basic distribution pattern has been established, it is possible to obtain a reasonably good approximation to the distribution pattern with a limited amount of experimental data, because it is not necessary to continue measurements until the more extreme and infrequently occurring members of the population have been sampled. Inasmuch as ship motions and hull-girder stresses are of rather small magnitudes during the greater por- 
tion of time, it is necessary to measure the smaller magnitudes in order to have a sufficiently representative sample for the statistical analysis. Too large a degree of truncation of the data would make it difficult to establish the distribution patterns with acceptable accuracy.

In engineering application very large values (extremes) of stress and motion, although they occur very seldom, may be of considerable importance. The reliability of predicting the magnitude of these extreme, but rare, values is of necessity very poor; nevertheless it would be desirable to have experimental data in this range if such predictions are to be made. In any case, if statistical predictions are to be made, it is necessary that measurements of the lower magnitudes, which occur relatively more often than the larger values be available. However, if rare extremes are not of particular interest, the reliability of theoretical predictions based on experimental data which do not include these rare extremes will not be affected appreciably by lack of observations of these extreme values.

\section{SUMmaRY}

The analysis of the voluminous data accumulated during the past several years has indicated that the pitch, roll, and heave motions of ships as well as the hull-girder stresses, follow the same general distribution pattern as do the heights of ocean waves.

It has been shown that the frequency distributions of pitch, roll, and heave motion of ships, as well as the over-all ship-girder stresses induced by the sea, can be represented by the one-parameter Rayleigh distribution when the environmental conditions of the sea, ship speed, and course are constant. Furthermore, the ship responses can be represented by the two-parameter logarithmically normal distribution when the environmental conditions are allowed to vary over the range that ships encounter over an extended period of service.

These logarithmically normal distributions thus are the result of the physical summation of a large number of Rayleigh distributions, each of which is weighted in accordance with the relative probability with which the environmental conditions pertaining to it are encountered in service.

It also has been indicated that the long-term distribution of wave heights and wave lengths may be adequately represented by the log-normal distribution. A study of wave observations taken regularly over a period of 6 years at 14 stations in the North Atlantic shows that distribution based on the observations taken over I year differs little from that obtained over 6 years. This fact suggests that inasmuch as ship motions and stresses are induced by the waves, 1 year is a sufficiently long test period for establishing a reasonably good statistical distribution pattern of ship motions and stresses.

The patterns which have been found to fit the experimental data can be specified in terms of one or two numbers which provides a considerable simplification of the problem when it is required to state what a ship is expected to do. The presentation of the Rayleigh distribution has been simplified by utilizing a change of variables, such that all Rayleigh distributions may be represented by means of a single straight line, as in Fig. 3. In addition to the basic distribution pattern, the form of the distribution of the extreme values of the ship response to the sea also has been specified.

It is desirable, from the standpoint of savings in time, and cost, that the actual distribution applicable to particular ships be determined in the future by means of either theory or model tests. There are far too many unknowns to make the purely theoretical approach practical. Model tests would seem to offer the most direct method that could be developed into a useful tool within the immediate future. It will first be necessary to compare the distribution obtained from model tests with those obtained from full-scale sea trials under comparable conditions. The required fullscale data are at hand and it should not be too long before preliminary comparisons can be made. The method of St. Denis and Pierson for computing the power spectrum of the ship response, given the power spectrum of the sea as well as the speed and course of the ship, is directly applicable for the calculation of the frequency distribution of the ship motions or bending moments, provided certain simplifying assumptions made in the derivation of their method are acceptable. Their procedure should be of great help in making it possible to use simplified model test results in regular waves for checking the validity of the model test procedure for predicting full scale distributions.

There are many practical applications of the frequency-distribution patterns. In the determination of the capacity of ship and shipboard stabilization equipment, it is necessary to have a reliable estimate of the probability of exceeding given angles of roll or pitch. The design of aircraft landing gear, rocket launchers, and fire-control apparatus requires a knowledge of the ship motions expected in service. The ability to land planes on a carrier in a given sea can be predicted on the basis of frequency distributions such as given herein.

In the design of the ship structure, endurance 
strength may well be a factor. Alternating stresses of moderate magnitudes superimposed on high mean-stress levels do reduce the strength of a structure subjected to repeated loading; furthermore, in places where cold-working is involved as a result of such stress combinations (as appears likely near welds) the notch sensitivity and transition temperature of the affected material are generally raised. In the design of structures for endurance strength, the frequency distributions here should be directly applicable.

\section{ACKNOWLEDGMENTS}

The data presented in this paper have been obtained as the result of the co-operative effort of many people, only a few of whom can be mentioned here. The excellent co-operation of the Esso Company, especially of Mr. Stewart and Captain Stober, made possible the collection of service data on a tanker, the Esso Asheville, under service conditions. The financial and technical contributions of the SNAME panel on "Strain Measurements in Full-Scale Structures" were essential to the planning and execution of the Esso Asheville and Gopher Mariner tests. The pleasant co-operation of Mr. H. M. Tiedemann (at the time connected with the SNAME office) was particularly helpful. Credit for the extensive data on the weatherships is due to both the U.S. Coast Guard and the Weather Bureau. The success of the sea tests on the carrier and destroyer is to a large measure the result of the tireless efforts of Cdr. R. Brooks, USN, and Mr. J. Birmingham of the TMB staff. The data could not have been secured without the extensive assistance of the ship's officers and personnel. The development of the automatic recording and counting instrumentation has been greatly expedited by the support given it by Mr. R. T. McGoldrick of TMB and Mr. J. Vasta of the Bureau of Ships. The advice and opinions of statisticians from various government and private activities have been solicited and used freely. In particular the advice of Mr. I. R. Savage and Dr. Lieblein of the National Bureau of Standards has been quite helpful.

\section{BIBLIOGRAPHY}

1 "Study of the Strain and Motions of the USCGC Casco at Sea," by N. H. Jasper, David Taylor Model Basin Report 781, May, 1953.

2 "A Statistical Approach to the Measurement and Analysis of Experimental Data on Structures," by N. H. Jasper, Journal of the American Society of Naval Engineers, vol. 63, August, 1951.

3 "Service Stresses and Motions of the Esso Asheville, a T-2 Tanker Including a Statistical
Analysis of Experiment $₫ 1$ Data," by N. H. Jasper, David Taylor Model Basin Report 960, September, 1955.

4 "Sea Tests of the USCGC Unimak, Part I-General Outline of Tests and Test Results," by N. H. Jasper and J. T. Eirmingham, David Taylor Model Basin Report 976, March, 1956.

5 "The Log-Probability Law and Its Engineering Applications," by V. T. Chow, Proceedings of the American Society of Civil Engineers, November, 1954.

6 "Mathematical Methods of Statistics," by H. Cramer, Princeton University Press, Princeton, N. J., 1946, Chapters 27 and 28.

7 Admiralty Ship Welding Committee, Third Interim Report Document FE/372, January, 1953. This report gives the strain cycle data measured on the Ocean Vulcan over a period of $21 / 2$ years.

8 "A Manual of Marine Meteorological Observations," U.S. Weather Bureau Circular M, eighth edition, 1950.

9 "Wave Statistics in the North Atlantic Ocean and on the Coast of Cornwall," by J. Darbyshire, Marine Observer, April, 1955, pp. 115-118.

10 "On the Statistical Distribution of the Heights of Sea Waves," by M. S. Longuet-Higgins, Journal of Marine Research, vol. 11, no. 3, 1952.

11 "Practical Methods for Observing and Forecasting Ocean Waves by Means of Wave Spectra and Statistics," by W. J. Pierson, G. Neumann, and R. W. James, Hydrographic Office Publ. 603, 1955.

12 "Statistical Theory with Engineering Applications," by A. Hald, John Wiley \& Sons, Inc., New York, N. Y., 1952.

13 "A Statistical Study of Wave Conditions at Four Open-Sea Localities in the North Pacific Ocean," by L. A. Harney, et al, NACA Technical Note 1493, January, 1949.

14 "Extrapolation, Interpolation and Smoothing of Stationary Time Series," by N. Wiener, John Wiley \& Sons, Inc., New York, N. Y., 1950.

15 "On the Motions of Ships in Confused Seas," by M. St. Denis and W. J. Pierson, Jr.; Trans. SNAME, vol. 61, 1953, pp. 280-332.

16 "The Truncated Normal Distribution," by R. A. Fisher, British Association for the Advancement of Science, Mathematical Tables, I, 1931, pp. 33-34.

17 "Numerical Tabulation of the Distribution of Kolmogorov's Statistic for Finite Sample Size," by Z. W. Birnbaum, Journal of the A merican 
Statistical Society, vol. 47, September, 1952, pp. 425-441.

18 "A New Method of Analyzing Extreme Value Data," by J. Lieblein, NACA Technical Note 3053, January, 1954.

19 "Statistical Theory of Extreme Values and Some Practical Applications," by E. J. Gumbel, National Bureau of Standards Applied Mathematics Series No. 33, February, 1954.

20 "The Application of the Statistical Theory of Extreme Values to Gust Load Problems," by
H. Press, NACA Technical Note 1926, November, 1949.

21 "SS Ocean Vulcan," Admiralty Ship Welding Committee Report R-8, H. M. Stationery Office, London, England.

22 "On the Stabilization of Roll," by J. H. Chadwick, Jr., Trans. SNAME, vol. 63, 195.5, pp. 237-280.

23 "The Outlook on Airframe Fatigue," by W. Tye, Journal of the Royal Aeronautical Society, vol. 59, May, 1955, pp. 339-348.

\section{Discussion}

Mr. E. V. LEwIS, Member: The author has carried out an ambitious program of assembling data on ship motions and stresses at sea and has demonstrated that statistical methods can bring them into some kind of order. It is particularly encouraging that he finds the short-term amplitudes (from peak to hollow) follow the Rayleigh distribution. Other writers have indicated that this should be so, but the author has made a distinct contribution in assembling such an impressive weight of evidence to prove that the Rayleigh distribution does apply to waves, ship motions, and hull stresses-over a wide range of ship types and conditions. Thus the great value of this paper is believed to be the way in which it adds to and fills out a growing knowledge of the sea and ship behavior.

It may help to see better how his work fits into the broad picture, by noting, for example, that the Rayleigh distribution is the same as that referred to as the "target or cbi-square" distribution by St. Denis-Pierson (reference 15 of the paper). The author's $E$ is in principle the same as the $R$ of St. Denis-Pierson-both are proportional to the mean square value of the record or the area under an energy spectrum. But the author's $E$ is numerically 4 times $R$. It is the writer's understanding that the "variation in pitch angle" and other quantities plotted-as in Fig. 2 of the paper-refer to the successive double amplitudes or peak-to-trough distances on the record. It should be noted that the Rayleigh distribution of amplitudes is entirely consistent with a normal or Gaussian distribution of points on the record, chosen either at random or at equal intervals of time. Since theoretically the Rayleigh distribution applies only for "narrow" spectra, it may be concluded from the author's work that most sea and ship response spectra are narrow, in this sense. It is only necessary then to know one parameter, $E$ (or for practical purposes $\sigma^{2}$ ), to define the distribution.

Model research at the Stevens E.T.T. in irregular head seas has shown that $E$ for motions and for external bending moment (hence stress) can be predicted accurately from a knowledge of the sea spectrum and of the characteristic response of the model to different wave lengths (frequencies), which easily can be obtained experimentally. Hence, it is comparatively simple to predict the distribution patterns, as noted by the author. (Model results on motions were presented before the Society last year, and work on bending moments sponsored by the S-3 Panel of the Hull Structure Committee is to be published soon.)

Actual distribution curves for amplitudes of model response have not been published, and therefore it may be of interest to show some typical plots we have just worked out for comparison with the author's full-scale data.

Fig. 24 shows distribution of wave, pitch and heave amplitudes for the Series 60 model reported on last year; speed 12 knots in high irregular sea (5 runs). The wave spectrum and the motion spectra were quite narrow and very good agreement is shown. It should be added that a typical case of 18 knots in a more moderate sea-with a broader spectrum which according to Pierson and Neumann is not so realistic-did not show such good agreement.

Fig. 25 shows distribution of bending moment for T-2 Tanker model reported in 1954. Again good agreement is shown at a speed of $14 \frac{1}{2}$ knots in a high irregular sea (3 runs).

The author's finding that long-term sea and ship data follow a log-normal distribution is also of interest, since it makes it possible to characterize a mass of accumulated data by two parameters- 

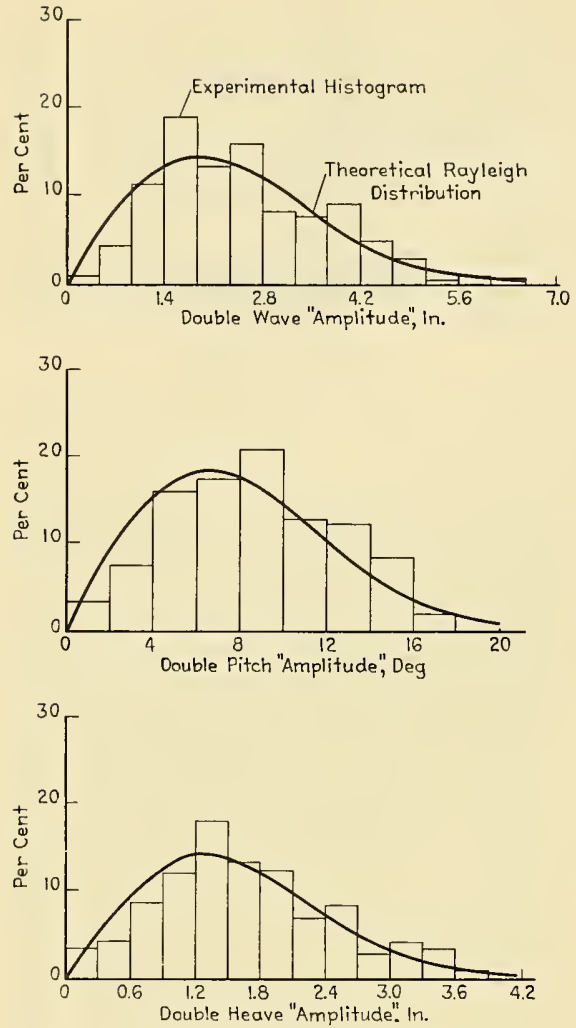

FIG. 21

the mean $\log$ value and $E$ (or $\sigma^{2}$ ). Variations in the parameters for different series of data, and hence in the lines plotted in Fig. 18 for example, are presumably due to such factors as the service in which the ship is engaged (i.e., average severity of the weather), the average loading of the ship, (i.e., always full or sometimes light), longitudinal weight distribution, and in the case of hull-girder stresses, the section modulus and other structural design features of the hull itself, and even the particular point at which the stress is measured. It does not seem surprising that if sea data exhibit a log-normal distribution (Figs. 13-15 of the paper) the ship responses also should follow this distribution.

It is somewhat disappointing that Fig. 18 does not extend to larger $P$ values and hence larger

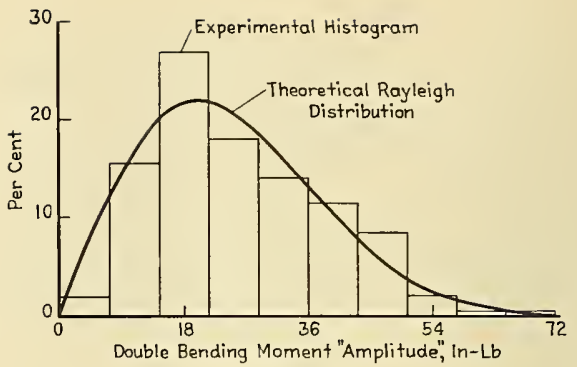

FIG. 25

stresses, since there is some indication of departures from the lines at the top of the graph. Table 9 indicates that a number of stresses have been recorded above $10 \mathrm{kips} / \mathrm{sq}$ in.

Coming next to the application of distribution patterns of motions, there can be no doubt that they will be of great value for the design of shipborne equipment, stabilization systems, firecontrol equipment, and aircraft launching and landing devices. As for hull-girder stresses, the author has performed a service in calling attention to the possible importance of endurance strength to the ship-fracture problem, and the distribution patterns are a necessary step in studying the problem. He is quite right in giving attention also to the extreme values that might be experienced over the life of the ship. In the writer's opinion, this is one of the biggest problems facing us in structural design at the present time. The statistical approach to this problem is interesting, but as he points out, is unsatisfactory. He says, "a better method....is by the use of the experimentally obtained distribution of extreme values." Presumably this means assembling much more statistical data, with emphasis on high values, and 1 am heartily in favor of this. However, I object strenuously to the statement, "Rejection of predicted values lying outside the range of experience would provide a proper safeguard against too extreme an estimate." This simply begs the question, and if such a policy were followed inevitably would doom many ships to the bottom.

Even with a great deal of data on high stresses recorded at sea, it appears doubtful that a satisfactory answer to the problem of expected maximum values can be obtained by statistical methods alone. There are definite physical limits to the bending moment exerted on the hull by the sea; wave steepness has an absolute maximum and the 
depth of the ship itself restricts the severity of the buoyancy distribution. But these physical limits on the external loads actually may provide the key to the problem of maximum stresses, by permitting the maximum loads to be determined on physical grounds. Hence, it is suggested that attempts be made to evaluate the maximum loads on the basis of purely physical considerations.

In this connection, the suggestions of Hazen and Nims in $1940^{19}$ may provide a promising lead. They made the following suggestion, assuming a satisfactory method for the computing machine calculation of bending moments (a joint project of the Society's S-3 and H-7 Panels is making encouraging progress here): "With a wave of any given shape at any given position along the hull assume a position and velocity for the ship in the heave and the pitch co-ordinates. These assumptions may be considered sufficient to fix the forces acting on the ship since the unbalanced force and moment, and consequently the accelerations, are fixed thereby. By investigating a series of such conditions with the hull having a wide range of positions and velocities with respect to the water it is possible that an envelope for moment curves would be defined which would represent the maximum moments that would be encountered by the hull for any position and velocity to which it might be subjected..." Once having determined the most extreme bending moment physically possible, statistical methods could be used to determine the probability of occurrence of this extreme condition.

In conclusion, I feel that the statistical analysis of sea and ship data presented here is of great value to the profession, and the work should be continued actively. I also agree with the author that simple model tests can continue to be of assistance in connection with such studies.

Mr. J. Darbyshire, ${ }^{20}$ Visitor: The author quotes data which I published in 1955 relating to wave records taken by the O.W.S. Weather Explorer with a ship-borne wave recorder developed at the National Institute of Oceanography. These records were taken at the positions "INDIA" ' $\left(61^{\circ} 00^{\prime} \mathrm{N}, 15^{\circ} 20^{\prime} \mathrm{W}\right)$ and JULIETT $\left(52^{\circ} 30^{\prime} \mathrm{N}, 20^{\circ} 00^{\prime} \mathrm{W}\right)$ and covered the period February, 1953 , to January, 1954. I have since checked the logarithmic normal distribution law by using all the data available from the ship from February, 1953, to December, 1955. The distri-

\footnotetext{
18 "Calculation of Motions and Stresses of a Pitching and Heaving Sbip," by H. L. Hazen and P. T. Nims, Trans. SNAMME, vol. 48, 1940 , p. 111.

${ }_{20}$ National Institute of Oceanography, Wormley, Godalming, Eagland.
}

bution law still appears to be satisfactory although there is some departure from it at heights below 5 $\mathrm{ft}$ and above $40 \mathrm{ft}$. The relation

$$
p=6.6 \exp -(\log x / 9.0)^{2} / 0.126
$$

was obtained where $p$ is the probability density expressed as a percentage and $x$ is the maximum wave height.

A similar relation was found for wave heights recorded at Casablanca from 1952-1955 and it was

$$
p=18.0 \exp -(\log x / 3.5)^{2} / 0.137
$$

A similar relation also could be fitted to the maximum wave heights recorded at Perranporth, Cornwall, England, during the year 1946-1947 and it was

$$
p=13.0 \exp -(\log x / 4.0)^{2} / 0.199
$$

This work has been published in greater detail. ${ }^{21}$

Mr. J. P. Comstock, Member: The two objectives of this paper as stated by the author obviously have been attained.

I concur with the author that "there are many applications in which a knowledge of the frequency distributions of hull motions, stresses, and the heights of ocean waves can be used to advantage." However, when it comes to deducing "the extreme value of the wave-induced stress that can be expected over the service life of the ship," I am not yet convinced that a study of statistical distribution of stress can do this for us.

To apply the example of estimating the safe life of a structure to a ship's hull would require the tacit assumption that ship failures are basically fatigue failures. Since, in all the voluminous records of ship casualties, there has been found, so far as I can determine, no correlation whatever between age of ship and incidence of fracture, I do not believe that ship fractures are basically fatigue failures. I think that in most cases they result from isolated fortuitous combinations of severe conditions which in all probability most ships never experience in their entire life, but which nevertheless, if they could be known, should be the basis of hull structure design.

The author states, "In engineering applications very large values (extremes) of stress and motion, although they occur very seldom, may be of considerable importance." So far as hull-girder stress is concerned, this is a gross understatement; they are of controlling importance. Yet, as the author warns us, "theoretical distribution cannot

\footnotetext{
21 "Distribution of Wave Heights," by J. Darbyshire, Dock and Harbour A utharity, (London), vol. 37, May, 1956, pp. 31-32.
} 
be relied upon at the extreme ranges of the function." This forces us back, in merchant ship design at least, to the basis of long-range service experience.

This is not to deny or even belittle the other applications of this sort of study suggested by the author.

Mr. John VAsta, Member: The author has demonstrated in a very able and convincing presentation that ocean waves and ship response, both as to motion and hull-girder stresses, fit into the framework of a Rayleigh frequency distribution. This is a novel and worth-while contribution to our knowledge of the behavior of ships at sea. One might logically ask now: Of what practical significance is this new information to the designer? With today's emphasis on special purpose ships, which impose exacting environmental requirements, the determination of the motions and structural deformations a ship is likely to experience in a particular seaway is of extreme importance. The question however still remains: Can we predict the ship response from known theories during the design stage or do we have to build the ship first and then send it out at sea to observe its behavior? The author states that the actual Rayleigh distribution applicable to a particular ship can best be obtained by appropriate model tests. He does not consider that this can be done by theory alone in its present form. Since model tests are time-consuming this means that, for planning purposes, adequate lead time must be allotted in the early design stage to obtain the optimum hull shape for ship motion without having compromised the speed characteristics adversely.

From the hull-girder strength standpoint, Fig. 18 is particularly significant and most illuminating. It shows for example that for a destroyer hull type a 10,000-psi stress range or less occurs 99.99 per cent of the time that the ship is at sea, and conversely, a stress range of this magnitude is exceeded but 0.01 per cent of the time. It is realized that this stress range considers sea loads alone. However, since the design stress range for this type of hull is well over 30,000 psi does it follow that the destroyer's structure reflects a disproportionate conservatism, or does it mean that the margin between 30,000 psi and 10,000 psi stress range constitutes a judicious insurance against those rare and extreme sea loads that occur but $1 / 100$ per cent of the time? Obviously economies in structural design can only follow after a realistic evaluation of the sea loads is made. Does the author feel that our present hull structures are designed too conservatively?
An important feature in the paper is Fig. 22 which illustrates a rule for estimating the "cumulative damage" factor for any typical structural component once the fluctuating stress pattern for the component is known. The life expectancy of 5.4 years has been worked out for a hypothetical case. It would have been much more significant if the example could have reflected a realistic case. The choice of the numbers for the purpose of this illustration is somewhat unfortunate for it creates the feeling that the useful life of ships at sea is relatively short, whereas the records indicate there have been many successful ships that have plied the oceans for 25 and 30 years without having had to worry about their endurance limits.

The author's contention regarding life expectancy of a ship with endurance limit as the controlling factor is misleading. It is general knowledge that ships have broken in two under stillwater conditions where the question of fatigue of metal was not involved. Moreover it has been established that by using a steel with a lower transition temperature a major improvement in life expectancy results even though endurance limit and stress levels are not affected. Thus, although the author is careful to acknowledge the "variability of the endurance strength of nominally indentical structures," it is the writer's opinion that the variability is of much more practical significance than the endurance-limit calculation.

In discussing prediction of life expectancy of structures, the author suggests that the quasisteady stresses, such as dead-load stresses, temperature-induced stresses, and built-in stresses must be estimated, and added to the sea-load stresses in order to reach a more realistic approach to the ship structural design. This suggested course should be approached with considerable caution. The writer contends that before new design procedures are instituted, one must balance the additional expenditure of efforts dictated by the new approach with the returns that he expects to obtain. In the final analysis the most effective design procedure is that one which is simple and direct to apply, and which in addition has had the benefits of accumulated satisfactory sea-service experience.

One can speak with ardor about combining several load factors such as thermal stresses, welding residual stresses, and so on, to the sea-induced stresses. The truth of the matter, however, is that if these factors were considered in today's design procedures the resulting hull structure would be much too heavy, and most likely economically unacceptable. The meticulous designer might welcome an elegant rational design approach, but 
the prospective shipowner might frown at the rationality of the refinements especially when the weight of the hull is increased over and above what is safe past practice. The writer wishes to emphasize that improvements in the hull structural design are made not so much by acknowledging the existence of many complex parameters and pleading for their acceptance for design purpose, but in determining how important and really significant they might be. Only research can separate the wheat from the chaff, and it is here that investigations such as represented by the subject paper can play their most important role.

Mr. WILbUR MARKS, ${ }^{22}$ Visitor: In recent years there has been a flurry of activity in the field of ship motions, hull stresses, and the like. Theoretical developments, though not fully verified, have reached the point where, given a particular ship and seaway, certain ship-behavior statistics may be predicted. One of the most prominent of these theories is mentioned in this paper (15). Although simplifying assumptions are used, the mathematics take on such a formidable appearance as the development progresses that the end result of statistically reducing the motion spectra, instead of providing a handy tool for ship-motions prediction, has created rather an atmosphere of uncertainty in many places.

Following this work by St. Denis and Pierson, a hue and cry arose, the substance of which was the demand for a simplification of the treatment and a set of rules (or graphs) from which a ship's captain, for example, could tell immediately his vessel's response for a given set of conditions. At this writing no such simplicity has evolved. The reason for this will be discussed. The fact remains that, although the answers are obtainable in principle, electronic analyzing equipment or expensive calculating machines are required. There is little doubt that a prediction system, albeit statistical, that is simple to apply is needed. The present paper attempts to solve the ship-performance problem by utilizing the experimental approach. The difficult task undertaken by the author can be appreciated readily. If any aspect of ship behavior under any particular set of conditions is considered to be an "event," then the infinite population of events being investigated is comprised of the different behaviors of all ships, in all sea states, traveling at all speeds and headings. The object of the experimental approach is to describe the population by a law (or laws) derived from a sample (or samples) whose properties are believed to be the same as those of the

22 David Taylor Model Basin, Washington, D. C. population. This then is the method used by the author in his attempt at solving the problem.

To be sure, the data collected are voluminous and a determined assault on such a veritable mountain of information is in itself praiseworthy. Yet it is implied in the summary that, to answer the question for a particular ship under particular conditions, more data, either full scale or in the model tank must still be collected. The fact is that the sample analyzed here is not in itself sufficiently adequate to answer all questions, but is intended rather to point the way to the solution.

There is little doubt that the analysis demonstrates the applicability of the Rayleigh and lognormal laws to the data sampled, even if the possibility that other laws may fit the data as well, or better, is not precluded. The difficulty lies rather with the number $E$. It is this factor which determines the slopes of the straight lines which pass through the origin and this must be known in order to find the distribution of $x$ for any particular case. For every possible combination of conditions there is an $E$, and in order to solve the seaworthiness problem a representative sample of $E$ must be obtained. Just how many are needed?

Consider for a moment, the number of tests required to make up an adequate sample of the population. The experimental variables might be: (a) 7 ship parameters (hull oscillations, heave acceleration, bow submergence, etc.) (b) 7 basic ship hull designs, (c) 3 loading conditions, $(d) 5$ seaways, $(e) 5$ ship speeds and, $(f) 5$ headings. The result is that 18,375 separate tests, either full scale or in the model tank, must be made, in order to characterize the population. Can data collection on such a scale be practical?

Suppose for the sake of discussion such data have been collected; what then? It will then be required, as it was of St. Denis and Pierson, to present these data in a simple form. If graphs of ship performance, as a function of ship speed and heading, are assembled, there will be 735 curves through which a ship's captain might have to pore and even then be faced with the problem of interpolation between different designs, loading conditions and seaways. It is quite possible that the presentation can be simplified and indeed the establishment of a central forecast agency, equipped with high-speed computers or a punch-card system, may solve the prediction problem but, as long as prediction rests with ship personnel, the data will necessarily be in a clumsy form, similar to those just described. This perhaps is the reason why the theoretical solution has not yet been reduced to a simple set of rules. By these arguments, I feel that the author has assigned himself a difficult task indeed, if he seeks to pur- 
sue this method tu fruition; namely, the prediction of service conditions of ships.

I think there is however a very definite place for the fine work presented in this paper. It seems reasonable that the ultimate solution to the ship-behavior prediction problem lies in a combination of theory and experiment. Theory must define the broad general aspects of the problem while experiment verifies and modifies the simplified mathematical model. As an illustration of the value of the material here presented, there has just been reported by Cartwright and Rydill ${ }^{23}$ the results of an investigation which clearly demonstrate the importance of full-scale experiments. The roll and pitch of a vessel (RRS Discovery $I I)$ were measured in long-crested seas for 12 headings and at $6 \frac{1}{2}$ knots and also head-on to short-crested storm seas. Waves were recorded by a ship-borne wave recorder. The records were spectrum analyzed and the amplitude distributions predicted. At the same time the motions were computed by the simplified equations of motion and again by the "advanced" equations which include coupling terms. Their findings are worth repeating: "The practical results are compared with theoretical relations derived by methods which ignore certain effects but are simple to apply, and advanced methods which estimate some terms with greater precision but at the cost of greater computational labor. The theoretical results are in general quite close to and never very different from, the practical results, the differences largely being due to statistical variations."

To be sure, the results of Cartwright and Rydill are encouraging, but nevertheless their experiments were not comprehensive and certainly not conclusive. This paper, however, comprises a cross section of material that covers almost every aspect of the ship-behavior problem that has been investigated theoretically. In addition, the data have been reduced to their probability distribution functions. If now theoretical predictions were made for each pertinent case analyzed in this paper and compared with the author's results, the work of Cartwright and Rydill will have been carried a good deal further in the direction of verification of theory. This appears to be the most profitable approach, at this time.

Prof. B. V. Korvin-Kroukovsky, Member: The author has presented an excellent paper which invokes admiration, but also a certain amount of criticism.

22"'The Rolling and Pitching of a Ship at Sea," by D. E. Cartwright and L. J. Rydill, Trans. INA, vol. 98, 1956.
The positive side is evident: A tremendous amount of careful observations were made on several ships under many different conditions and the results were analyzed.skillfully and presented in a compact and clear set of graphs. The very complex and varying conditions of sea and ship motions are shown to follow a simple statistical law on the basis of which certain conclusions and predictions can be made.

On the negative side is the over-concentration on pure statistics, and the lack of any reference to the physical nature of the situation (except in the excellent section on endurance strength). This aspect of the problem is taken up in the previous literature on this subject which should not be ignored. Two papers will be cited here as instructive examples.

The first is by A. J. Williams ${ }^{24}$ who has shown a comparison of the Rayleigh distribution with experimental observations on the rolling of a ship at sea. The importance of this reference lies in that, although the term "Rayleigh distribution" was not used, the expression was derived for use in this particular case on the assumption of sea waves being composed of a number of waves of different amplitudes $A$ and phases $\phi$ traveling in one direction. The waves were of a somewhat peculiar type in that the amplitude $A$ was assumed to be a function of time, while the angular frequency $\omega$ was taken as constant. Thus the expression was shown to result physically from an event which has two degrees of freedom in $A$ and $\phi$.

It is clear from the derivation that it applies directly to sea waves. In application to a rolling ship an additional physical factor enters in, that of the ship response to waves. Thus it can be seen that in using the Rayleigh distribution several factors are neglected, most obvious of which are the spectral composition of waves in regard to the frequency, the well-known variability of wave directions at sea and the ship-response factor for a specified type of motion (i.e., pitching or rolling) and the direction of ship travel with respect to the mean direction of wave propagation. In view of these physical conditions, it is a pleasant surprise that Figs. 2, 4, 6, 8, and 10, show such a good agreement between the Rayleigh distribution and the observed data. Such discrepancies as are found to exist should not, however, be attributed to chance errors, but rather to the failure to use a distribution function corresponding to the appropriate number of degrees of freedom of the wave-ship system under consideration.

As the second reference on sea waves the paper

24 "An lnvestigation into the Motions of Ships at Sea," by A. J. Williams, Trans. 1NA, vol. 94, 1952. 


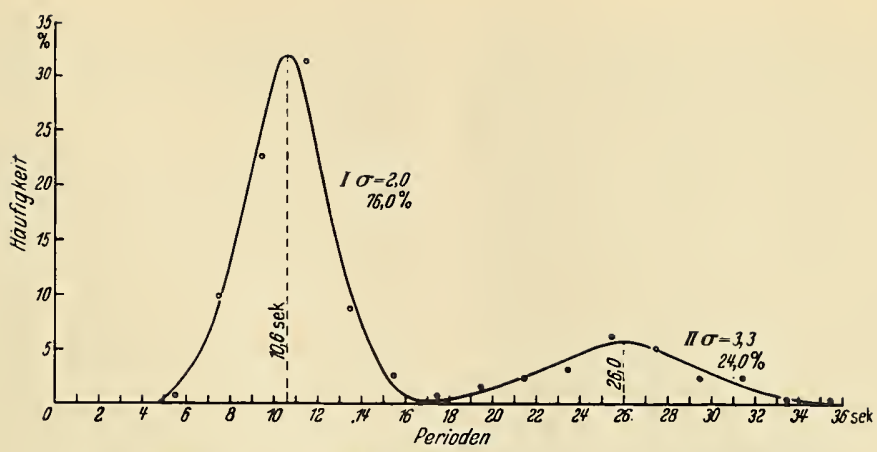

Abb. 3 b. Versuch RL I, Häufigkeitsverteilung der Schlingerperioden.

FIG. 26

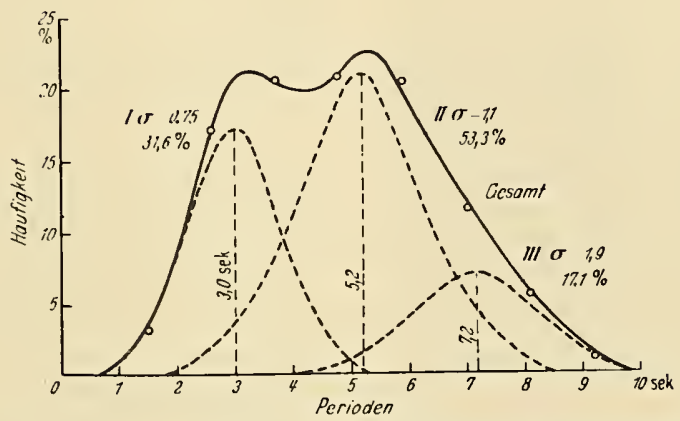

Abb. (a). Versuch II 41 , Häufigkeitsverteilung der Wellenperioden, relative Häufigkeit auf mm-Teilung.

Fig. 27

by Willi Langmaack ${ }^{25}$ can be cited. In the present connection the reference is of particular interest in demonstrating the value of the "normal distribution" method. As Dr. Jasper points out in the early part of his paper, the Rayleigh distribution is convenient in that it depends on a single parameter $E$. While for many problems the resultant common form of distribution is of value, for others it may be of interest to bring out the differences of existing conditions. In this particular case the "normal distribution" brings out the mean value of a quantity, and the spread of dis-

25 "Hãufigkeitsverteilung der Schwingungsperioden und amplituden eines Schifles in Seegang," by Willi Langmaack, WerftReederei-Hafen, Heft 13, 1941, pp. 204-211. tribution about the mean value. This is illustrated by Fig. $3(b)$ of the reference mentioned ${ }^{25}$ (Fig. 26 of this discussion). The plot represents the frequency distribution of rolling periods plotted against the period. Two values of the maximum frequency of occurrence can here be seen at the periods of 10.7 and $26 \mathrm{sec}$, with the normal distribution about each of these. This plot evidently represents two superposed oscillations, the first at the frequency of wave encounter and the second at the natural frequency of ship's rolling. Air example of distribution of wave periods is shown on Fig. 6(a), ${ }^{25}$ (Fig. 27 of this discussion), where the total motion is seen to be the result of three superposed wave trains. 
The two examples taken from the previous literature have shown that ship motions in a seaway follow certain well-known statistical laws. The present author collected much more data and presented the case so forcibly that no possible doubt about this can exist. On the other hand, it appears to be clear that it is not advisable to concentrate completely on one method of statistical presentation, as in doing so certain valuable features of wave and ship motions or ship stresses can be overlooked. In particular, a distribution of a Rayleigh type should not be taken as an arbitrary statistical law of a fixed form, but the applicability of a given form to the problem must be considered on a physical basis. The distribution will take somewhat different forms (i.e., more peaked or flatter) depending on the number of variables affecting the variate which is under study.

Dr. V. G. Szebehely, Member: The writer will begin his comments by quoting Dr. von Kármán: "The layman is amazed and the expert is left wondering." We are amazed by the fact that such a great amount of data could be organized according to relatively simple basic laws. The profession is grateful to the author for collecting this useful information and we wish to congratulate him for the clear and orderly presentation of the data. The amazement and wonderings of the reader might justify the following questions in order to evaluate the merits of the paper under discussion.

1 Why log-normal and why Rayleigh distributions? Have other laws been tried also? Is there a more basic physical law which governs the phenomena and from which the foregoing named statistical distribution laws can be derived? Does the long-term distribution follow from the shortterm distribution, or to state the question another way-should there exist in principle a definite relation between the two distributions which, after all, represent basically the same phenomenon?

It is suspected that the answer-to at least some of these questions - is affirmative.

2 How are the results of the paper to be used to answer the ever recurring questions: What will be the performance of a ship in a given sea? If two sets of ship lines are given, which vessel should be built for a certain operation? Will a ship with a U-bow lose more speed in a state 5 sea than a ship with a V-bow? What is the speed at which slamming starts for a given design in a given sea? What is the threshold for operation; i.e., what is for instance the maximum speed and maximum sea state in which the pitch angle will stay below $5 \mathrm{deg}$ ? (It is possible that these questions cannot be answered from the impressive amount of data in this paper.)

3 What is the real significance of the line giving the hull-girder stress distribution for a destroyer in Fig. 9? Would this line be entirely different for another destroyer? Do we have to measure stresses for long periods of time on several destroyers in order to find out the relative merits of the various designs? Wouldn't it be simpler to run several destroyers parallel in the same sea for, say, $30 \mathrm{~min}$ and compare the results?

4 An elaboration on the claim of the paper"to predict service conditions for ships"-would be appreciated. What is the relative merit of the following approach? Determine the transfer functions of a given vessel in regular waves on model scale and then, using the energy spectrum of a certain sea, find the expected behavior of the vessel?

Answers to these questions will not destroy the appreciative amazement and might help to guide the wonderings.

Mrs. Margaret D. Bledsoe, ${ }^{26}$ Visitor: This writer recently had the opportunity to perform statistical analyses of motion records obtained during full-scale trials of Dutch destroyers. It is believed that these results might serve to corroborate the work of the paper under discussion. The analyses were performed both by using the author's approach of assuming the motions to be described by the Rayleigh distribution and by using the autocorrelation technique to find the associated power spectrum. The two methods should yield the same results for the total energy provided most of the energy is concentrated in a narrow frequency band, i.e., the assumption of the Rayleigh distribution is valid. From a knowledge of the total energy one can, of course, determine such quantities as significant amplitude of motion, average height of the upper tenth highest waves, and so on.

The analyses were performed for several samples of pitch data where a continuous recording was obtained for 10-min intervals. Of the samples analyzed, some were obtained in head seas, both moderate and heavy, and some were obtained in moderate quartering head seas. Ship speeds varied from 12 to 22 knots. The theoretical Rayleigh distribution was computed and compared with the experimental histogram and in all cases the Rayleigh distribution was found to de-

\footnotetext{
${ }^{26}$ David Taylor Model Basin. Washington, D. C.
} 
scribe the actual data with a degree of significance comparable to that shown by the author.

By reanalyzing the data according to the powerspectrum concept, the total area under the spectrum was obtained and this was compared with the author's parameter $E$ which defines the Rayleigh distribution. The maximum discrepancy found was of the order of 7 per cent. This, of course, means only a 3.5 per cent error in the determination of the significant or average height of the motions.

One sample might be cited in particular for which the test conditions corresponded to those in Fig. 6 of the paper with the exception of the significant wave height which was $10 \mathrm{ft}$ instead of $14 \mathrm{ft}$ (the significant wave height appropriate for Fig. 6). The Rayleigh distribution for this case showed that the pitch angle having the highest frequency of occurrence was about $1.9 \mathrm{deg}$. If linearity of response can be assumed, the most probable pitch angle when the ship is running in waves whose significant height is $14 \mathrm{ft}$ would be $2.7 \mathrm{deg}$. This appears to be in close agreement with the results of the author's Fig. 6.

One further remark may be of some interest. Data obtained on the pitching motions of a transport ship also were fitted by the Rayleigh distribution. The data were collected at $1 / 2-h r$ intervals over a $36-\mathrm{hr}$ period. The significant wave height varied from approximately 5 to $15 \mathrm{ft}$ and the wave period varied from 5 to $12 \mathrm{sec}$. The wave direction during this period changed by 3.5 deg. The average speed of the ship was 17 knots. While, according to the author a log-normal distribution should more accurately describe the data, the Rayleigh distribution was found to provide a very reasonable fit in this case also.

Finally, one might remember that while the author's method does seem to offer a convenient method for organizing a large amount of data, the power-spectrum technique, while more laborious, appears to offer a solution of even greater practical significance.

Prof. W. J. Pierson, JR., ${ }^{27}$ Visitor: This very fine paper will certainly provide the naval architect with important design criteria in his work. The words of warning in the author's discussion are particularly apt, and they should be heeded! The author of these comments agrees with a major portion of the results of the paper and believes that quite a few years will elapse before they are superseded by more refined analysis.

A few points need to be made, however.

\footnotetext{
${ }^{27}$ Department of Meteorology and Oceanography, Research Division. College of Engineering, New York University, New York,
N. Y.
}

The author states, "the experimental approach taken in this paper should complement the theoretical work of St. Denis and Pierson, although the present study was developed independently of theirs and is not limited by the assumptions required by their mathematical analysis." In my opinion, all of his results are strictly limited by the assumptions of the mathematical analysis employed by Mr. St. Denis and the writer. In particular our assumption that the sea surface could be represented by a stationary Gaussian process and that the response of the ship to the waves is linear is at the very root foundation of the Rayleigh distributions studied in this paper. It also follows that these assumptions are at the foundation of the log-normal distribution.

It is interesting to note that the Rayleigh distribution and the log-normal distribution fit so well. However since a stationary Gaussian process is a linear process, since waves are definitely nonlinear, and since extreme ship motions are nonlinear, it follows that neither the log-normal nor the Rayleigh distribution will truly describe conditions at extremely high values. That no such discrepancy was detected in this work is probably due to observational error and sample size, but nevertheless it must exist.

As an example, consider a sea generated by a $30-$ knot wind blowing for an infinite length of time over an infinite fetch. A wave record from such a sea would have a definite $E$ value. If one waited long enough, according to the extreme-value theory of Longuet-Higgins, a wave higher than any preassigned arbitrarily high value would pass. However, the sea surface is nonlinear, and the spectrum appears to have no energy below a certain frequency. Therefore waves in excess of a certain height cannot exist because they would break. Our knowledge of the process is not sufficiently precise to tell us whether the limiting nonlinear wave is given by the highest wave out of $1000,10,000,100,000$ or $1,000,000$ according to the statistics of Longuet-Higgins. Similar remarks are true about any other quantity with a Rayleigh distribution in this paper.

Similarly there is an upper bound to the wind speeds possible over the ocean, to the duration of the wind and to the length of the fetch over which it blows. And there is a highest possible wave due to nonlinear considerations for these conditions. The log-normal distribution may well be too high for higher values for the foregoing reasons.

The Rayleigh distribution fits a great deal of these data quite well. Since the "Chi Square" test gives the probability that a sample truly 
drawn at random from a population actually with the probability density function being tested could differ by chance by as much as it does from the theoretical distribution, one can argue that characterizing the data as in Table 3 by terms such as "fair fit" or "very good fit" is not justifiable. One can only state that the hypothesis that the data were drawn from the theoretical population being tested cannot be rejected at the 5 per cent significance level. It is odd that in one hundred such tests of ship motion or hull stresses no discrepancies at the 5 or 1 per cent level were found. One should expect to reject the hypothesis at the 5 per cent level about 5 times in 100 trials and once at the 1 per cent level (despite the fact that it is true).

Recently Cartwright and Rydill ${ }^{23}$ have found that the Rayleigh distribution did not fit certain ship-motion records and wave records which they were studying due to the fact that the spectrum was not a narrow band. They give a more refined formula which fits the data better.

Dr. J. H. Chadwick, Associate Member: It has been said often that the main object of scientific research is to discover and explain regularities in the data. In this sense the paper is certainly a contribution to marine science as well as to marine engineering - for what could be more regular than a straight line? This paper will be, I am sure, another important landmark on the trail recently blazed by St. Denis and Pierson in the paper they presented before this Society in 1953. Where St. Denis and Pierson emphasized theory and frequency distribution (power spectrum), the present author emphasizes fact and amplitude distribution. Taken singly or together, these papers offer us an infinitely more realistic view of ocean waves and ship motions than we have had heretofore.

The two papers are closely related and complement each other in a natural way. I have to violently disagree with my friend Dr. Pierson, however, when he argues that Jasper's results are based on his linear model assumptions. The author's results are largely factual, and it is a fundamental principle of science that theories are based on assumptions, while facts are based on measurements. In support of this view may I quote the epigram that appeared at the head of the original St. Denis-Pierson paper (15): "Mathematics can never tell us what is; only what would be if." (Poincare). It is true that some of the author's results can be explained (i.e., predicted) in terms of the linear model assumptions; which is to say that his facts so far tend to confirm the. St. Denis-Pierson theory.
Nevertheless, theories are not facts, and never the twain shall meet.

Both of these papers have as a central theme, the notion that waves and wave-induced ship motions are stochastic processes; i.e., essentially random in nature. Actually, this is something that marine science has recognized implicitly for a long, long time, but we have stood shivering on the verge of an idea, unwilling to plunge into the seemingly infinite mathematical complexities of the statistical approach, until Messrs. St. Denis and Pierson came along to push us in. A surprising number of us survived this immersion. To the few that have felt themselves going down for the third time, the author now throws a life-ring.

Mr. St. Denis, in another paper on ship motions, once quoted Lord Rayleigh as saying: "The basic law of the seaway is the apparent lack of any law." It is pleasantly ironic that one basic law of the seaway, discovered during the evolution of these new theories, is that peak amplitudes over the short term tend to fall on a Rayleigh distribution, a fact not known in Rayleigh's lifetime. This little joke of fate tells the whole story. The basic law of the seaway is randomness, but randomness itself obeys statistical laws, some of them as simple as straight lines.

The author stresses engineering applications, and the point is well taken. Since the present models are vastly more realistic than the old singlesine-wave models they also have a much greater potential value to the engineer. The amplitudedistribution data presented in the paper are particularly important with respect to the economic side of design.

In the collection of his data, the author has used a technique the importance of which cannot be overemphasized; namely, the collection of data at predetermined times. This technique provides objective data with the minimum intervention of theory, and hence provides the best possible test of theory. In its application, this technique has certain consequences: It tends to call for a longterm, low-level effort; it requires automatic recorders; and it uses a minimum of shipboard personnel. At the other extreme we have the grand expedition approach, using short-term, high-level efforts, subjective recording and a maximum of shipboard personnel. History has shown that the expedition approach is an extraordinarily inefficient method of collecting data about waveinduced ship motions. The San Francisco and Ocean Vulcan expeditions are cases in point, particularly the former. It is to be hoped that in the near future we will see the same type of recording technique used by the author for amplitudes applied also to power spectra and cross spectra. 
Mr. R. P. ERICKSON, ${ }^{28}$ Visitor: The excellent statistical description of ship data, discussed in the paper, has as a major application the establishment of design criteria. Because the data are empirical they fit ideally only the ship on which the data were gathered and must be extrapolated for new ship designs. If these new designs are not distinctly different from the tested design it follows that the extrapolation would be satisfactorily accurate. The purpose of this discussion is to mention a problem where previous similar experience is not available and thereby point out a need for the statistical description of derived, as well as empirical, data.

This problem arises in the specification of environmental conditions encountered during the shipboard handling and launching of large ballistic missiles. The structural loads imposed on the missile by the motion of the ship is one of a number of similar problems that represents a critical design criteria. Minimum structural weight is absolutely essential to the effective utilization of the missile as a weapon. Minimum weight implies minimum acceptable structural strength. The emphasis on weight reduction is so strong that missile designers are prepared to accept a statistical risk of structural failure if a known statistical risk can be defined.

The establishment of a statistical design criteria for ship-launched ballistic missiles must be based upon an intelligent specification of the maximum operational sea conditions in which the weapon must be utilized. Then attempts must be made to determine the statistical description of the sea, or preferably of the ship motions, encountered under this assumed steady environmental condition. Thus far the attempt to define a design approach can benefit significantly from the work of the author. Now, however, because of a lack of previous experience, additional information as to missile structural loads must be derived by engineering analysis and the statistical properties of the derived information must be determined.

To date, with the co-operation of the Navy, especially Bu Ships, the Hydrographic Office, and the David Taylor Model Basin, we have been able to define statistical wave-height and wave-length distribution based on constant underlying parameters. We have been forced to extend this information to the statistical definition of missile loads by relatively crude graphical methods. This technique can be improved by additional experimental data on ship response which is now being gathered. The eventual goal of this program is to be able to describe derived data in a

${ }^{28}$ Supervisor, Applied Mechanics Grotp, Missile Operations, Chrysler Corporation. convenient statistical form similar to that substantiated by the author for experimental data.

Mr. Harry PRess, ${ }^{29}$ Visitor: The author is to be congratulated in making a valuable contribution to the problems of ship behavior in disturbed seas by his collection and analysis of statistical data on ocean waves and ship responses. The paper is of particular interest to me in that it closely parallels some of our recent studies on the analogous problem of the airplane behavior in rough air published in the National Advisory Committee for Aeronautics Technical Notes 3362 and 3540 .

The paper considers two major points: The first point is concerned with the demonstration of the applicability of the Rayleigh distribution for describing the probability distribution of ocean wave heights and ship responses for steady ocean conditions. The second point is concerned with the probability distribution of wave heights and such ship responses as disturbed motions and structural stresses under broader operating conditions, presumably over-all ship operations. The author claims that such distributions are well represented by a log-normal probability distribution. In both cases, the evidence presented is almost entirely empirical and the conclusions reached based on statistical tests on the data of these hypotheses.

A few comments on the two major points of the paper appear warranted. In regard to the Rayleigh distributions for steady ocean conditions, the statistical evidence presented in most cases seems to be quite convincing. It is unfortunate that the author didn't more closely tie the present statistical evidence to the closely related recent work on the response of linear systems to Gaussian random processes. Results obtained in the theory of stationary processes indicate that the distribution of peaks for a Gaussian process having a narrow power spectrum should tend to adhere to a Rayleigh distribution (Rice). The work of Pierson and St. Denis has served to demonstrate that, to a very good first approximation, the disturbed sea under given conditions may be considered a stationary Gaussian random process. Consequently, if the ocean wave power spectrum is narrow and peaked, which appears to be the case frequently, the distribution of ocean wave heights, either peak to trough or mean value to peak, may well be expected to approximate a Rayleigh distribution. This approximation would tend to deteriorate as the spectrum broadens.

In regard to the distribution of peaks of the ship

\footnotetext{
29 Head, Gust Loads Branch, NACA, Langley Field, Va.
} 
response such as pitch, structural stresses, etc., the distribution of peaks may be expected to depend upon the characteristics of the ship's frequency-response functions assuming that the ship is a simple linear system. As long as the ship response involves a single degree of freedom that is relatively lightly damped (and thus yielding a narrow and peaked frequency-response functions), the Rayleigh distribution may still be expected to apply. However, if the ship response is more complicated involving several significant degrees of freedom, the resulting power spectrum of the response may no longer contain a simple peak but may contain multiple peaks. For such cases, the Rayleigh distribution would not appear to be adequate, and the more general distribution given by Rice would have to be used.

The writer is not familiar with how serious the foregoing objections actually may be in practical applications. The experimental data presented do, however, show sufficient departure from the assumed hypotheses to warrant a more detailed consideration of the foregoing types of limitations.

In regard to the second major point, the applicability of the log-normal distribution, we are here concerned with a distribution of peaks for the summation of a large number of stationary Gaussian processes. There does not appear to be any theoretical a priori basis for the choice of a distribution function, and one is forced here to rely more heavily on the purely empirical observations.

The empirical data show generally good adherence to the assumed log-normal distribution function, but again the data appear to show departures from log-normal distributions that suggest the possibility of the need for a more detailed consideration. It appears clear that the appropriate distribution may well be expected to vary depending upon the detailed nature of the operations being considered and the climatology of the ocean waves. In an analogous problem in airplane studies, no single distribution was found to apply in general to gust velocities encountered by airplanes and to airplane response distributions under full operating conditions.

One further point is worth noting. The author has chosen to describe the ocean characteristics in terms of the probability distribution of the ocean wave heights. Although this is a useful description for many purposes, it is not adequate in regard to the problem of determining the ship response since the response of a ship will depend upon not only the individual wave heights but also upon the preceding waves or more concisely upon the power spectrum of the ocean wave height. Thus, a more fundamental and useful description of disturbed seas would appear neces- sary in the long run if adequate predictions of ship behavior in operations are to be achieved.

In concluding, I should like to reiterate the valuable nature of the present paper. It certainly provides some reasonable and useful definitions of the ocean wave field and the character of the ship response. The principal criticisms in the foregoing are concerned with the absence of expressed limitations to the hypotheses claimed and the suggestion is that refinements to the simple picture presented may often become necessary.

Comdr. R. L. Brooks, USN, Associate Member: This paper provides a working tool of great value to the naval architect for obtaining, interpreting, and using full-scale data. By means of the distribution pattern and with a minimum of observations, many seaworthiness problems can be clarified in terms of actual results obtained at sea on a properly chosen hull.

That the need for reliable data respecting ship responses to the sea is a matter of great importance has become better appreciated, as the solution of each new seaworthiness problem was found to depend on full-scale data which were seldom readily available in the form or ranges which were needed. Examples of critical problem areas in which progress no longer needs to be hampered by the lack of full-scale data, now that this distribution pattern technique is available, include: $(a)$ The determination of how much ships must slow in heavy seas, $(b)$ the checking of assumptions upon which are based theories for predicting ship motions, $(c)$ the improving of present strength design methods, and $(d)$ the development of shipboard computers for selecting optimum courses and speeds for a variety of tactical situations, as for example fueling of destroyers in moderate to heavy seas.

While the need for reliable data has long been acknowledged, the difficulties which stood in the way of obtaining it at sea, have been so serious as to hold up solutions to many of the important problems for several years.

Consideration of a few of these difficulties helps to show that the present paper represents a task of large magnitude, because each difficulty was a major problem in its own right. The following examples are mentioned: (a) The development of specialized recording instruments which would require a minimum of attention, $(b)$ the planning of how the many variables which define the environment and the ships' responses should be handled, (c) the detailed co-ordination of instrument installation and operation, so as to harmonize with ship schedules and internal routine, $(d)$ the difficulty of defining each sea 
state in a manner which would have consistent meaning to all who would be involved in the work or would use the results, and (e) the presentation of data in a manner which would lend itself to a maximum of usefulness.

The work involved in this paper required several years of patient, painstaking, and persistent effort; and called for great vision and faith on the part of the author. He not only has succeeded in developing the necessary instruments and methods, but also has already used them on many ships, and has applied the tools of statistics and oceanography in collecting and presenting the results. These much-needed accomplishments are deserving of great credit to the author. Much credit also is due to the several organizations which nurtured this work, in particular to the Society, the Navy, the Model Basin, and the Coast Guard.

With the advent of nuclear power for driving surface ships, it is well that this paper gives us the tools for defining and correcting the weaknesses of hull designs, before they become handicaps under nuclear speed requirements.

Admiral Rickover has stressed this point in a recent issue of Naval Institute Proceedings in the following manner: "With nuclear power, the Navy can go where it wants, when it wants, at top speed without worrying about fuel economy."

However, this highly desirable goal cannot be attained unless the hull is also adequate as to its seaworthiness characteristics. Thus, nuclear power undoubtedly will bring greater emphasis on these three questions: (a) How much of the speed potential must be given up in medium and heavy seas? (b) If the hull is inadequate, in what way must its design be changed? (c) To what extent do physiological and psychological factors influence the decision to slow ships in heavy seas? The answers to these questions are important for conventionally powered ships and become even more so for those with nuclear drive.

It is hoped that work in this field will be carried forward vigorously; and particularly that the problems of determining distribution patterns by model testing, and of determining fully the influence of alternating stresses on hull structures and the limitations as to heavy sea operation, whether from stresses or motions, will be completed within the next few years.

Dr. Julius Lieblein, ${ }^{30}$ Visitor: It is understood that some comment has been raised concerning a statement in the paper to the effect that

30 Applied Matbematirs Laboratory, Code 820, David Taylor Model Basin, Wasbington, D. C. statistical tests of significance showed no significant deviations in any of the more than one hundred distributions tested. The argument raised was that even with a significance level of say, 95 per cent, about 5 per cent of the tests should show significance even when none is present.

First, it may be noted that the statement of nosignificance cases may have been based upon visual inspection in conjunction with calculation of some values of "Chi-Square." This could allow a few cases to be actually significant without appearing so to the eye.

Secondly, for the practical engineering purposes intended, the postulated Rayleigh distribution seems amply supported by the data and past experience. In fact, the quality of statistical treatment is above that usually to be found in investigations of this character, and the issue of combining numerous statistical tests is rarely, if ever, raised-perhaps because the data seldom allow calculations to be carried that far. Moreover, the too few significance cases might not be a rare occurrence. It may be pointed out that extensive undertakings are often carried out on the basis of conclusions obtained without detailed investigation of the results of significance tests.

Prof. E. J. Gumbel, ${ }^{31}$ Visitor: Being a statistician, I want to talk only about the statistical aspects of this paper. The graphical way he used the Rayleigh distribution is very able, because he reduces it to the exponential distribution. This simplifies considerably the plotting, because a semi-logarithmic paper can be used.

The main point of his contribution is the statement that "distribution of wave heights," and many connected phenomena, "may well be approximated by the Rayleigh distributions, provided that environmental conditions are steady and that the same variables will be reproduced by a logarithmically normal distribution if the underlying environmental conditions are allowed to vary over a wide spread."

The first statement has a theoretical basis; while the second statement is purely empirical. This leads to the question how to prove that a convolution of Rayleigh distributions leads to a logarithmic normal distribution.

The logarithmic normal distribution is not (as the author and bad textbooks claim) the normal distribution of the logarithm. In reality, the probability function is an integral and the distributions are transformed as functions under an integral. The incorrect statement, however, has

\footnotetext{
s1 Columbia University, New York, N. Y.
} 
no influence on the merit of the paper or on the results, because only the probability function is used.

If we define the significant wave heights as being the mean third highest wave, then the distribution of the third highest value is a modification of the distribution of the largest value. The probability points for the distribution of the third highest values are given in the Bureau of Standards Tables on extreme values.

The distribution of the largest value and of the third largest value have some geometric similarity with the logarithmic normal distribution. But in our case, it is more natural to use the distribution of the third largest value for the significant wave heights. The means of the third highest value should be normally distributed, just as the means of the largest value are normally distributed.

I agree with the final statement: If the stresses are logarithmically normally distributed, then the largest stress has the first asymptotic distribution of the largest value. These remarks are given only from the statistical standpoint and should not be considered as a critique of the intrinsic technical value of this paper.

DR. JASPER: The wide interest shown in this paper is greatly appreciated and the author wishes to thank the discussers for their contributions which will add considerably to the value of the paper. Several discussers (Professors KorvinKroukovsky and Pierson, Dr. Szebehely, Messrs. Press and Marks) indicate the desirability of providing a theoretical foundation for the proposed distribution patterns. The author fully agrees that this would be desirable but is neither in a position to do this adequately nor to evaluate available theories of ship response to waves, such as have been proposed by St. Denis and Pierson, on the basis of the measurements reported here. Therefore, there would appear to be little reason to elaborate on these well-known theories at this time.

The distributions given here are based on physical measurements, i.e., facts; the statistical theory is utilized to describe these facts concisely and to test if there are significant differences between the assumed statistical distribution and the factual data. Therefore the proposed distributions are derived from experiment alone, that is they are empirical and therefore are not limited by prior assumptions such as always are the basis of theories. This is contrary to the opinions expressed by some discussers. Dr. Chadwick's comments on this matter are very much to the point and are fully concurred in.
It is not precluded, as pointed out by several discussers, that mathematical distributions may be found which fit the data better than those suggested here, though no doubt at the expense of additional complexity. Undoubtedly the true physical distribution is much more complex than any discussed here but this does not prejudice the practical utility of a much simpler distribution.

It has been stated by Mr. Lewis and others that the Rayleigh distribution applies only to time-stationary processes with narrow spectra and that therefore the author's work indicates that most sea and ship-response spectra are "narrow." Objections can be raised to the term "narrow" spectrum even if the assumption of a stationary time series process is accepted, although the applicability of this or other distributions is obviously not restricted to timestationary processes. A paper by Cartwright and Longuet-Higgins $^{32}$ has demonstrated that, for the representative cases studied by them, no significant deviation between the Rayleigh distribution and test data was apparent for spectra with a "root mean square width" $\epsilon$ of less than 0.48 , where $\epsilon=0$ corresponds to the exact Rayleigh distribution and $\epsilon=1$ to the normal distributions. Although they did find significant deviations from the Rayleigh distribution for some ocean-wave records no such deviations were indicated for the ship's response to the waves. We might then define "narrow" spectra as those for which $\epsilon \overline{<}$ 0.50 .

Several discussers (Marks and Pierson) have mentioned the recent paper by Cartwright and Rydill $^{23}$ which makes some comparisons between distribution patterns obtained by theory and by sea tests. The statistical function used by them to represent the short-term distribution of ship motions is more general than the Rayleigh pattern. They applied it to the distribution of the maximum deviations from a mean value rather than to the peak-to-peak variations dealt with in the present paper. It should be noted that these two variables in general would not be accommodated by the same function. The authors claimed that there were no significant differences between the theoretical distribution and the experimental histograms but did not give the basis for this claim. Personal correspondence with the authors indicates that the question of goodness of fit had been somewhat neglected and that there were indeed significant departures from the

\footnotetext{
12 "The Statistical Distribution of the Maxima of a Random Function," by D. E. Cartwright and M. S. Longuet-Higgins, Proc. Royal Society, vol. 237, 1956.
} 
assumed distribution. However they felt that no valuable (statistical) conclusions could have been drawn from their results since they were not really in a form suitable for vigorous significance tests. Nevertheless, the short-term distribution used by them ${ }^{23,32}$ probably would be theoretically more accurate than the Rayleigh distribution.

Professors Pierson and Korvin-Kroukovsky have indicated that the fit of the proposed distribution to the data is "unusually" good whereas Messrs. Lewis and Press note occasional appreciable departures of the data from the theoretical distributions. The fit is really not "too good to be true." Dr. Lieblein's discussion bears directly on this question.

It should have been stated in the paper that not every one of the hundred or so distributions was actually subjected to statistical tests. Rather, all these distributions were examined visually and then several typical distributions as well as several relatively poorly fitting distributions were selected for statistical testing. This seemed to be a reasonable procedure. Also the confidence limits fitted to the cumulative distribution are applicable individually to each experimental fractile but they do not by their nature extend to very small or very large fractiles, unless very large samples are used. Thus nothing can be said about the fit at these extremes and it is therefore quite possible that occasional significant deviations could indeed be present at these extremes, without being detected. Of course from the standpoint of practical application all that is desired is a fit good enough to permit making reasonable estimates. The latter criterion has been satisfied, it is believed, to a good degree for the ship's response to the sea. The author cannot conclude that the deviations from the proposed distributions, which were noted by Messrs. Lewis and Press, are statistically significant.

Messrs. Lewis, Comstock, and Vasta have emphasized the importance of being able to estimate the extreme value of hull girder stress, raising the question as to how this could be done adequately. The long-term distribution would not be suitable for this purpose, as stated in the paper. The following method is suggested as reasonable:

Determine $E_{m}$ for the Rayleigh distribution of stress corresponding to the worst combination of sea state, ship speed and heading that a ship is likely to experience, utilizing either model tests, full-scale data, or theory. Estimate the longest duration that the ship will operate continuously under this combination of steady conditions and note the number $N$, of variations experienced in this length of time. Next, estimate the number of times $n$, that these extreme operating condi- tions (storms) will be experienced during the service life of the ship. Thus $(n N)$ stress variations are expected corresponding to a basic distribution defined by $E_{m}$. Then, utilizing Formula [2] of the paper, we can estimate the fraction $f$ of all similar ships which, on the average, will exceed $\sigma_{m}$ over their service life. Thus $f$ represents the risk of exceeding $\sigma_{m}$. Since for the Rayleigh distribution

$$
\left[1-P\left(\sigma_{m}\right)\right]=e^{-\sigma_{m}^{2} / E_{m}}
$$

we have from Formula [2]

$$
1-f=\exp \left[-e^{-y}\right]
$$

where

$$
y=\frac{\sigma_{m}^{2}}{E_{m}}-\log _{e}(n N)
$$

Table 1 of Bureau of Standards bulletin "Applied Math Series No. 22" tabulates the value of $\exp \left[-e^{-y}\right]$ as a function of $y$. Thus for a specified risk $f$ of exceeding the stress $\sigma_{m}$ one may look up the corresponding value of $y$ and then solve for the desired stress from the relation

$$
\sigma_{m}^{2}=E_{m}\left[y+\log _{e}(N n)\right]
$$

Another way of making the estimate is to utilize the approximation that if $f_{1}$ is the probability of exceeding $\sigma_{m}$ in a single storm then $n f_{1}$ is the probability of exceeding $\sigma_{m}$ in $n$ storms. That is $f=n f_{1}$. The formulas given here thus far are valid only if $f$ is much smaller than unity which will be true if we are looking for extreme values. The exact expression for $f$ is

$$
f=1-\left(1-f_{1}\right)^{n}
$$

As an example consider an aircraft carrier with $E_{m}=16, N=1000, n=100$, and take $f=$ 0.001 ; i.e., one chance in a thousand. Then $y=$ 7.0 and

$$
\sigma_{m}=[16(7.0+11.5)]^{1 / 2}=17.2 \mathrm{kips} / \mathrm{sq} \text { in. }
$$

The method of Hazen and Nims referred to by Mr. Lewis is likely to result in an overestimate of the stress but otherwise appears to offer an attractive solution. These approaches may be utilized to establish an upper limit to the longterm distribution also.

The short-term Rayleigh distributions fitted by Mr. Lewis to experimental model test data of wave height, ship motions and bending moments (Figs. $24,25)$ do show encouraging agreement. It is the author's expectation that, once agreement between model tests and full-scale tests has been established, model tests will be used to define the distribution patterns. Mr. Lewis' fear that an 
underestimate of the extreme wave-induced hullgirder stress would "inevitably doom many ships to the bottom" is believed to be rather on the pessimistic side. There are many other stresses present besides the wave-induced stress and not all will be likely to experience their maximum value at the same time.

The comments of Mr. Darbyshire are particularly welcome as he has pioneered in the measurement of ocean waves with a shipborne wave recorder. His data provide the first extensive series of measurements of ocean-wave heights. It is very gratifying to note that Mr. Darbyshire finds ${ }^{21}$ that the proposed log-normal long-term distribution fits the ocean data satisfactorily. It might be well to note at this point that the author did not study the short-term distribution of wave heights and made no attempt to show that their distribution was of the Rayleigh type; rather he stated that "it has been accepted generally that the heights of ocean waves passing any given point follow the Rayleigh distribution..." Recent studies indicate that of all the variables discussed here, the short-term pattern of the height of the wave surface is least well represented by the Rayleigh distribution.

Both Mr. Comstock and Mr. Vasta express the opinion that endurance strength is not a problem in ship structures, inferring that only the maximum total stress need be considered. It is not believed that there is a sound basis for this conclusion. A study by Dr. Weck ${ }^{33}$ has shown that fatigue failures of typical welded plate-stiffener combinations may occur at very low nominal stresses $( \pm 2$ tons/sq in.) at the point of failure. Such cracks, when noted, probably would be repaired without coming to the attention of designers; they could on occasion form the nucleus of a major fracture in the presence of large temperature-induced, dead-load, or seaway stresses.

The discussions of Weck's paper force one to one of two conclusions, quoting Dr. Weck: "Either that fatigue failures do not occur in ships, which seems to be contradicted by the majority of those who have contributed to the discussion, or that they are not recognized as such. .." It also may be timely to quote the following from his paper: "It is difficult to see why it should be profitable to distinguish between the main hull structure of a ship and the rest when considering the incidence of fatigue. This distinction may well be convenient for purposes of design, but it does not correspond to reality."

"A study of ship failures sometimes referred to

33 "Fatigue in Ship Structures," by R. Weck, Qtaarterly Transactions INA, July, vol. 95,1953 , pp. 305-327. as providing a basis for concluding that fatigue failures are not important is the "Final Report of a Board of Investigation" dated 15 July 1946, which was made for the Secretary of the Navy to study the high incidence of failures in welded ships. The service data given in that report are heavily weighted in favor of failures incident to the brittlefracture problem because the ships were especially subject to this "disease" and thus could be expected to "die" thereof before an endurance failure could develop. What is needed is a consistent and thorough system of reporting structural failures and "defects" even though they may not appear dangerous. The author did not intend to convey the impression that "fatigue" is a major structural problem in ship design-he does not know-however, this problem should be studied together with the other possibilities of causing failure, without prejudice.

The author is not in a position to answer Mr. Vasta's question as to whether hull-girder structures are designed too conservatively; as he has no sound basis for a definite conclusion. However the author "feels" that the sectional moment of inertia is probably more than adequate in many ships. On the other hand the constructional details with which the structural material is put together may not always be adequate and furthermore the local strength, such as that of bottom structures subjected to slamming, is on occasion insufficient. It is really not realistic to separate local strength from hull-girder strength. The author fully appreciates Mr. Vasta's other comments and is in general agreement with them.

Mr. Marks is increasing the scope of the paper when he states that it attempts to solve the shipperformance problem. This is not so. The object, as has been stated repeatedly, is to establish that the long and short-term distribution of ship motion and stresses approximate to the Rayleigh and log-normal distributions, respectively, and to give illustrative engineering applications of this result. True, it was hoped that a knowledge of the form of the distribution would simplify the solution of the ship-performance problem. As stated in the summary, it is expected that this solution will take the form of model tests in waves which will be utilized to make predictions for particular ships in a particular service analogous to the procedure now used to determine power requirements in smooth water by model tests.

Professor Korvin-Kroukovsky feels that in the paper there is a lack of reference to the physical nature of the situation. The physical nature is of course reflected in the parameter $E$ (the mean square value of the physical motion) which relates the mathematical distribution to the "physi- 
cal situation." A paper by Williams was referred to as an illustration of a physical basis for the Rayleigh distribution. The mathematical expression given by Williams for a "fluctuating oscillation" together with the stipulated assumptions made by him does give rise to the Rayleigh distribution. But what is the advantage of carrying out such a derivation? If the mathematical model did describe the physical situation correctly and generally, this would indeed prove the Rayleigh distribution to be the applicable distribution function. However, there appears to be no reason to believe that this mathematical model is the correct one, and if it is not, then the mathematical development is superfluous.

It was the intention in this study to work directly with service motions and stresses of ships thus arriving at results which do not depend upon the validity of $a$ priori assumptions. Thus there has been no attempt made here to relate cause and effect. If a theory relating the sea to the ship's response should be proven practical to apply, then distribution functions would still have to be established. Thus it seemed prudent to start by making an attempt to establish these probability distributions directly since they would be of immediate utility, irrespective of the availability of any suitable theory on waves and the ship response to waves.

The comments of Professor Pierson have, for the most part, already been discussed. The author agrees that the proposed distributions cannot be valid for very extreme values; this limitation was stated in the paper. 'The limitation is however not serious in many practical applications. For example, steady-state conditions of ship speed, heading, and so on, will not generally be maintained long enough to result in predictions which are too extreme.

The remarks of Dr. Chadwick are much appreciated especially so because he, in a way, represents the consumer. $\mathrm{He}$ is in a position to utilize the information presented here and it is pleasing to hear his fresh and forthright comments on the paper and on some of the points raised by others. In fact, Dr. Chadwick has effectively answered some of the points raised by other discussers.

Mr. Erickson's problems are typical of those met more and more often in recent years. The question of specification of environmental conditions as to rigid-body motion, vibration, and shock may well benefit by consideration of statistical methods for the collection, presentation, and analysis of the data. In some of these areas we are not as yet much concerned with a high degree of accuracy in specifying the environmental con- ditions but rather with assigning a reasonable order of magnitude and the probabilities associated with them.

Dr. Szebehely is amazed "by the fact that such a large amount of data could be organized according to relatively simple basic laws." He probably means to imply that the basic laws are really much more complex. The author does not doubt that this is true and has not claimed that the Rayleigh and log-normal laws are applicable basic laws. He merely takes the position that these simple laws give results which are good enough to be useful and possibly just as good as would be obtained if the correct law were known, considering the statistical variations together with the various unknowns and inaccuracies that enter the problem.

The author is reasonably satisfied to accept the good fortune of having simple laws available which describe the situation fairly well without knowing why this is so. Life and Nature are full of mysteries-if we should refuse to accept their mysteries unless given a scientific explanation, progress would be at a snail's pace.

I shall attempt to answer several of Dr. Szebehely's questions. A number of statistical laws were tried before testing the log-normal law. The latter was tried because it has been found applicable in a number of other physical phenomena. As far as I can determine there is no definite relation between the short-term Rayleigh distribution and the long-term log-normal distribution on a purely mathematical basis unless one assumes an a priori distribution of Rayleigh distributions. Nature of course provides a distribution of shortterm distributions and it may eventually be possible to establish the connection then.

The question raised as to the manner of applying the results of this paper to the evaluation of ship performance could be discussed at length. However, briefly the following may be suggested:

(a) Assuming the model test procedures are shown to be valid then model tests may be utilized to determine $E$ for short-term distribution. The parameter $E$ is an index of performance. Thus a single number may be a good criterion of performance rather than a graph or a table of values.

(b) Long-term distributions of ship response may be prepared by synthesis, utilizing typical short-term distributions of ship response each specified by the parameter $E$, together with the long-term distribution of sea conditions given in the paper. This has been done in TMB reports.

(c) Expected extreme values can be given on the basis of the parameter $E$ and the expected number of variations.

(d) Measurements on both model and full 
scale could be made directly in terms of the parameter $E$ rather than measuring the variable as a function of time.

Dr. Szebehely's question regarding the longterm distribution applicable to a destroyer shown in the paper can be answered as follows: (a) The line would be different for different operating conditions or for a substantially different destroyer. It would not be necessary to measure stresses for long periods of time to evaluate the relative merits of various ship designs. One would need to find the parameter $E$ for representative operating conditions utilizing either model or full-scale tests or theory. The long-term distribution could then be synthesized as noted before. Running several destroyers side by side in the same sea for 30 min would give a comparison for the test conditions but not for other operating conditions unless recourse can be had to a valid theory. Furthermore, it would appear to be a rather impractical solution. The best approach, at this time, would appear to be in the use of model tests to determine and compare the desired distributions.

Dr. Szebehely's suggestion of determining the transfer functions by model tests in regular waves and then utilizing the energy spectrum of the sea to find the behavior of the ship is, the author believes, probably the best immediate solution to the entire problem. However it requires that the method be shown to be applicable over a sufficiently wide range of conditions.

It is heartening to see the good checks Mrs. Bledsoe was able to provide between the direct application of the Rayleigh distribution and the autocorrelation technique. If a rapid computer such as the UNIVAC is available then the use of the autocorrelation techniques may be just as quick and certainly more informative than the direct method of computing the mean square value of the measured variation. However the availability of such computing facilities is a severe restriction on the general utility of the autocorrelation technique.

Mrs. Bledsoe indicates that significant and average heights, and so on, can be obtained from a knowledge of the total energy of a power spectrum. This is not believed to be generally true; it is of course true for a "narrow" spectrum.

The physical example of a distribution problem of pitch motion was cited in which the significant wave heights varied over a range of from $5-15 \mathrm{ft}$ and the Rayleigh distributions still gave an adequate representation. This is of course interesting and significant but it does not in any way con- flict with the applicability of the log-normal distribution for representation of long-term distribution. The variation of the environmental conditions simply did not cover a wide enough range. This illustrates the fact that although a narrow spectrum gives rise to a Rayleigh distribution the reverse is not necessarily true. This point seems not to have been given emphasis thus far and is pertinent to the comments of Professor Pierson.

The comments of Commander Brooks as wefl as the considerable personal contributions made by him to this program during his tour of duty at TMB are deeply appreciated by the author. Commander Brooks has rightly called attention to the possibility that with the advent of nuclear power it may occur that full utilization of the available speed potential will be limited by the lack of adequate seaworthiness characteristics. This may well become a major problem facing the naval architect in the not too distant future.

Dr. Gumbel is a well-known authority on extreme value theory and the author is pleased to receive the approval of so well-qualified a statistician on his approach. The author regrets he did not appreciate the fine distinction between the logarithmic normal distribution and the normal distribution of the logarithm. For the record, the definition from Cramer (reference 6 ) will be given: If $\log x$ is normal $(u, \sigma)$ then the variable $x$ itself has the frequency function

$$
p(x)=\frac{1}{\sigma x \sqrt{2 \pi}} e^{\frac{-(\log x-u)^{2}}{2 \sigma^{2}}}
$$

This distribution is called the logarithmic normal distribution. Thus the same physical situation is equally well described by the normal distribution of the logarithm of $x$ and by the logarithmic normal distribution of $x$. The only difference is in the mathematical expression utilized; i.e., semantics. In order to keep to the usage of statisticians the author lias in the paper now given the expression for the probability density of $x$ rather than the density of $\log x$.

Dr. Lieblein's comments are greatly appreciated because, coming from a statistician, they should help engineers evaluate the adequacy of the statistical treatment.

In closing, the author wishes to express his sincere thanks to all for their interesting discussions. It is hoped that some of the questions raised have been answered. Any further questions that may arise will receive the serious attention of the author. 


\section{INITIAL DISTRIBUTION}

Copies

CHBUSHIPS, Library (Code 312)

5 Tech Library

1 Tech Asst to Chief (Code 106)

1 Naval Arch Planning Coord (Code 320E)

1 Applied Science (Code 370)

1 Vibration (Code 377)

1 Ship Design (Code 410)

1 Preliminary Design (Code 420)

1 Hull Design (Code 440)

1 Scientific \& Res (Code 442)

1 Interior Commun, Fire Control, etc. (Code 565) 1

1 Radar Systems (Code 821)

CHBUORD

CHBUAER

2

CHONR, Mech Br (Code 438)

1 CNO

NAVSHIPYD, NYK

2 Matl Lab (Code 992 and $912 b$ )

1 Sci \& Test Group

1 NAVSHIPYD, BSN

Attn: Sci \& Test Group

1

NAVSHIPYD, PUG

Attn: Sci \& Test Group

1

NAVSHIPYD, NORVA

Attn: Sci \& Test Group

1

NAVSHIPYD, MARE

Attn: Sci \& Test Group

CO, USN Med Res Inst, NatI Nav Med Cfr, Bethesda, Md.

1

Hydrographer, US Navy Hydrographic Office

2

CDR, Military Sea Transport Service

13

COMDT, USCG HdqIS

10 Sec, Ship Struc Comm

2

US Weather Bureay

DIR, Natl BuStand

General Electric Co, Phila., $\mathrm{Pa}$. Attn: Mr. Samuel Levy, Spec Proj Div

The Martin Co, Baltimore 3, Md. Attn: Mr. H.C. Johnson

Ryan Aeronautical Co, Lindbergh Field, San Diego, Calif. (Operations Res)
Copies

1 Hydrodynamic Lab, Calif Inst of Tech, Pasadena, Calif. Attn: Executive Comm

DIR, Appl Physics Lab, Johns Hopkins Univ, Silver Spring, Md.

Admin, Webb Inst of Nav Arch, Long Island, N.Y.

2 American Bureau of Shipping

1 Mr. A. Gatewood, Ch Eng Survey

NNSB\&DD Co, Newport News, Va. Attn: Mr. Comstock

Sun SB\&DD Co, Chester, Pa. Aftn: MI. F.L. Pavlik

Engin Soc Library, New York, N.Y.

Prof R. Hechfman, Eng School, George Wash Univ, Washington, D.C.

Dr. W.H. Hoppmann, Dept of Mech Eng, Johns Hopkins Univ, Baltimore, Md.

Prof J. Ormondroyd, Dept of Eng Mech, Univ of Mich, Ann Arbor, Mich.

Dean D.E. Marlowe, School of Eng \& Arch, Catholic Univ, Washington, D.C.

Prof J.W. Tukey, Dept of Math, Princeton Univ, Princeton, N.Y.

Prof H. Piers on, Dept of Oceanography, New York Univ, N.Y.

Dean College of Eng, Univ of Notre Dame, Notre Dame, Ind.

Dr. G.P. Heinblum, Univ of Hamburg, Berliner Tor 21, Hamburg, Germany

Dr. Yoshio Akita, Dit, Ship Struc Div, Transportation Tech Res Inst, Tokyo, Japan

Prof Georg Schnadel, Dr. of Eng, 28 Ferdinandstr, Hamburg 1, West Germany

Dr, F.H. Todd, Supt, Ship Div, Natl Phys Lab, Teddington, England

Natl Inst of Oceanography, Wormley, Godaıming, England

DIR, BSRA

Si. M. Acevedo y Campoamor, Director, Canal de Experienceas Hidrodinamicas, El Pardo, Madrid, Spain

Dr. J. Dieudonné, Directeur, Institut de Recherches de la Construction Navale, 47 rue de Monceau, Paris (Be), France 





\begin{tabular}{|c|c|c|c|}
\hline \multicolumn{2}{|l|}{ 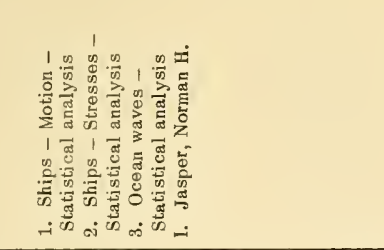 } & \multicolumn{2}{|l|}{ 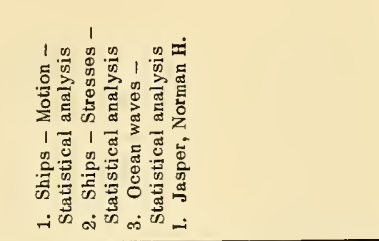 } \\
\hline 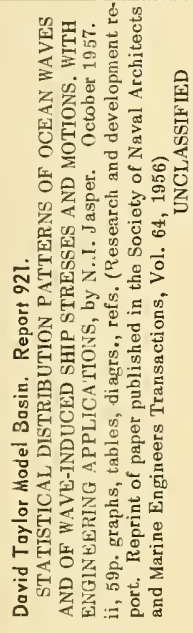 & 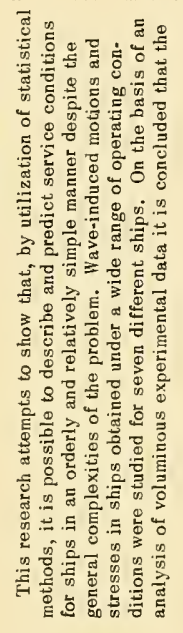 & 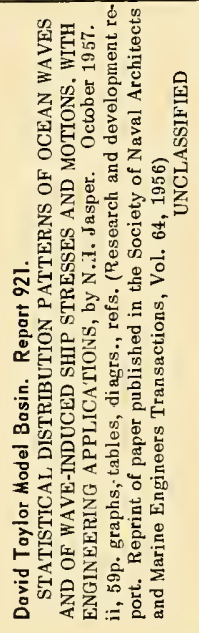 & 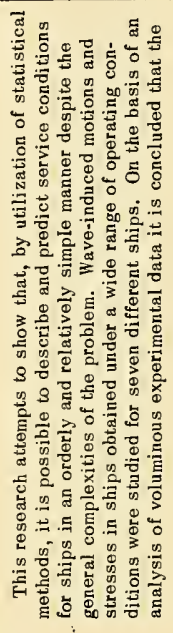 \\
\hline 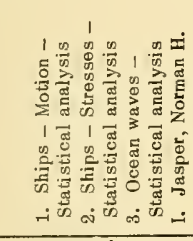 & & 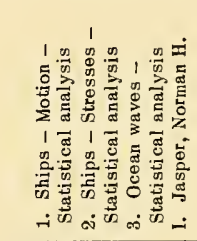 & \\
\hline 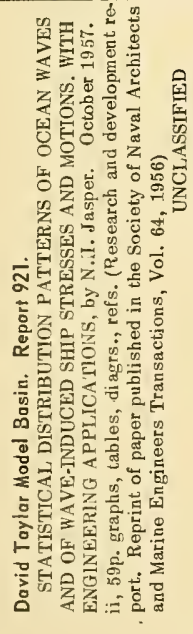 & 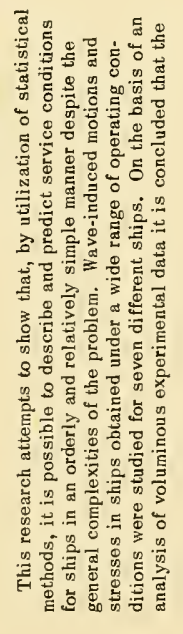 & 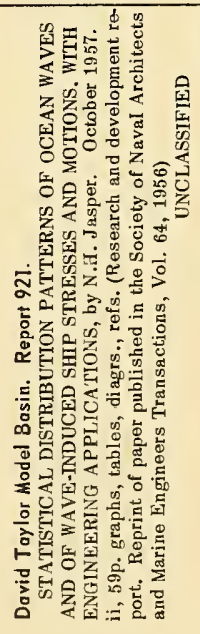 & 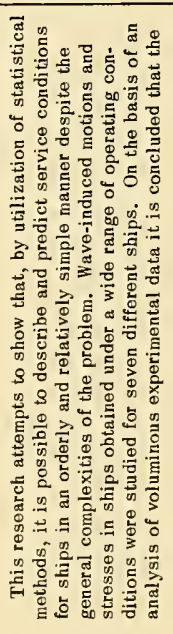 \\
\hline
\end{tabular}



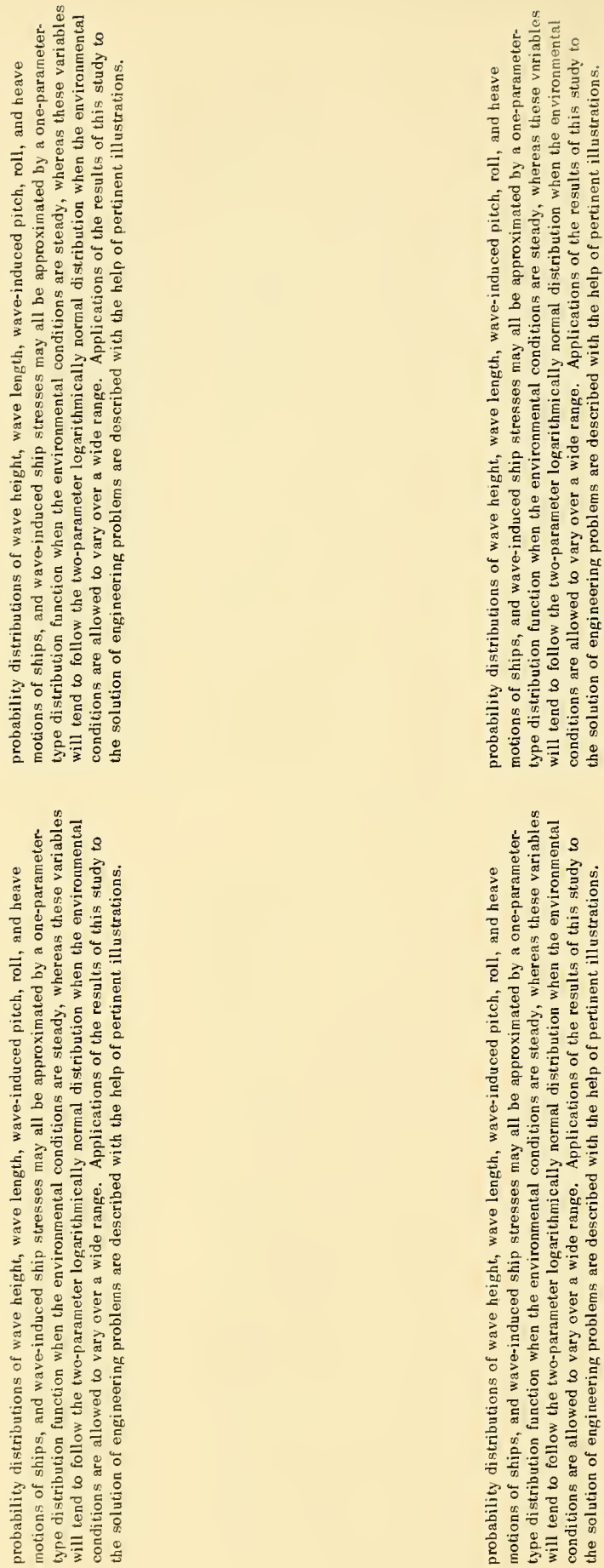


\begin{tabular}{|c|c|c|c|}
\hline \multicolumn{2}{|l|}{ 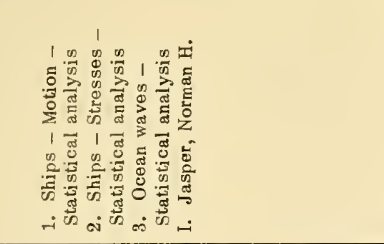 } & \multicolumn{2}{|l|}{ 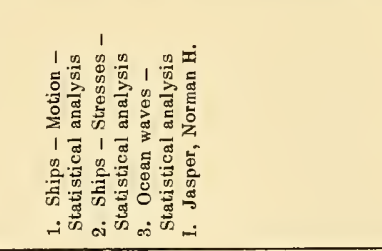 } \\
\hline 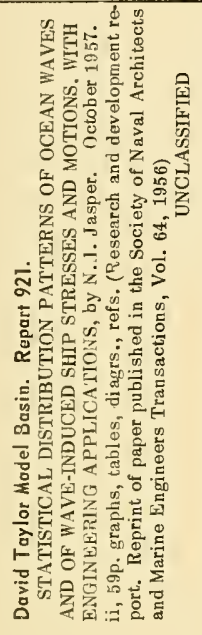 & 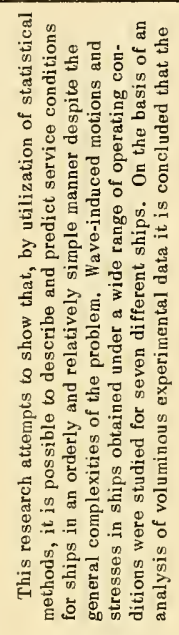 & 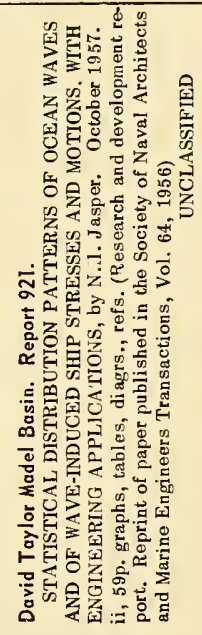 & 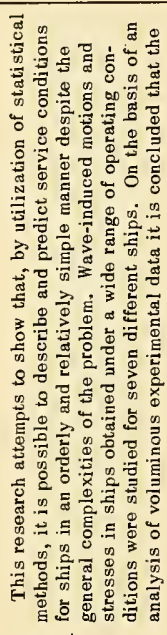 \\
\hline 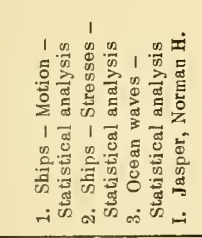 & & 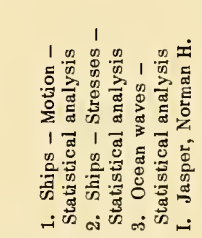 & \\
\hline 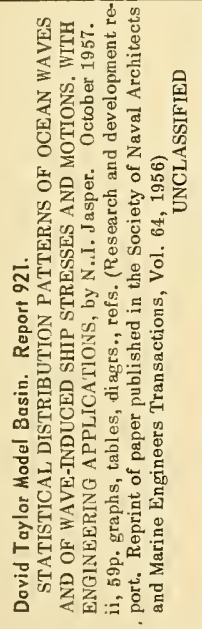 & 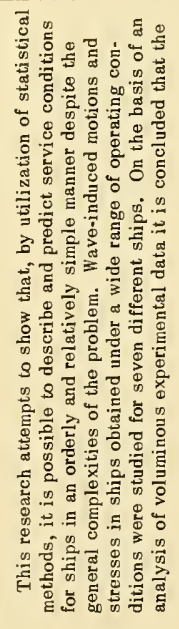 & 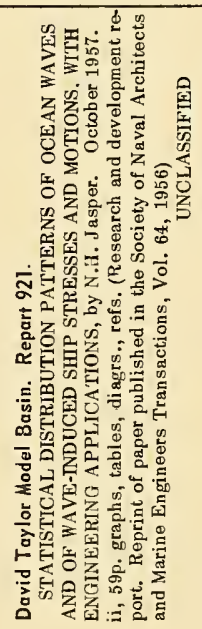 & 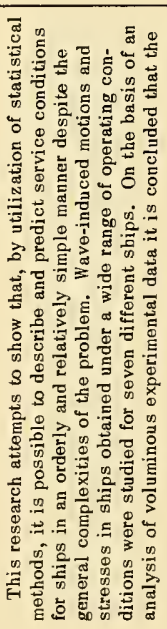 \\
\hline
\end{tabular}



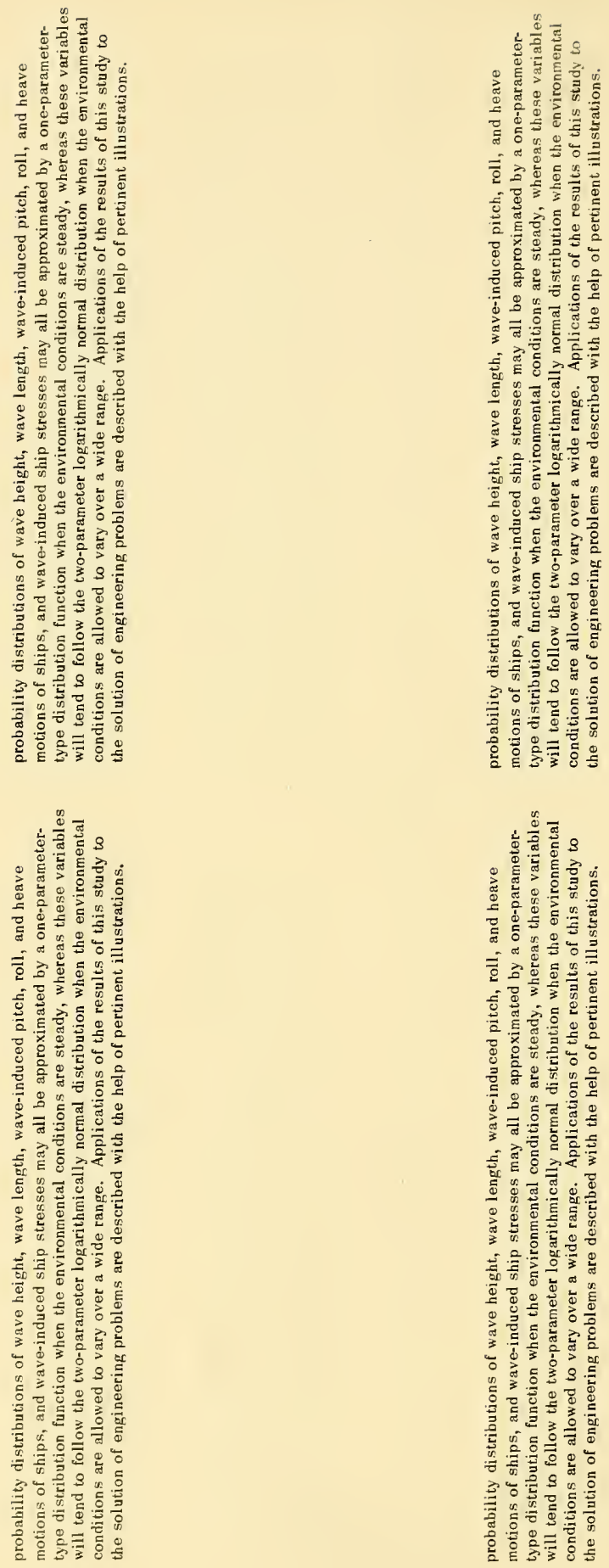
